\title{
Localise It
}

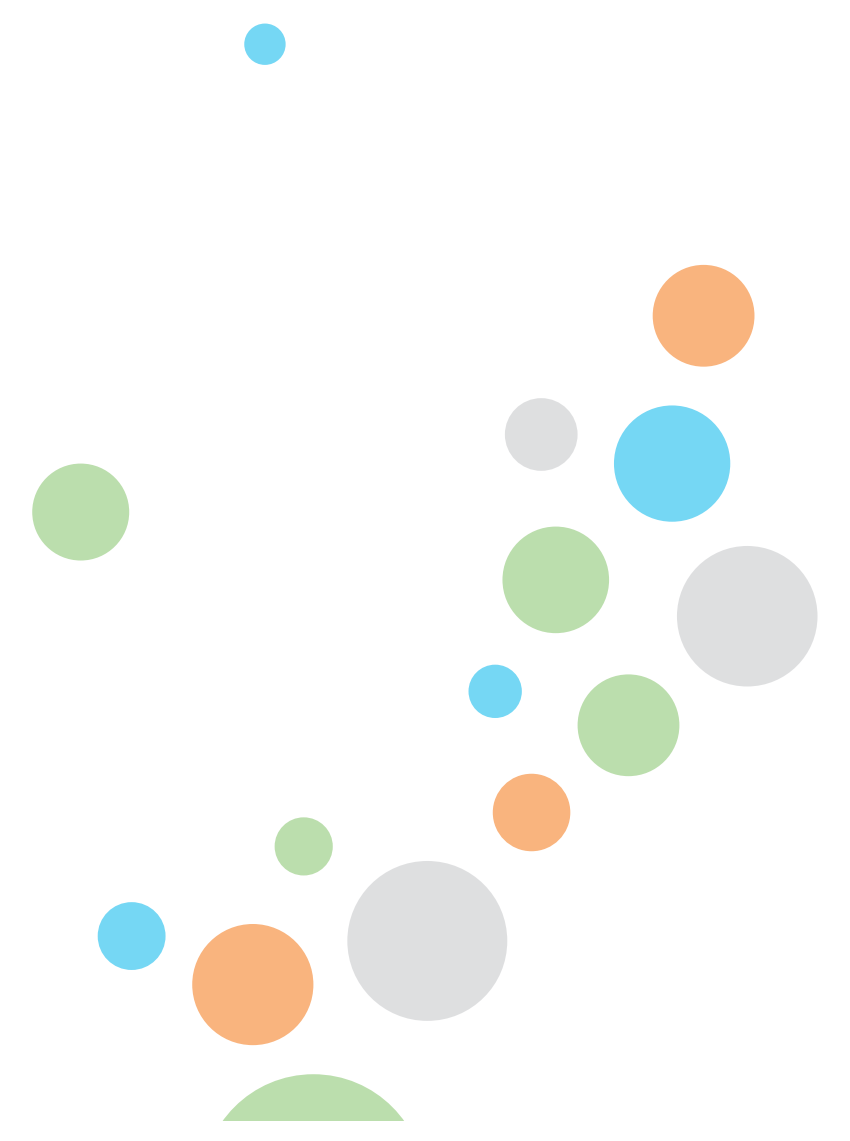

○ 


\title{
Localise It:
}

How Landscape Architecture contributes to creating sustainable public spaces in Wellington City as a method of recovery.

\author{
By \\ Anna Lee Sobye \\ A 120 point thesis \\ submitted to the Victoria University of Wellington \\ in partial fulfilment of the requirements for the degree of \\ Master of Landscape Architecture
}

Victoria University of Wellington

School of Architecture

2019 
Christophe Schmachtel says:

"The difference between being in a earthquake and being in a disaster is the level of preparation."

The Guardian.

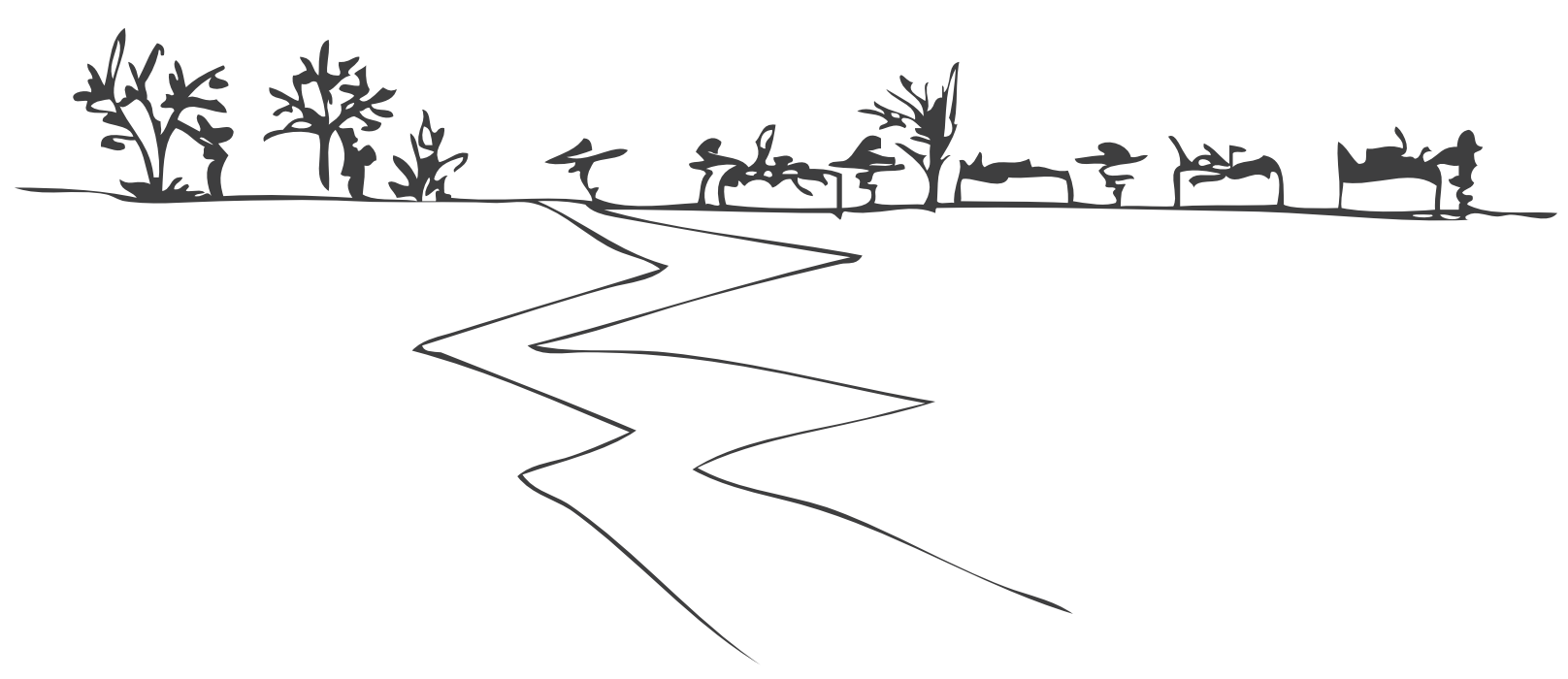




\begin{abstract}
Wellington is located on a fault line which will inevitably, one day be impacted by a big earthquake. Due to where this fault line geographically sits, the central city and southern suburbs may be cut off from the rest of the region, effectively making these areas an 'island'. This issue has absorbed a lot of attention, in particular at a large scale by many different fields: civil engineering, architecture, infrastructure planning \&e design, policymaking.

Due to heightened awareness, and evolved school of practice, contemporary landscape architects deal with post-disaster design - Christchurch, NZ has seen this. A number of landscape architects work with nature, following increased application of ecological urbanism, and natural systems thinking, most notably at larger scales.

To create parks that are designed to flood, or implement projects to protect shorelines. A form of resilience less often considered is how design for the small scale - people's 1:1 relationship with their immediate context in exterior space - can be influential in forming a resilient response to the catastrophe of a major earthquake. This thesis intends to provide a response to address the shift of scales, as a paradigm for preparation and recovery.

After a large-scale earthquake, state and civic policies and agencies may or subsequentially not go into action. The most important thinking and acting will be what happens in the minds, and the immediate needs, of each and every person; and how they act communally. This is considered in general social terms in state and civic education programmes of civil defence, for example, but much less considered in how the physical design of the actual spaces we inhabit day-to-day can educate us to be mentally prepared to help each other survive a catastrophe. Specifically, the identification of design of typologies can provide these educative functions.

Typology inherently a physical form or manipulation of a generic and substantial prototype applicable in contexts is something that exists in the mind. Working with the physical and social appearance and experience of typologies can also/will change people's minds.

Socially, and economically driven, the community-building power of community gardening is well-proven and documented, and a noticeably large part of contemporary landscape architecture. The designs of this thesis will focus on community gardening specifically to form typologies of resilience preparation and response to disaster. The foundation will remain at the small scale of the local community. The specific question this thesis poses: Can we design local typologies in landscape architecture to integrate community gardens, with public space by preparing for and acting as recovery from a disaster?
\end{abstract}




\section{Preface}

Growing up rurally and knowing my community has driven my interest, and passion for this thesis topic. While living in the city during my studies it became apparent that we take having neighbourhood communities for granted. By not knowing the people around us we are making ourselves less resilient in a disaster because we have to be completely self-reliant. Communities are the one thing that can hold people together in times of grief, and change. This urban condition of anonymity has been more obvious to New Zealanders in these past few years. We don't realise how knowing the people around us will be of benefit to us.

In contrast rural infrastructure systems had their own way of dealing with wastewater, the land that we could grow food, and water we could get out of the streams, within the landscape.

Now I call myself a proactive person, and I want to know what will happen after that first week in the urban context. Where I will get my food and water from? Supermarkets will be out of supplies and unable to get more due to the disconnect to existing infrastructures. Recent drilling for suitable places for bores, note the closest point of water I may have access to. These aren't all in place and most people wouldn't know how to store their basic needs of water for 2 months. Food is a whole different story, as this demands active participation of communities. 


\section{Acknowledgements}

The completion of my Master of Landscape Architecture degree would not be possible without many people keeping me sane throughout these last 5 years.

I would like to thank my Supervisors Brennan and Warwick for helping me organise my thoughts and keeping me moving forward with my research.

I would also like to thank my classmates, family and friends for making my time at university more bearable and for your unwavering support. 


\section{Contents}

Abstract

Preface

Acknowledgements

Definitions

1.0 Introduction

1.1 Background and Founding Pretexts

1.2 Questioning the Current Issues

1.3 Aims + Objectives

1.4 Methodology

1.5 Scope of Research

2.0 Analysis and Scale

2.1 Context/ Wellington City

2.2 Mount Cook

2.3 Site Specific Analysis

3.0 Literature Review

3.1 Urban Agriculture and Productive Spaces

3.2 Spatial Composition with Urban Parks and Functionality

3.3 Resiliency and Public Space (Interaction/ Hybridity)

3.4 Reflection

46

47

4.0 Precedent Review

49

4.1 Vacant to Vibrant

50

4.2 The Getty Salad Garden 
4.3 Reinventing Vilonia

5.0 Design with and for Opportunities and Constraints 59 5.1 Typology 1: The View (To See or to be Seen) 61

5.2 Typology 2: Shared Orchard (A Passive Interaction)

5.3 Typology 3: Learn + Play (Multigenerational Production)

5.4 Typology 4: Movieable (Multifunctional Programming for Resilience and Recovery)

5.5 Typology 5: Accessible Levels (Paradigm For Context and Community)

5.6 Typology 6: Lounging Lunch (Active Social Construct)

6.0 Developed Design 6.1 Typology 1: The View (To See or to be Seen)

6.2 Typology 2: Shared Orchard (A Passive Interaction)

6.3 Typology 3: Learn + Play (Multigenerational Production)

6.4 Typology 4: Movieable (Multifunctional Programming for Resilience and Recovery)

6.5 Typology 5: Accessible Levels (Paradigm For Context and Community)

6.6 Typology 6: Lounging Lunch (Active Social Construct)

6.7 Network of Spaces

Bibliography 
Localise to me means to make local places where you can have everything you need. to me local symbolises a community.

From the noun local: a person from the area or place that a person visits regularly.

But also localize is to limit something to a particular area.

Public Space is a space that any member of the public feel comfortable using.

Community Garden is a space that allows plots for families or friends to grow food for themselves.

Productive is when it produces crops/ food.

Community Hub is a space that people know they can go to get help after a disaster. 


\section{Introduction:}

This thesis explores different landscape architecture typologies and how iterative design can be implemented locally in a way that forms an overall network of spaces. These typologies are precedented on acting as regular public spaces before a disaster and a refuge for communities after.

The Wellington fault lines have a high probability of rupturing in the next 50 years. It is estimated to be 10\% (Mowll 11) Due to site unpredictability and when this event will occur we have to be prepared before our infrastructure and community split. This becomes a problem when the earthquake cuts us off from our resources.

The city's geographic location remains a driving issue but not what I'm focussing on. Having all our infrastructure built right next to the fault line is also an issue but not something we can change. The prime fact that the road infrastructure will be impacted and that we get our food from the outer parts of the region is one of the main resultants that I'm launching my thesis upon. Another issue is the water and that although our current water is locally sourced, it's not local enough that it avoids being affected if an earthquake hits.

We know New Zealanders are resilient, because we've seen it through the last big earthquakes and most recently the mosque shooting. Some things we just truly can't prepare for. In this regard and study we can prepare Wellington for an earthquake, by making sure we have enough resources and what we'll need to survive afterwards.

Resiliency and Sustainability have been discussed critically lately through many professions, including Landscape architecture. In this study I use resilience to refer to how we as communities support each other through social harvesting and can offer our services to help each other when needed. Sustainable in this study is to not go backwards in terms of health or living situation. That communities and urban conditions will not need to rely on sources that are finite, while products are reusable. 


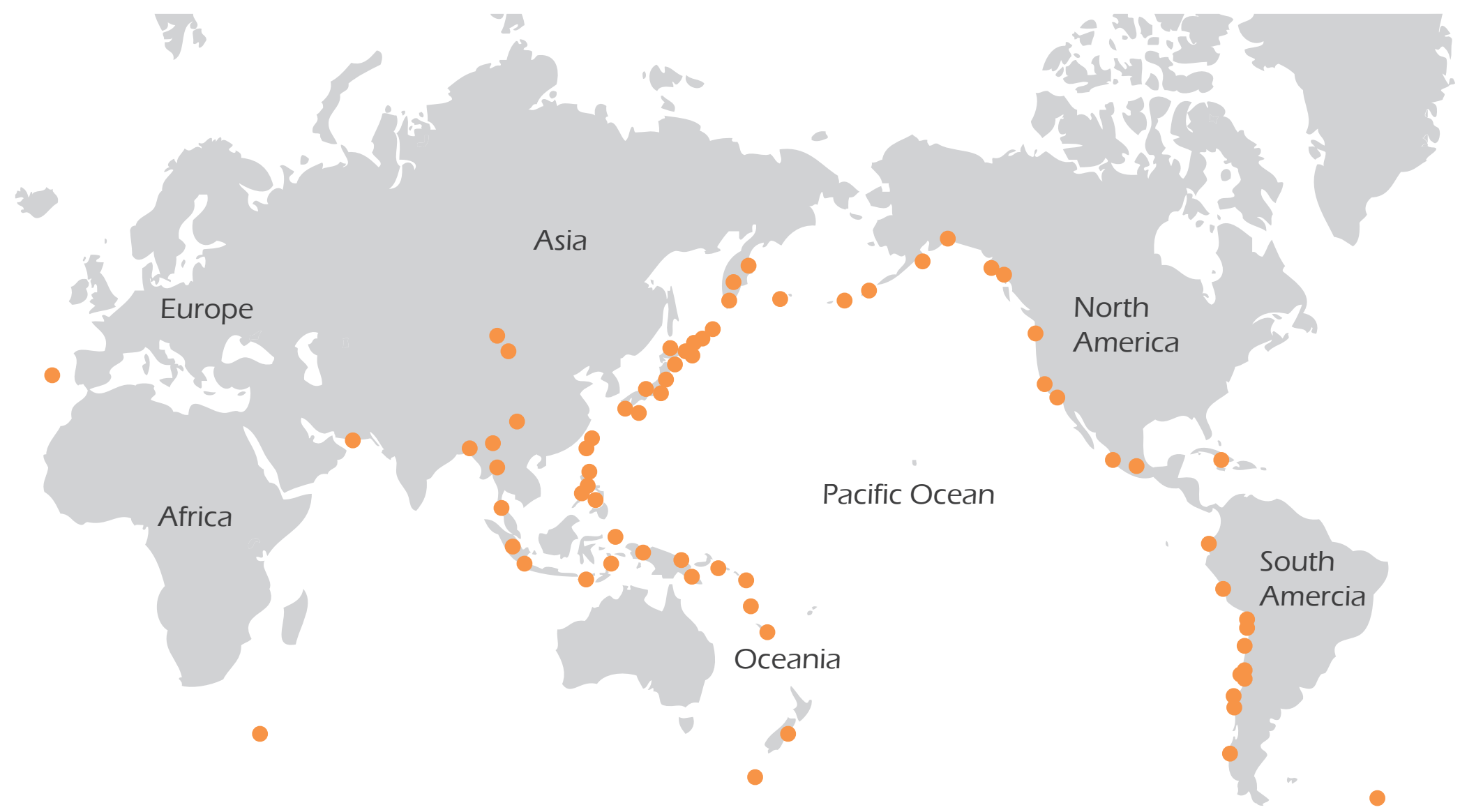

Figure 1.1.1. World Map showing the concentration of significant earthquakes around the Pacific ocean. 


\subsection{Background and Founding Pretexts:}

New Zealand is not unique. Earthquakes occur around the world [fig 1.1.1.] this map shows where they are most concentrated. In fact, what is prominent here in Wellington is undoubtedly present in many urban territories/regions.

Natural disasters are a part of New Zealand, we have had many in the past and we will continue to have them. Christchurch and Kaikoura earthquakes most recently hit and these have catalysed Wellingtonians, both the public and the civic people into trying to prepare for what could happen when the big one hits the Wellington fault line.

"Lifeline Earthquake risk assessment" defines an earthquake scenario with the biggest effects to be a 7.5 magnitude one centred at a depth of less than 30 metres on the Wellington fault line somewhere in the harbour. This would create a displacement of up to $5 \mathrm{~m}$ horizontally and $1 \mathrm{~m}$ vertically which would really disrupt the infrastructure that runs beside it. (Mowll ll)

Wellington city is located on this fault line which is due to produce an undesired effect. As a result, the city and southern suburbs will be cut off from the rest of the region due to infrastructural damage, effectively forming an 'island'. This will mean that the 'island' will have to be self-sufficient in terms of the major needs it provides to the community. I propose to bring a sense of security through creating off grid networks of public/community gardens. As a place of community, while actively responding to the after effects of an inevitable disaster.

Wellington Council has been making it known over the last year that we need to be prepared with enough water and food for 7 days for our entire household.

Appendix A outlines Wellington Waters' response and actions for these minor, and 


\section{Redacted Copyright Image}

\section{Redacted Copyright Image}

\section{Redacted Copyright Image}

Figure 1.1.2. Wellington Water map of where the emergency water stations are situated

Figure 1.1.3. Plan for each water collection point. 


\section{WREMO's 4 R's:}

major events. Although they are strategically framed, I feel that there needs to be more designed solutions.

Wellington Water, has a strategy for the water supply, in Wellington there has been recent drilling to establish sites for viable emergency water stations, these are situated on [fig 1.1.2.]. They will then have water collection points within $1 \mathrm{~km}$ from every home, allowing you to get your allocated 20L from day 8 .

Ministry of Civil Defence and Emergency has 4 Rs: Reduction, Readiness, Response and Recovery. These are to manage and minimise risks. I chose to focus on readiness and recovery and all that landscape architecture can address.

An earthquake of this magnitude would almost surely wipe out our main transport corridors to the city and would definitely cut our power, water and waste (supply). Although we have prepared for a week's worth of being self-sufficient most utilities won't be available for up to 4 months after the earthquake, as shown in the "Lifeline Utilities Restoration Times" report. (Mowll 24)

My aim in this study is to provide a network of 'local' public spaces that communities can use before and after an earthquake, to allow a resilient public in the way they live through the destruction/disruption that the earthquake has caused. This is best carried out by introducing nodes of social and disaster driven links across the city.

Using 6 sites as the base of an investigation to explore a range of different landscape typologies, that allow me to experiment with surrounding communities before, during and after an earthquake.

Fundamentally driven by our major needs after an earthquake, I generated an open, contextual framework as reasons for my designs. The need for water, food, and a sense of community, are a key part of having a resilient city, and must be taken into account when designing such spaces.

\section{Reduction}

\section{Readiness}

Developing operational systems and capabilities before a civil defence emergency happens; including self-help and response programmes for the general public, and specific programmes for emergency services, lifeline utilities and other agencies.

\section{Response}

\section{Recovery}

The coordinated efforts and processes to bring about the immediate, mediumterm and long-term holistic regeneration of a community following a civil defence emergency. 


\subsection{Question:}

Can we create typologies using landscape architecture to integrate community gardens, with public space by preparing for and acting as recovery from a disaster? 


\subsection{Aims + Objectives:}

These aims and objectives were important aspects of my project and come from how I addressed my question.

- To design a network of spaces throughout Wellington City that could become logical destinations and gathering points for people suffering shock, fear, confusion and disorientation after an earthquake.

These spaces would use different typologies that can 'plug-in' to unused spaces throughout the city.

-To design typologies that provide for our major needs before and after a disaster.

From establishing what our major needs are and using landscape and all that it encompasses to test out spatial conditions on the sites.

-To integrate the 'community garden' with the 'public space'

By creating productive public space through merging the boundaries these spaces have associated with them.

-To use multifunctional design in these spaces.

By allowing adaptability of spaces and allowing the elements to have many functions. 


\subsection{Methodology:}

This thesis explores how a landscape architect can integrate community gardens and public space allowing them to be a part of a resilience plan for Wellington. To have uses before, during and after an earthquake.

This design led research was situated at community scale provoked by earthquake preparation pamphlets distributed by Wellington City Council and WREMO. This led me to question what will happen if an earthquake strikes, even if we are prepared in the way they suggest we should be.

Using the scenario that an earthquake of 7.5 magnitude erupts on the wellington fault line. The research started with finding out what will happen a week after this event, in which the community would need to be self-sufficient in our own homes. Knowing this allows me to analyse the current plan and to find ways that landscape architecture can be used for communities to keep functioning like they normally would.

From initial analysis of the city and its emergency infrastructure, I will narrow my scope slightly to find sites that create a network from within one suburb. This involves analysing the existing public spaces and finding localised spots that become a community hub.

WREMO's emergency planning document (appendix B) is one of the key parts to understanding what would be beneficial to our cities. I intend to consult literature such as The Permaculture City by Toby Hemenway and articles from Penny Allen and Martin Bryant, and Anne Whiston Spirn to further research into design approaches 


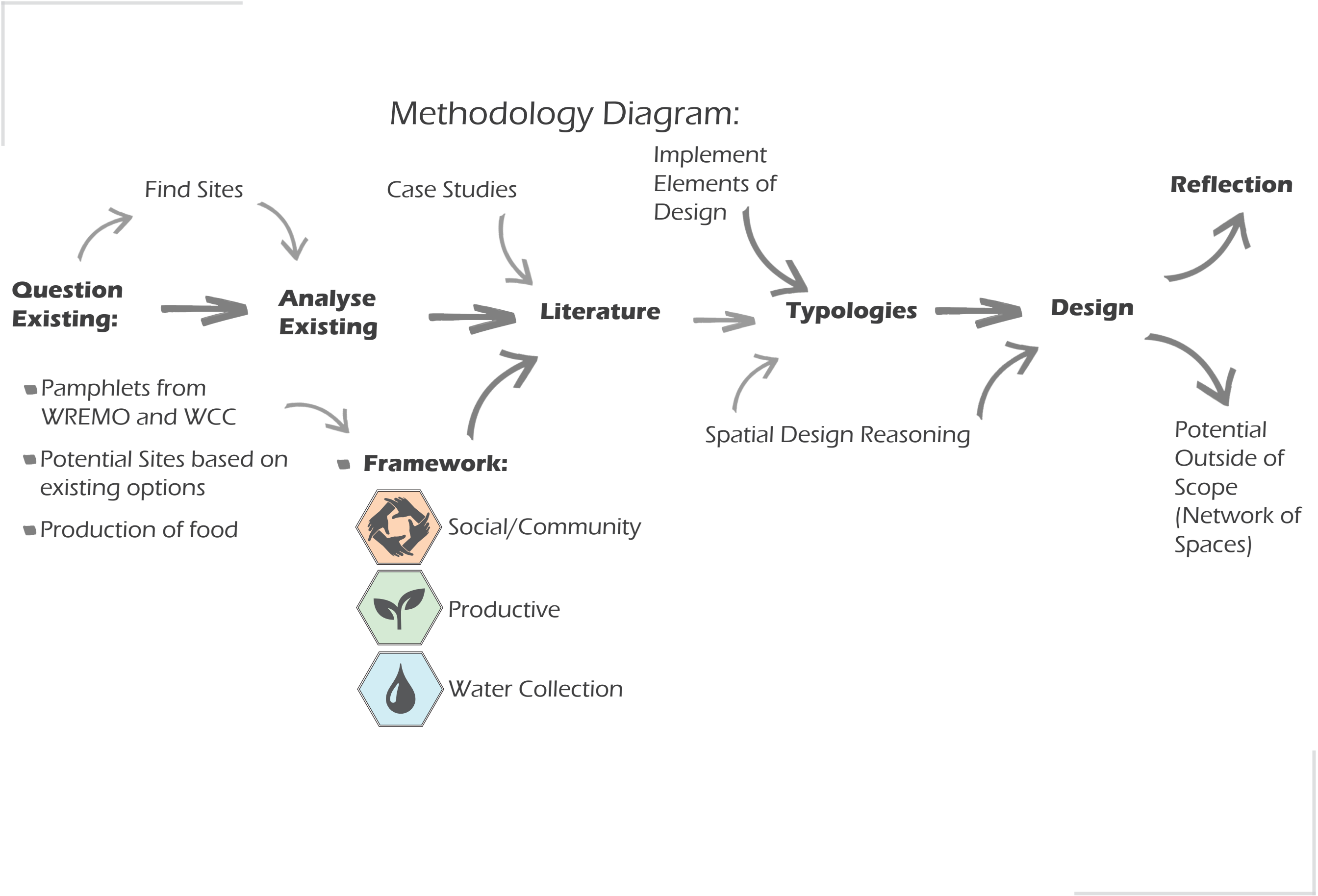


and perspectives for public spaces, disaster and recovery.

From these texts three key themes emerge:

-Urban agriculture and productive spaces which examine why productive spaces are needed throughout the city even at a small scale.

-Spatial composition of urban parks and functionality which introduces how the spatial composition of parks is important and can be used to design functional public spaces.

-Resiliency and public space (interaction/hybridity) which allows the topic of sustainability to influence how we can provide resilience for our cities.

Using these key themes and the analysis of precedents, filter out principles which help design typologies addressing preparation and recovery.

Focusing on the way that the local landscape provides resilience for our city with productive food spaces, water collection and a sense of community. I intend that these will become plug-in, off the grid opportunities. 


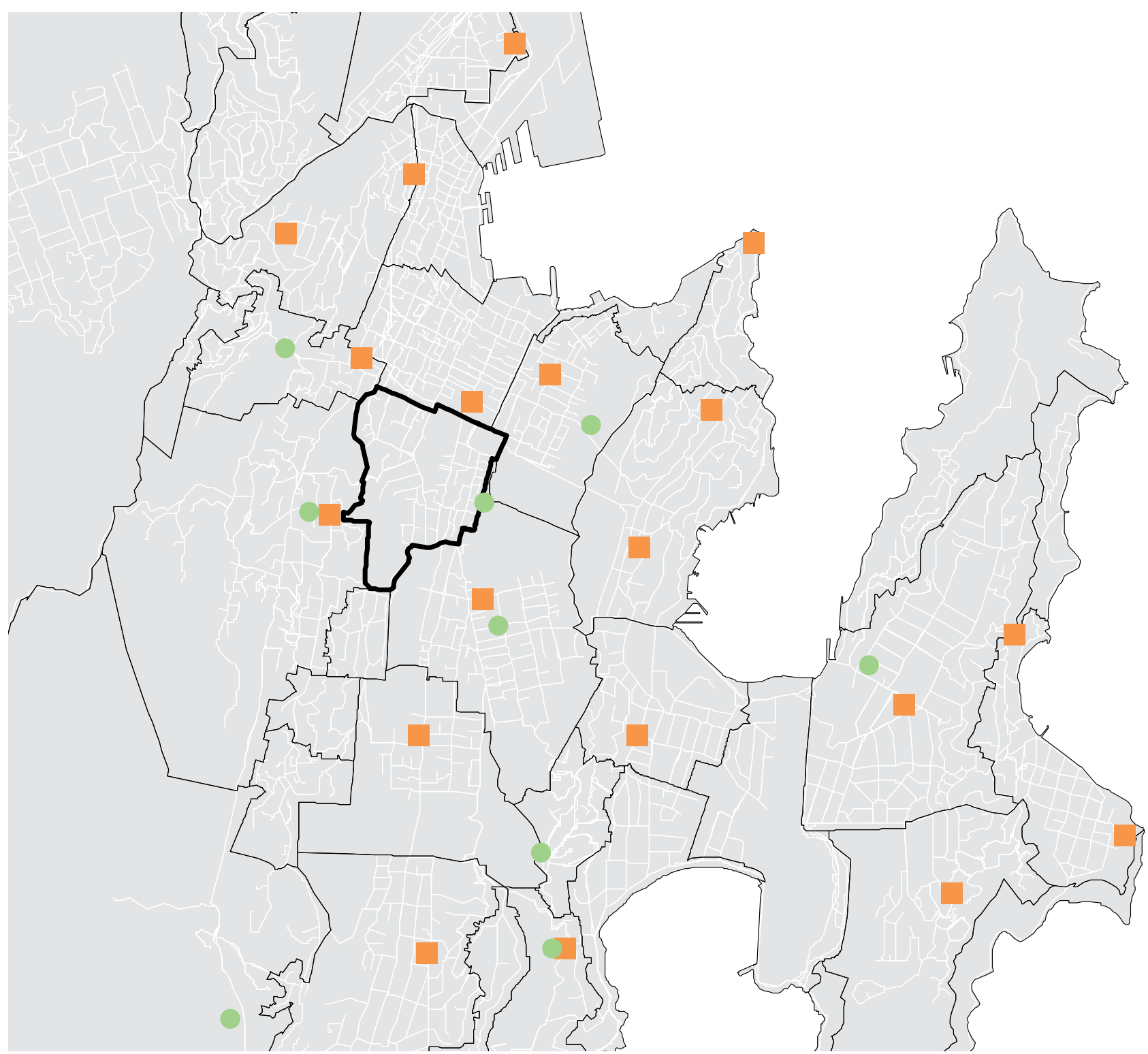

Key:

Emergency Community Hubs

Community Gardens

Figure 1.5.1. Map showing there are no community hubs in Mount Cook 


\subsection{Scope of Research:}

The landscape context of this research is based within Wellington City but the findings and strategies potentially could be used in other cities or towns that would benefit from having local productive spaces, within New Zealand and possibly throughout the world. Limitations to the research were needed to establish a boundary for my site selection process and to prevent the research for being too broad.

One limitation I set was to have as little site demolition as possible. This is partly due to needing to get the sites established so that they are in working order for when the earthquake hits. Another limitation included mostly easy construction so that people within the surrounding communities could participate.

The scope of the design was in Wellington city southern suburbs due to being affected for the longest time after an earthquake. The research focused on Mount cook as it is populated and has none of the existing community hubs in its boundary [fig. 1.5.1.]

The research tried to achieve growing food and collecting water within the city. Limiting myself to one suburb was crucial, to understand a community and their site, and focusing on the general programme of the site and other ways it could be used, across the users. This was ultimately limited in the political boundaries of Mount Cook. Which may be beneficial to implementing typologies as a standard in such defined boundaries. 
Refer to appendix $B$ and $C$ these are the key needs that Wellington is indicated to require before living through a disaster. 
Key Needs from disaster preparedness pamphlets for before a disaster:

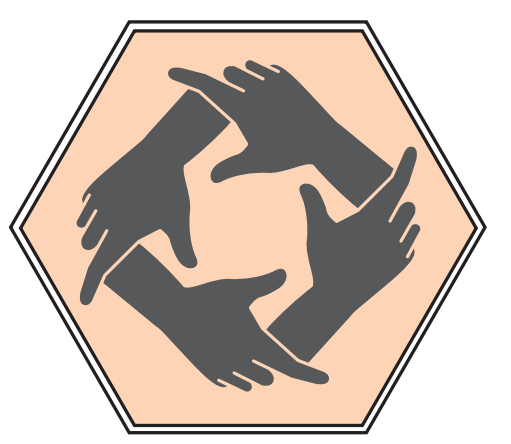

- Building Community

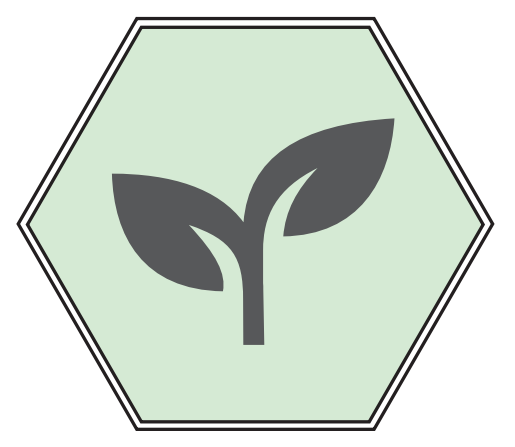

- Growing/Storing Food

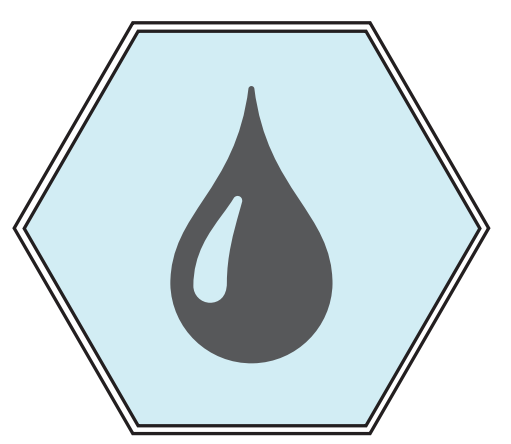

- Collecting Water 


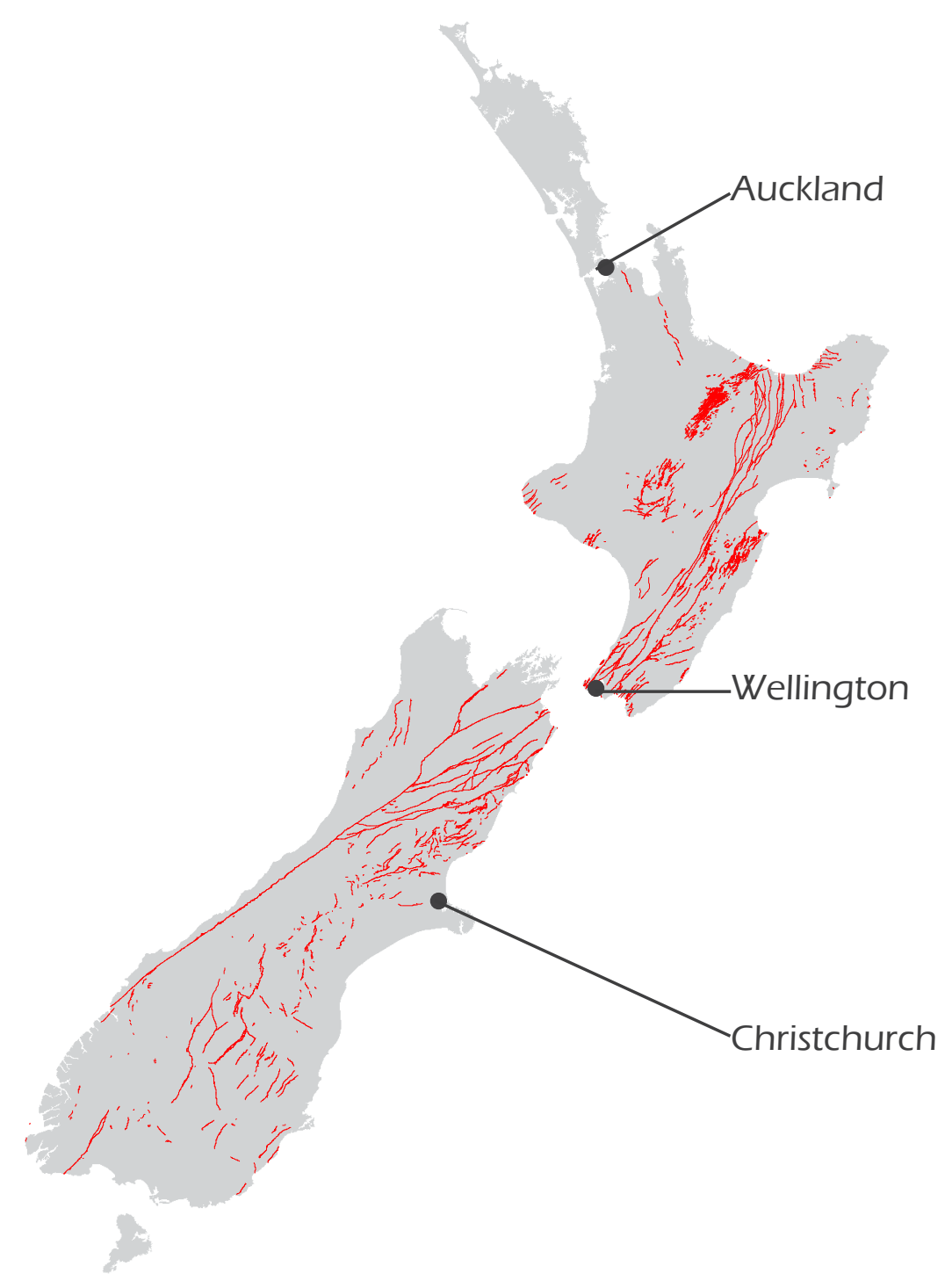

Figure 2.0.1. Map of New Zealand Fault Lines with reference to our major cities. 


\section{Analysis and Scale:}

Wellington City [fig2.0.1.] is located at the bottom of the north island and due to its geographic location poses many vulnerabilities in terms of earthquake risks. Making it uniquely exposed to earthquake related damage. Wellington is a city located on the south western tip of the North Island. Its harbour and steep landform shape and constrain the innermost city. With the city being so steep and exposed it doesn't have much fertile land for food production but the rest of the region manages to provide food via transport lines. Water for the city's population also comes from beyond the city flowing through a pipe running next to the major faultline. Combining this with its proximity to an active fault line it becomes apparent that in the event of an earthquake the infrastructure will be unusable.

The following analysis looks at the existing emergency infrastructure in Wellington, and the demography. First at the regional scale, then narrowing the scope and concentrating on one suburb for developing these typologies. This analysis then focuses on Mount Cook and develops into direct site analysis of the six sites I have chosen. 

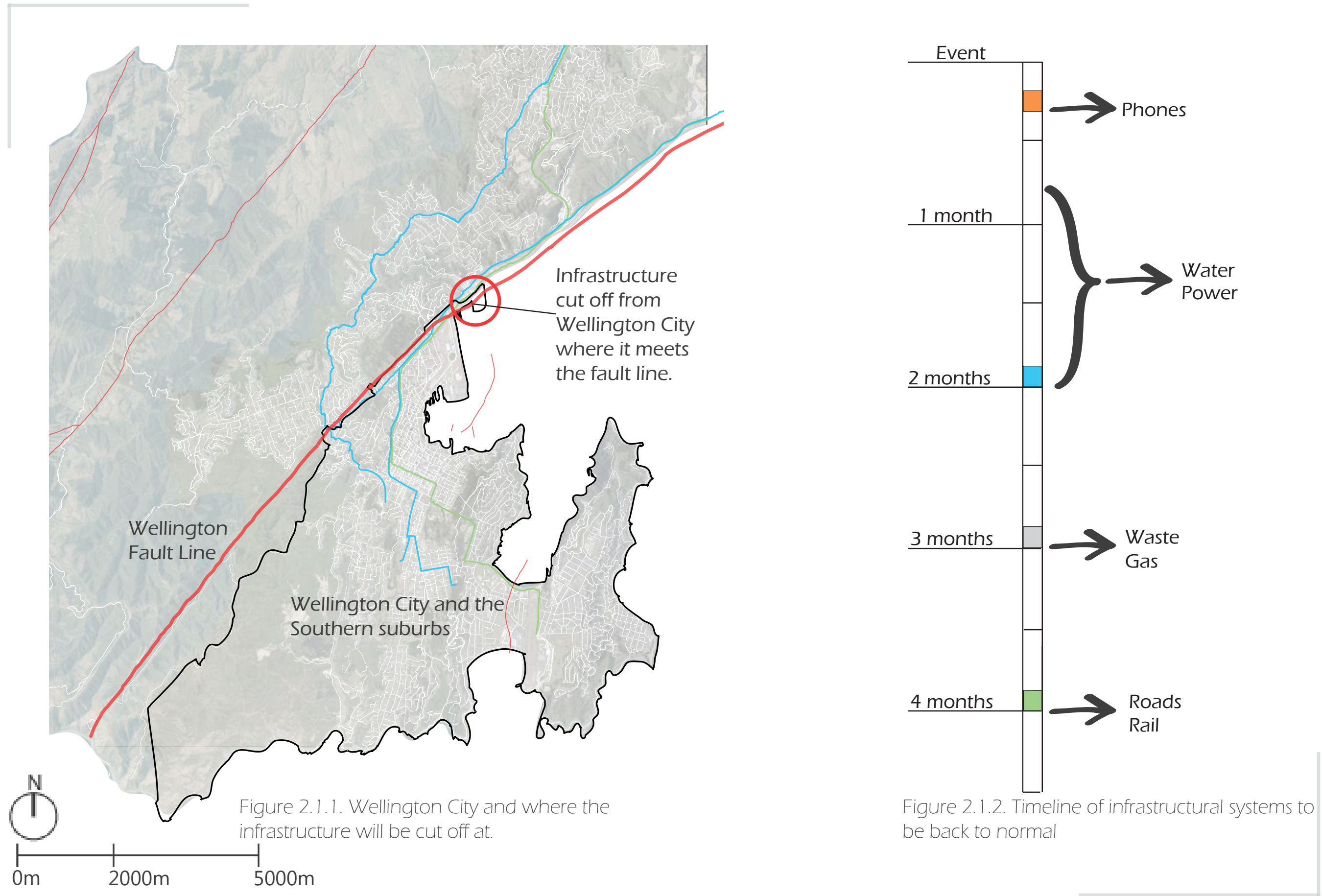


\subsection{Context - Wellington City}

Through looking at the geographic location of Wellington and how it sits next to a major fault line [Fig2.1.1.]. The assumption that it will be a resource island is not entirely unbelievable. Due to a rupture along the fault line the infrastructural damage running along this line would be imminent and will take up to 4 months to be checked and repaired back to normal standard [fig2.1.2.]. This infrastructure involves a number of lifeline utilities including power, gas, telecommunications, water, wastewater, and land access (transport-food, fuel, and plants and other materials) (Mowll 24)

To avoid dependency after a disaster the people in the Wellington City and southern suburbs would have to be self-sufficient within our 'island' in terms of our resources and what we need and use. The population of Wellington City is 179000 ("Wellington Population 2019.") and that means we need 358,000kg food per day and 3,580,000 L of water per day (Mowll 24) for the entire city.

Wellington city's food comes primarily from Levin and Grenada north [fig 2.1.3.] (Fong 18 ) where it is grown and then stored in a warehouse till it comes down by truck to our weekend markets or gets distributed through the supermarkets in the city on the transport network. The water for the city comes from Lower Hutt and Wainuiomata, with the main pipes running beside the fault line. The Kaitoke Stream supplies Porirua and Karori and then makes its way to some of the reservoirs in Wellington City.

Currently we don't have the resources and land available to be self-sufficient for food and water in the city boundary. As a political response Council is implementing drilling to find water bores throughout the city that would be able to produce our water needs these are the proposed emergency water stations [Fig 2.1.4.].

A plan for food for Wellington City has the council relying on defence forces to courier it in; although in a survival situation this would also be rations and probably refugee style. Community gardens currently in the city total nine, and are spread out. This is 


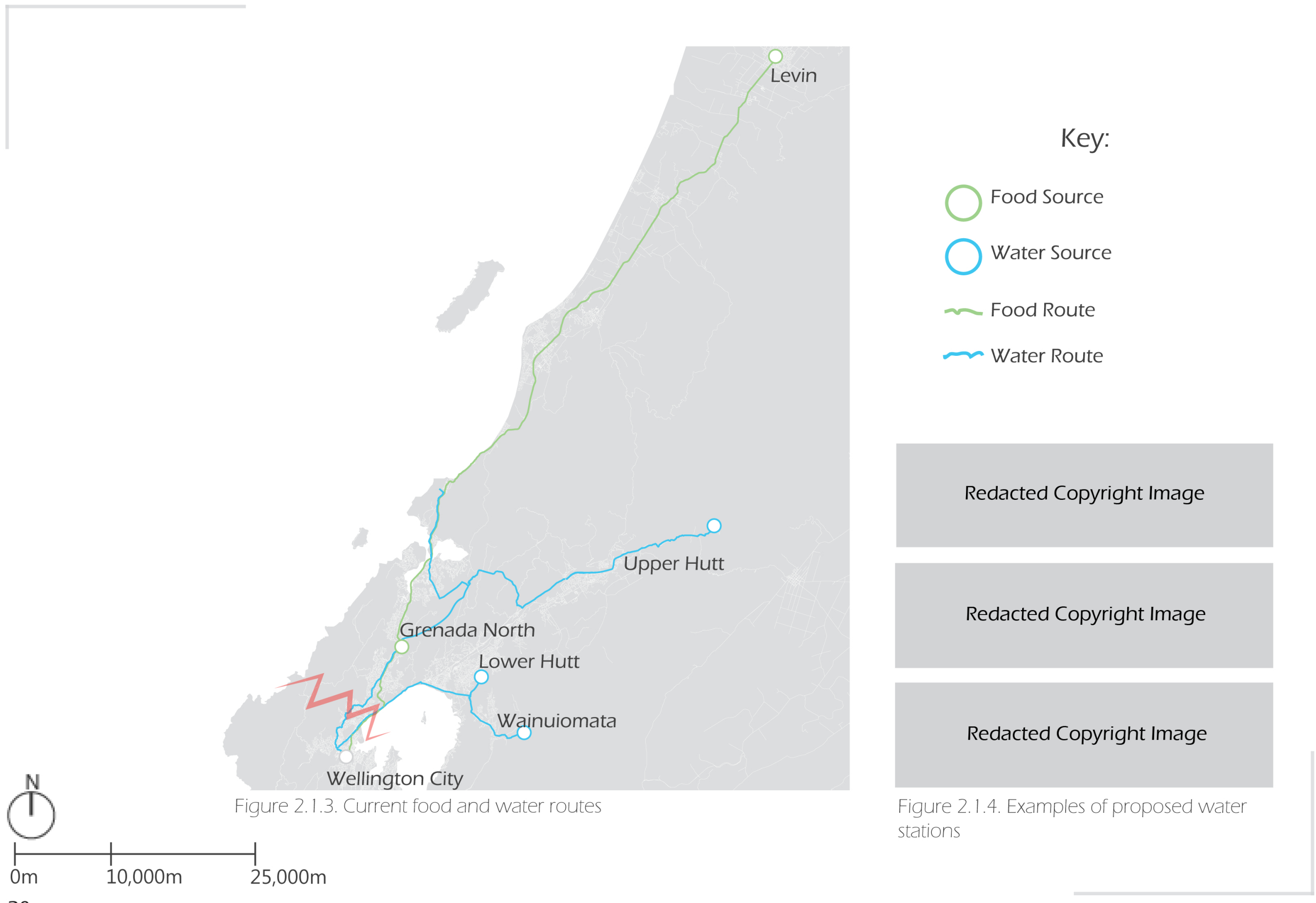


definitely not enough to have a moderately healthy diet for four months.

The used public space within the city is either part of the green belt, (generally fields or bush,) or it is a very constructed space with lots of hard surfaces. The spaces that aren't used as a comfortable public space include carparks, little in-between pockets or roadsides of grass people just walk past every day. [fig2.1.5.] This raises the question of why we don't make all the extra spaces community gardens and maximise food growing in the city?

I identified 6 different types of spaces within Mount Cook that could become a refuge after a significant disaster, if designed based on my framework.

My framework came from the fundamental reasons I chose this project to begin with. A big earthquake will hit Wellington, we don't know exactly where or when but it will impact the city in more ways than structural damage. It will stop the city's food and water supply and will probably leave some people without homes. It's at this time we will need to come together and these community spaces can help with this. These will be refuge spaces where some will be equipped with shelter, most with some sort of water and food.

Creating good community space is about knowing your users. I did a user study of the spaces and who lives in the area as well as predicting how the residents will change due to demand for flats and location to the city.

When I looked at the food, water, and community hubs spread over Wellington city[fig 2.1.6.] it became clear that due to Mount Cook's lack of identity and a community hub there was a need for public spaces to be designed. Based on landscape contexts, I decided to use Mount Cook as a catalyst for a whole network of localised spaces.
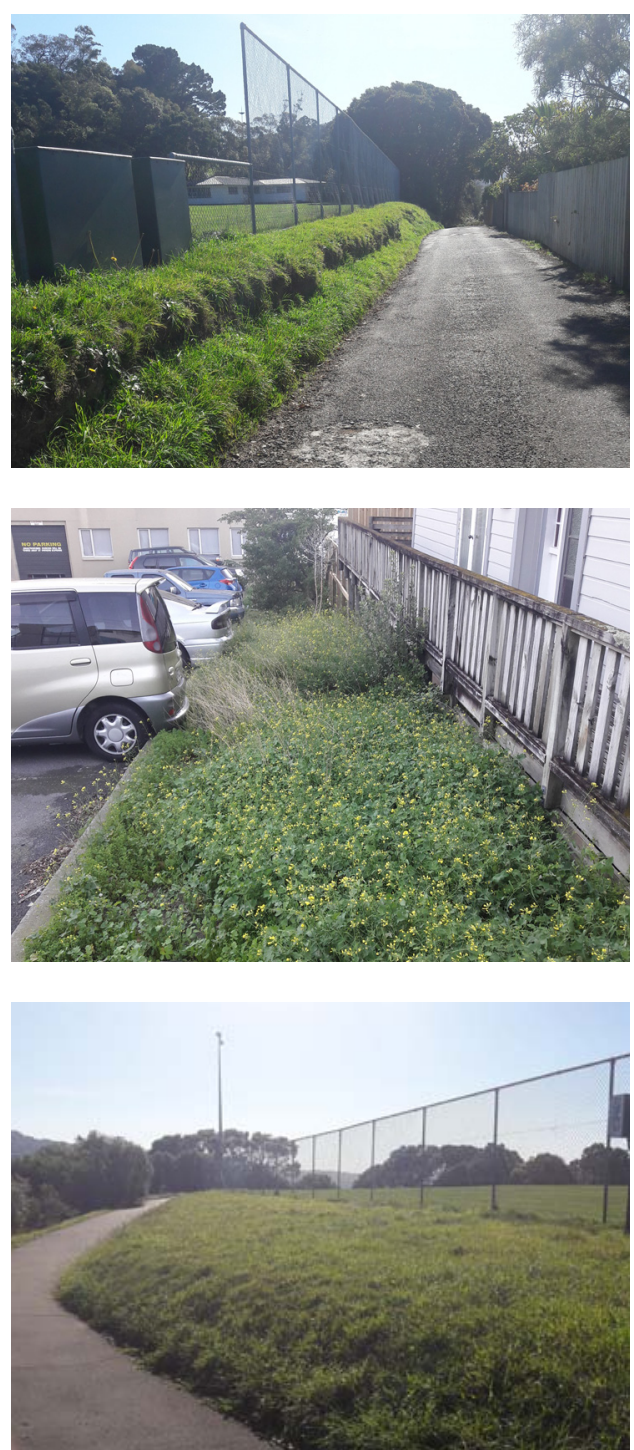

Figure 2.1.5. Unused spaces around Mount cook 


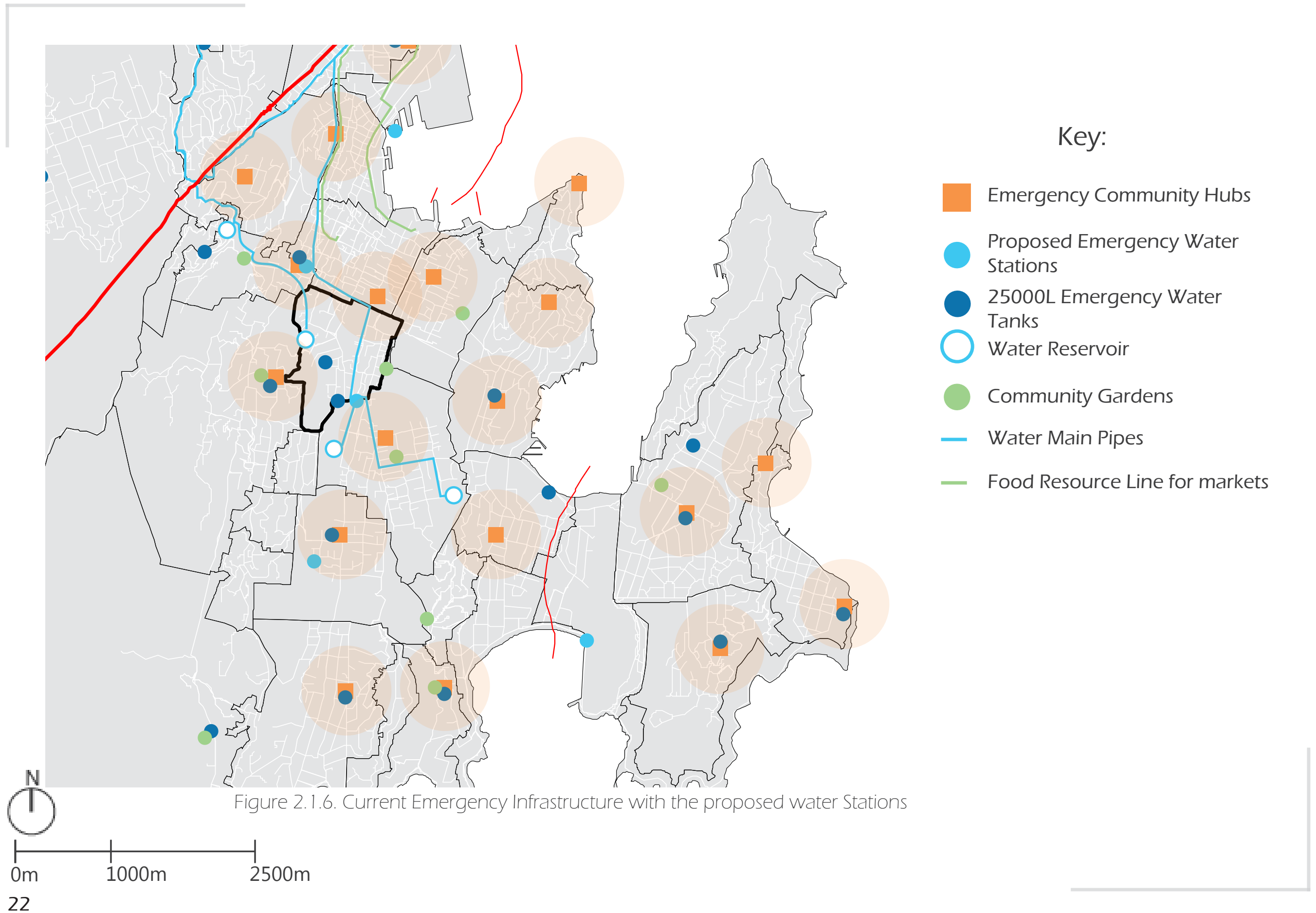




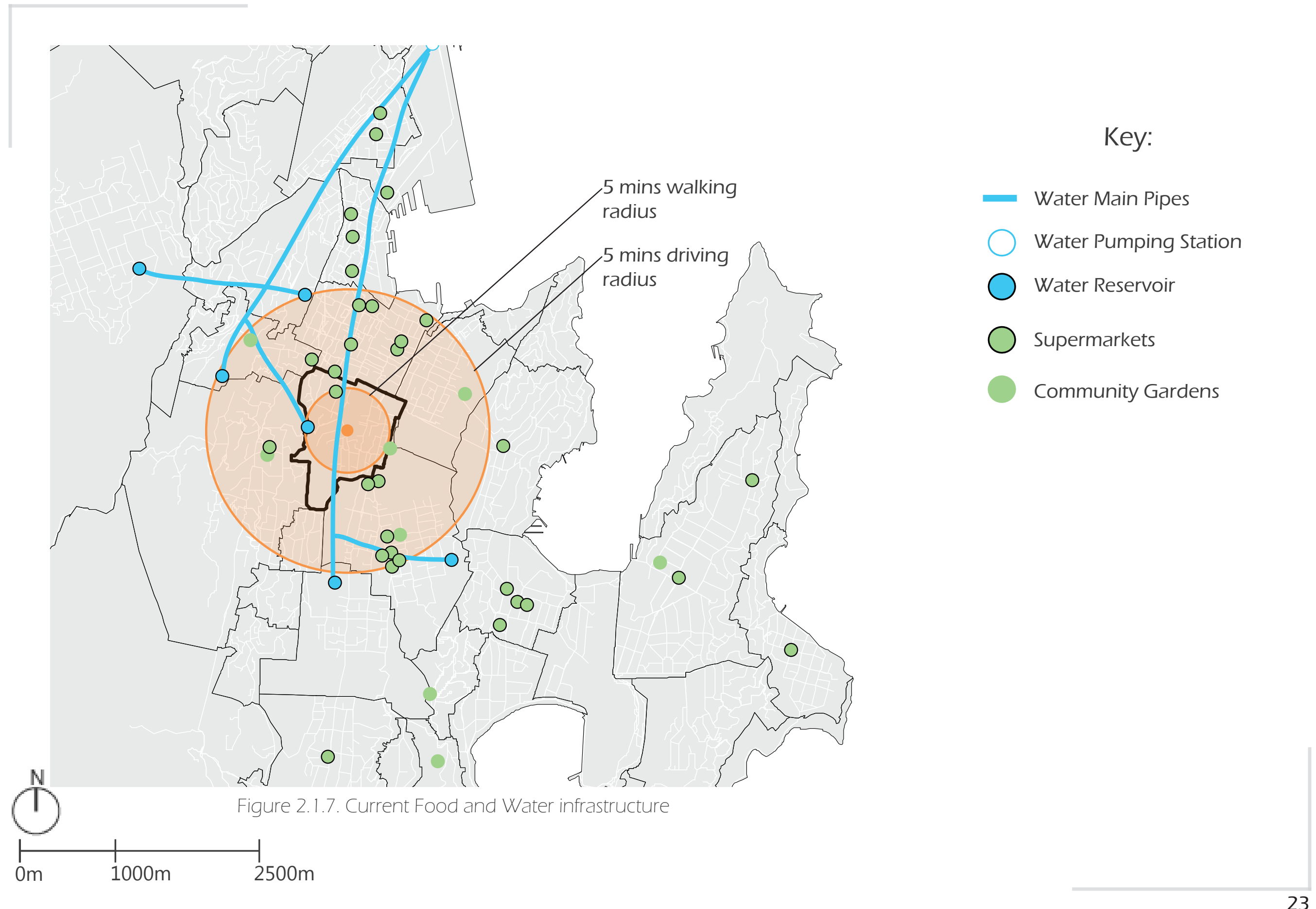


Large open fields, used for sport
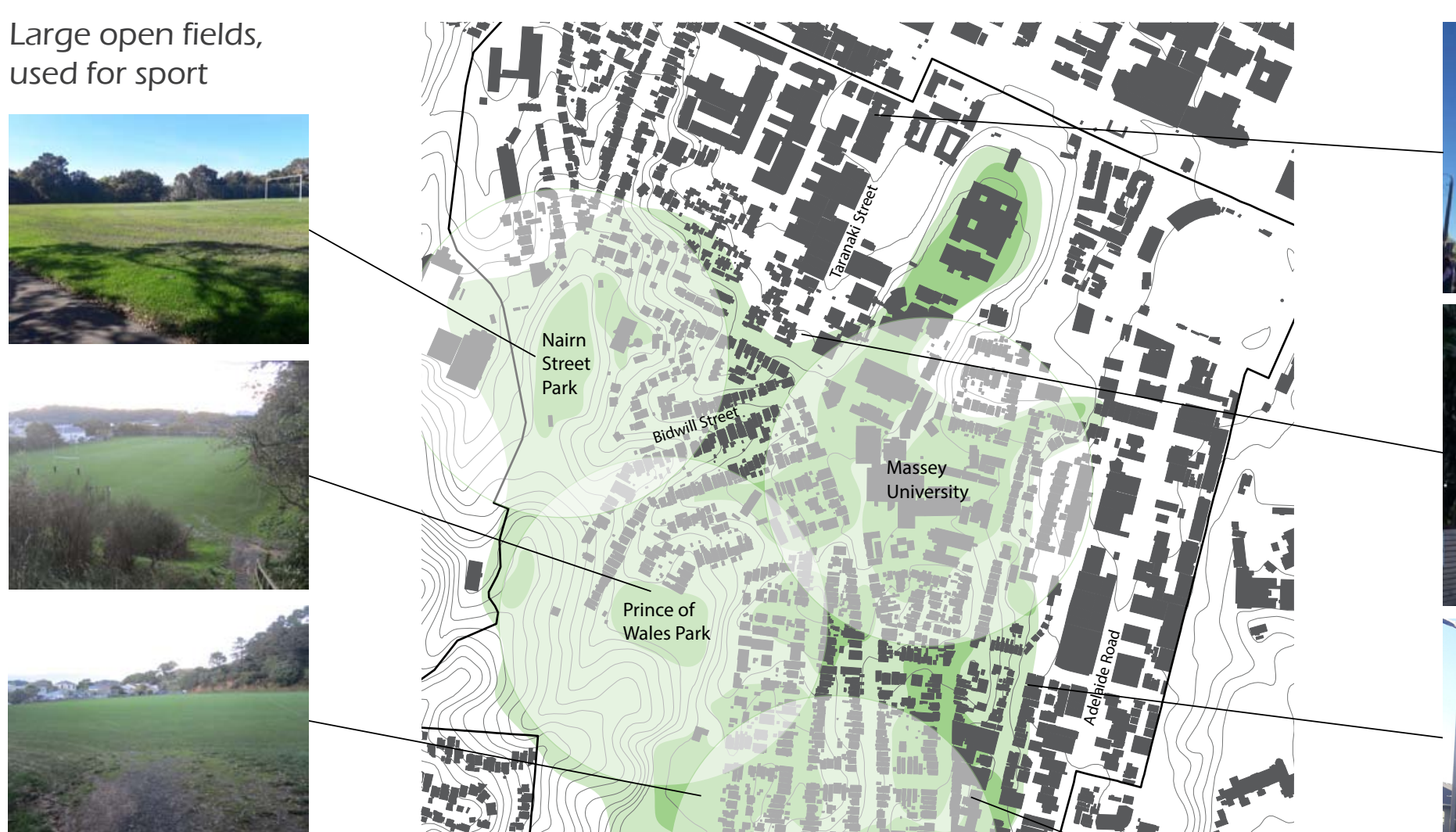

Park with nothing except a playground

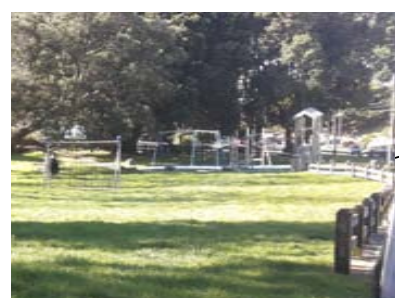

${ }^{N}$
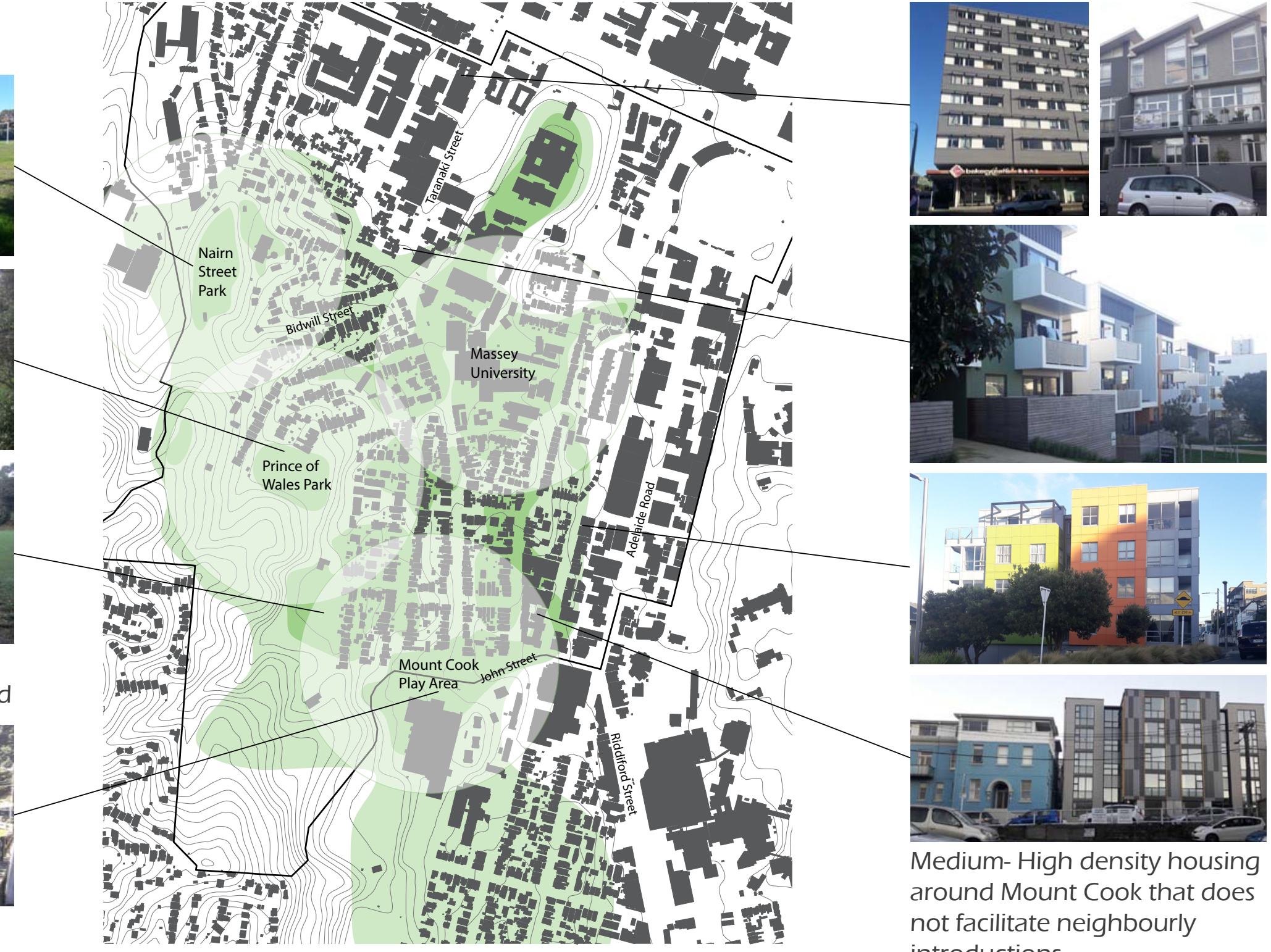

Figure 2.2.1. Location of Existing Public Spaces

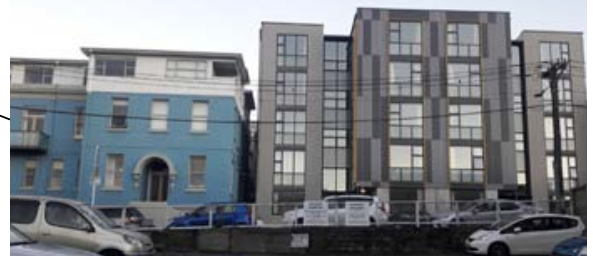

Medium- High density housing around Mount Cook that does not facilitate neighbourly introductions

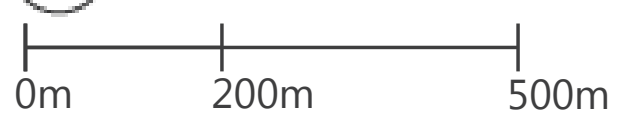




\section{2 : Mount Cook}

Mount Cook is a populous suburb with 6,579 (Statsnz) people living there, they are mainly students and young professionals with $64.7 \%$ aged between $18-34$. This provides an opportunity to create public spaces for students and young professionals can use while optimising a space that a community can prosper.

It is an in-between suburb of industrial and residential space and due to its proximity to Te Aro has a mixture of medium to high density apartments. These create spaces that aren't community based as they are very closed off and inhabitants aren't encouraged to meet their neighbours.

Mount Cook has a few grass fields and parks which aren't comfortable due to lack of seating. This creates areas that are unused unless sport is being played. Other unused spaces around Mount Cook go unnoticed even though people walk past every day. Mount Cook park is the only one that draws people in because of its playground that gives people something to sit and play on.

Overlaying the hazards risk map over Mount Cook we see that most of the suburb is between low to medium risk with the occasional part being medium risk. From the lower risk parts of Mount Cook and with overlaying the contours I was able to find the possible spaces that were of lower slope and that weren't residential back yards. [fig 2.2.2.]

After visiting these possible sites and taking out the fields as they were too expansive and were being used, I had defined six sites within Mount Cook. These as a whole created a loop through the residential area. 


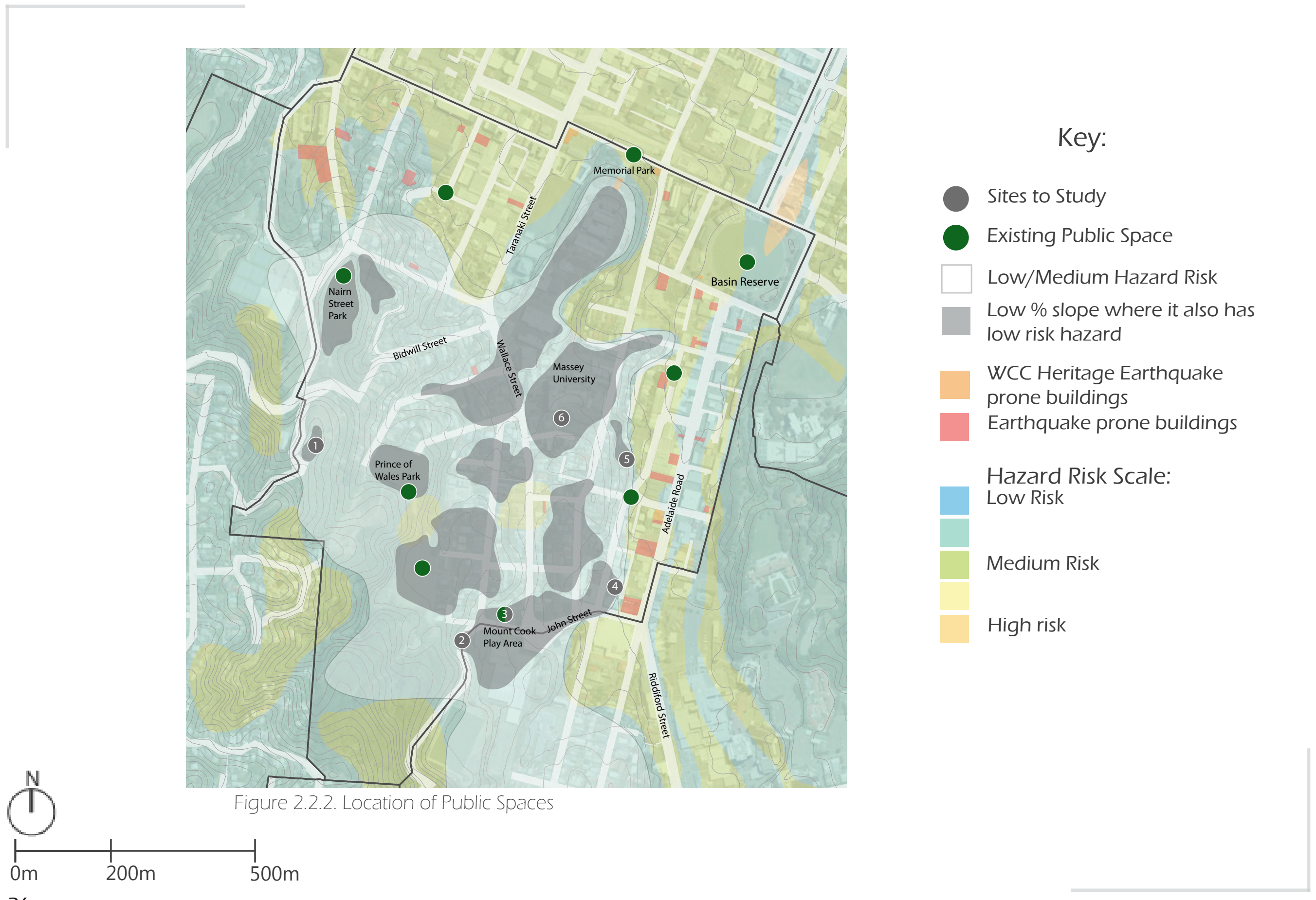




\subsection{Site Specific Analysis}

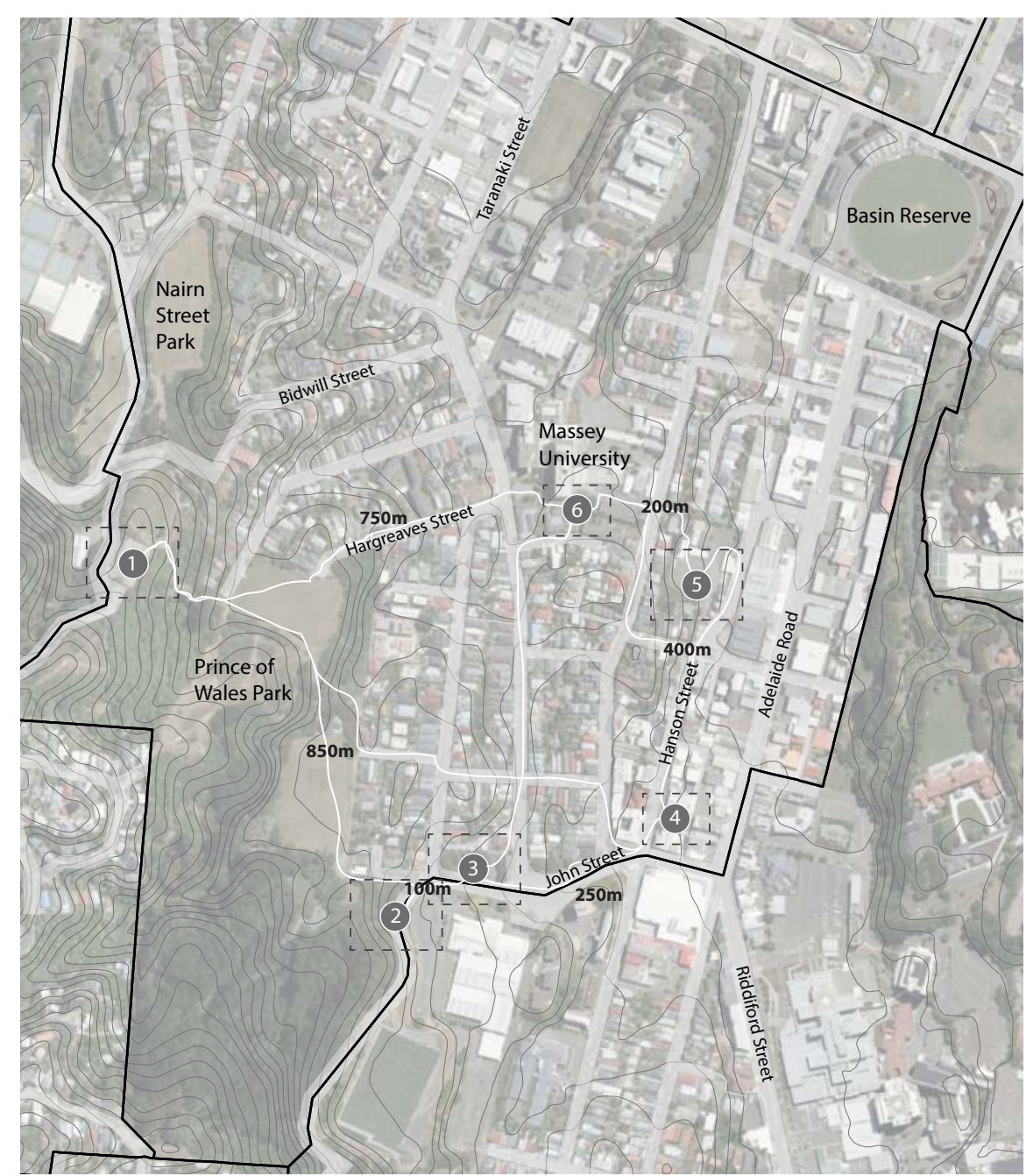

Figure 2.3.1. Location of Sites and their relativity.
These six sites are between low and medium risk in terms of hazards. And create two different paths from Brooklyn to Newtown. Each site is on the boundary/edge of residential area, while some are also on the edge of Mount Cook, or on the border between the industrial and residential areas.

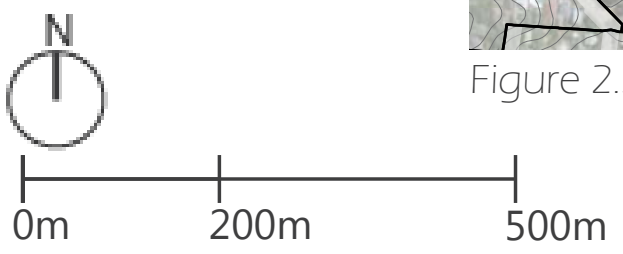



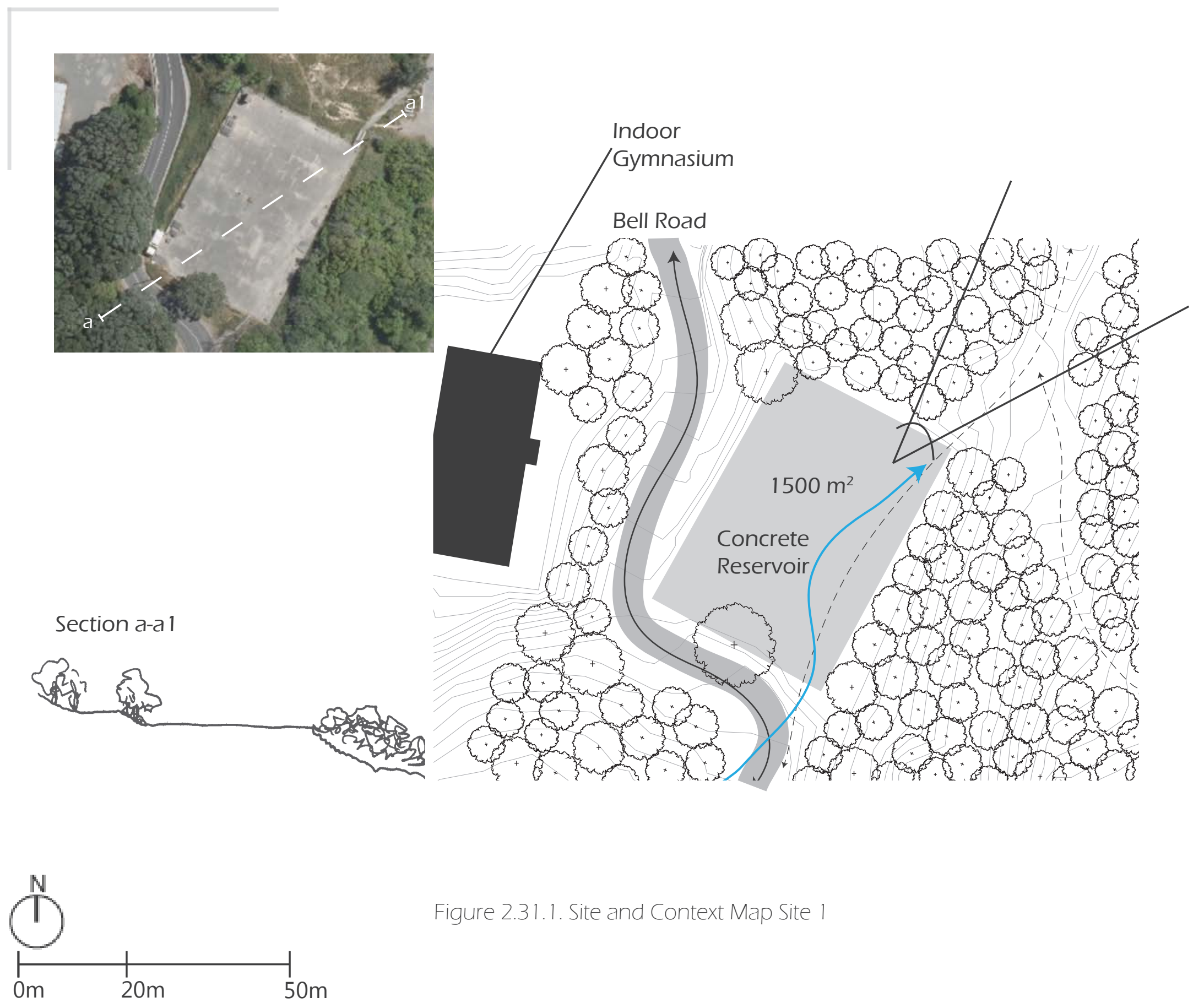

Figure 2.31.1. Site and Context Map Site 1 


\section{Site 1: The View}

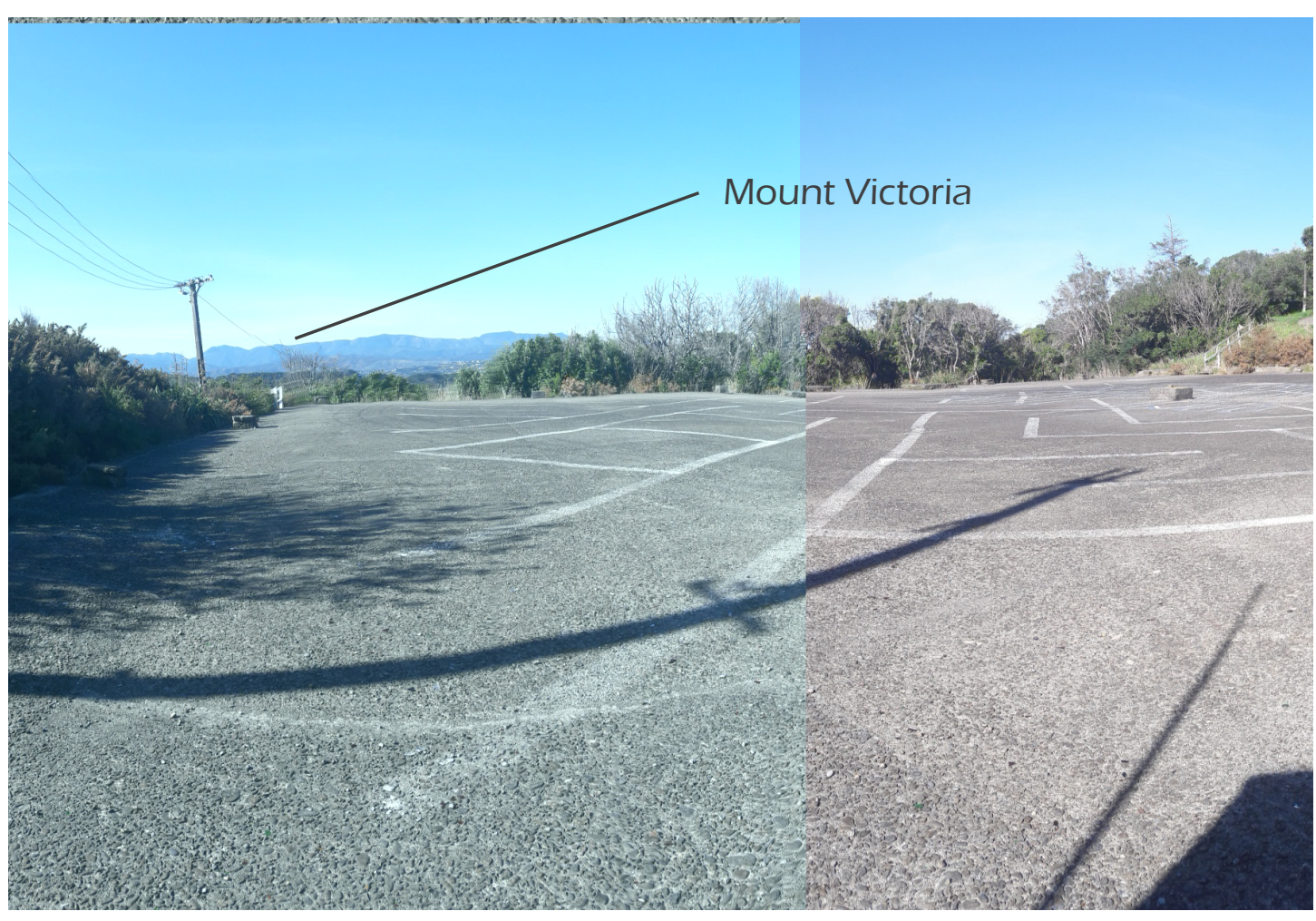

This site is the top of the Bell road water reservoir between Mount Cook and Brooklyn, making it an exposed site with a view out to the harbour [Fig 2.31.3.]. It is a high thoroughfare route for people walking to work in the city and an occasional hangout for school age children on their way home.

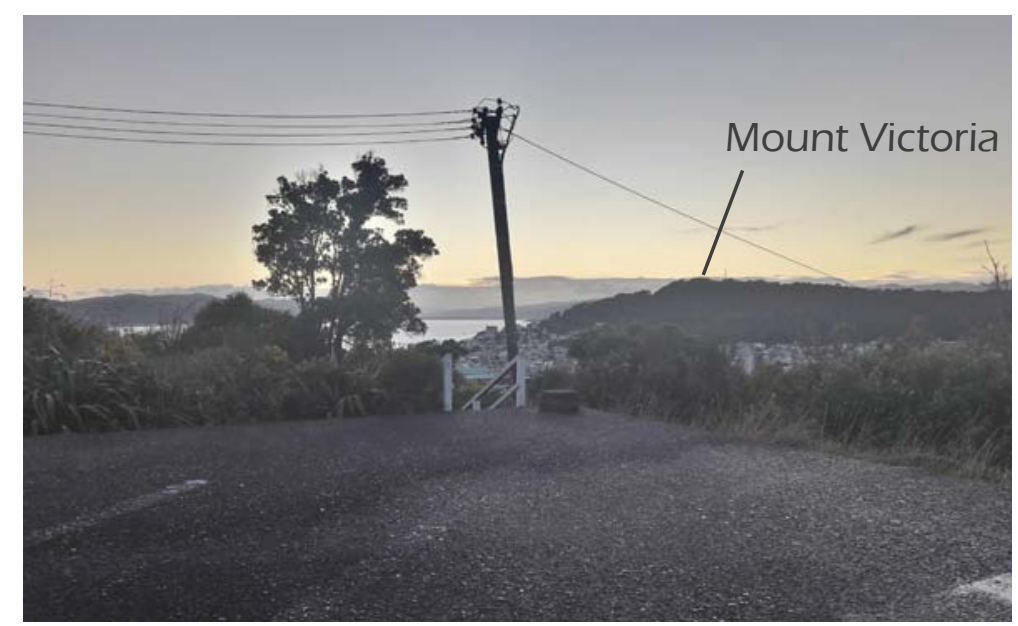

Figure 2.31.2. Image showing site

Figure 2.31.3. View out to the harbour 


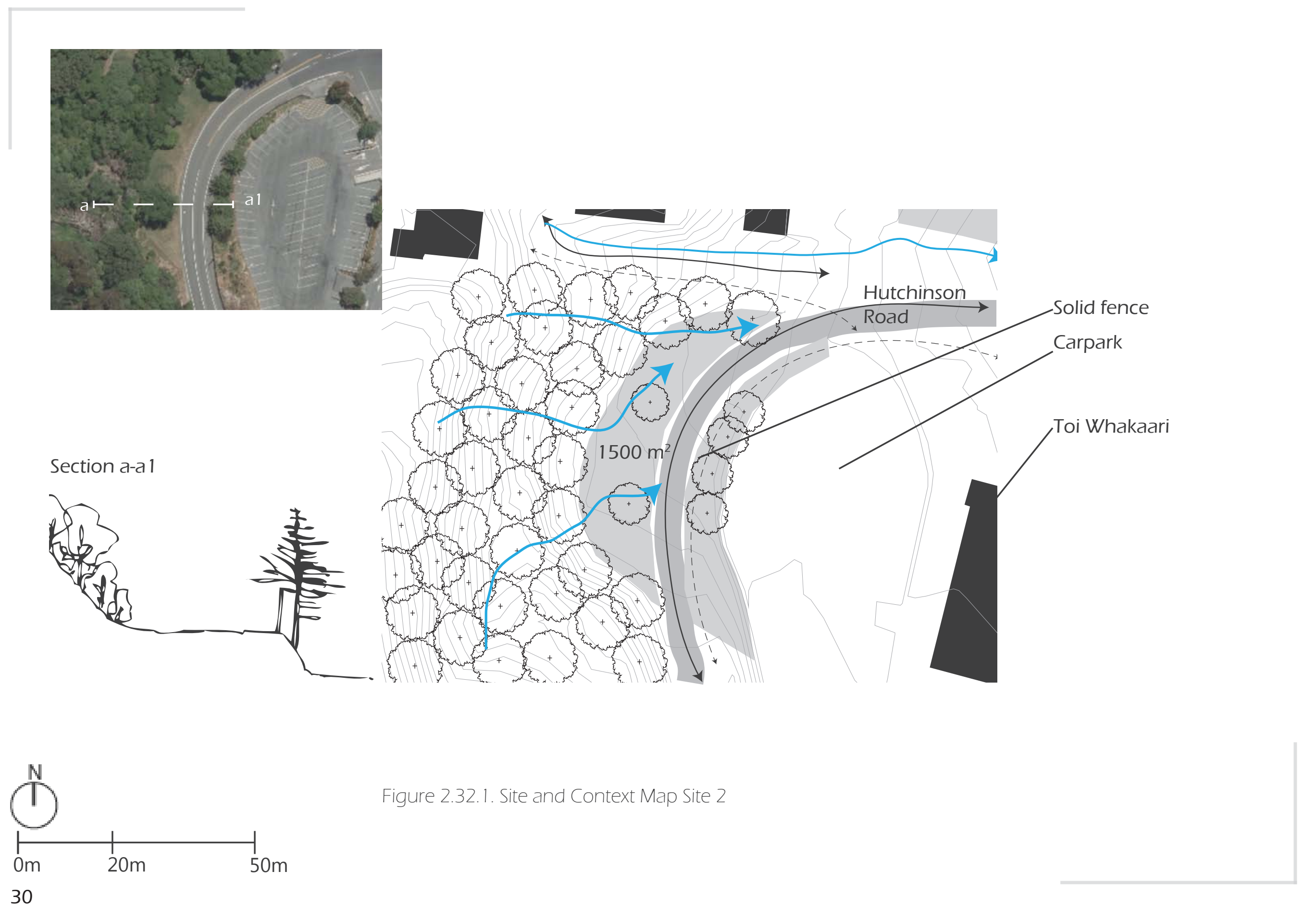




\section{Site 2: Shared Orchard}

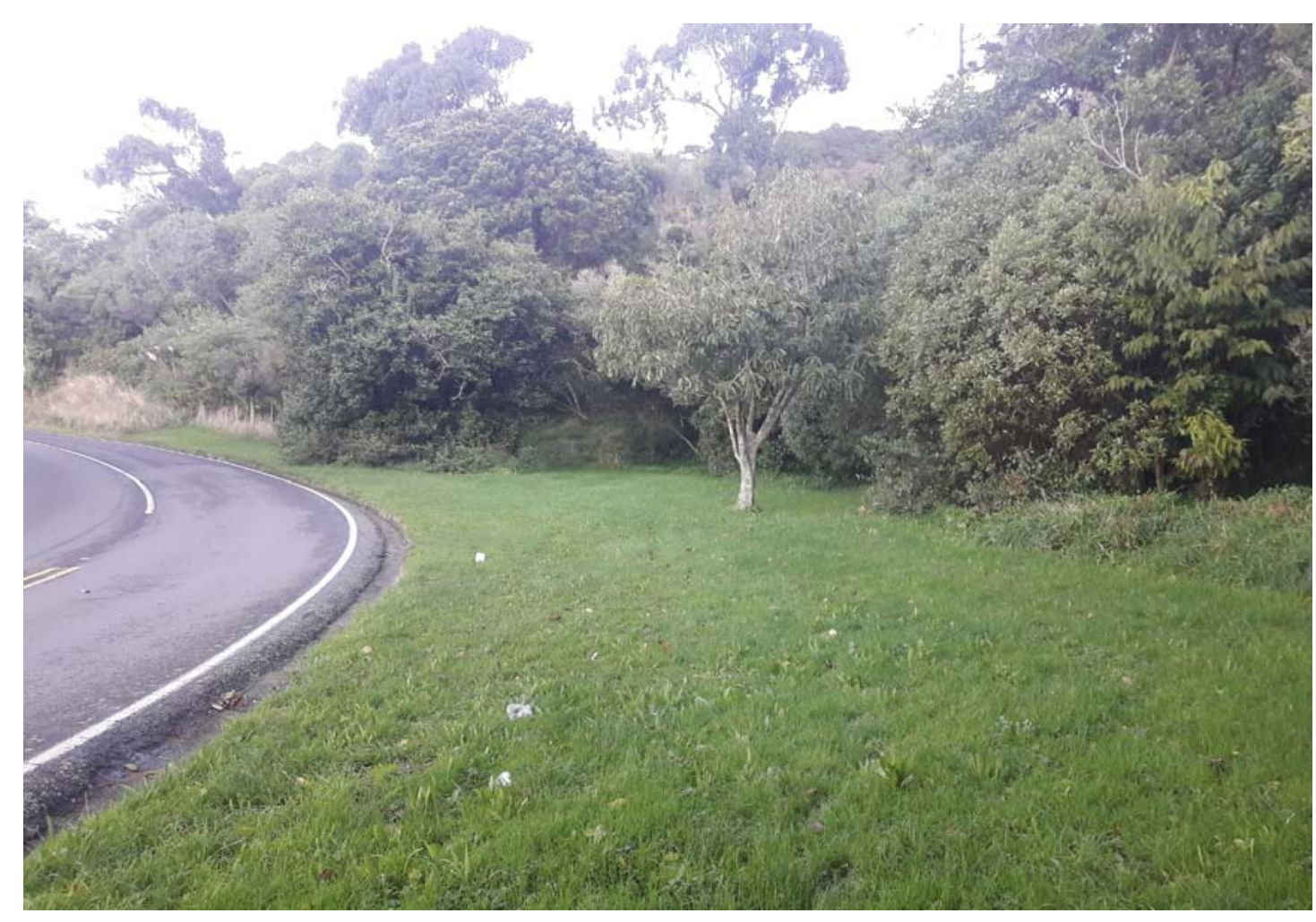

This site is an unused roadside space on the edge of the green belt. Native bush surrounds one side and on the other It has a road and then a giant carpark. This has created a very thin walkway along only one side of the road and makes it very uncomfortable due to the solid high fence right next to you [Fig 2.32.3.].

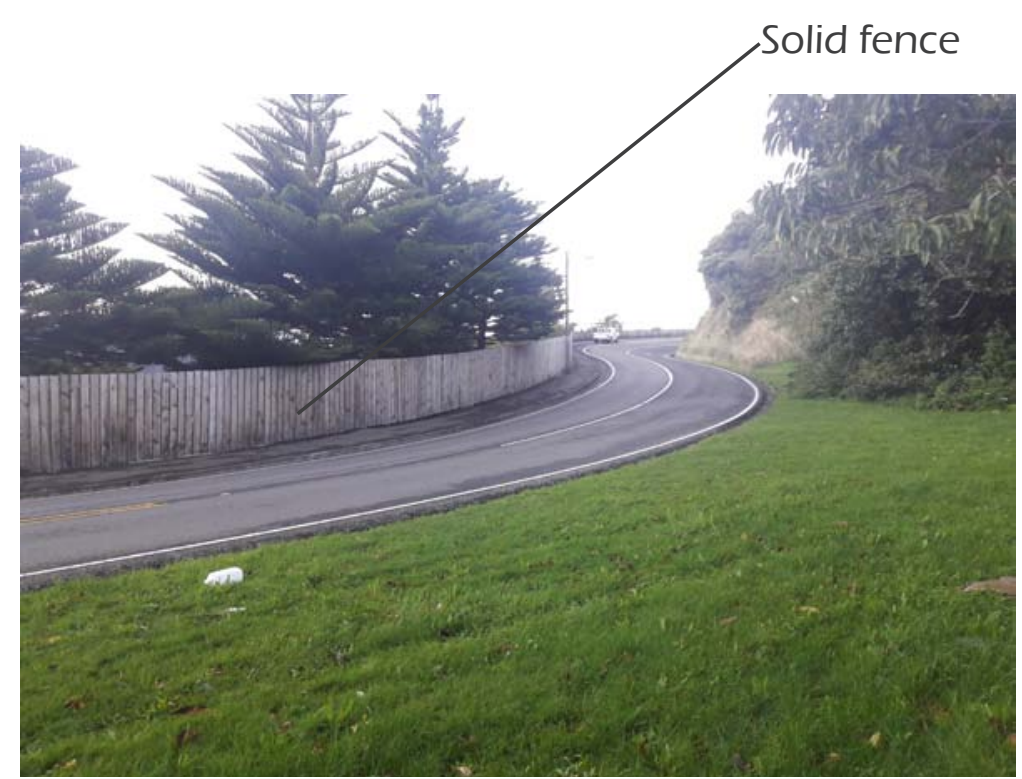

Figure 2.32.2. Image showing site 

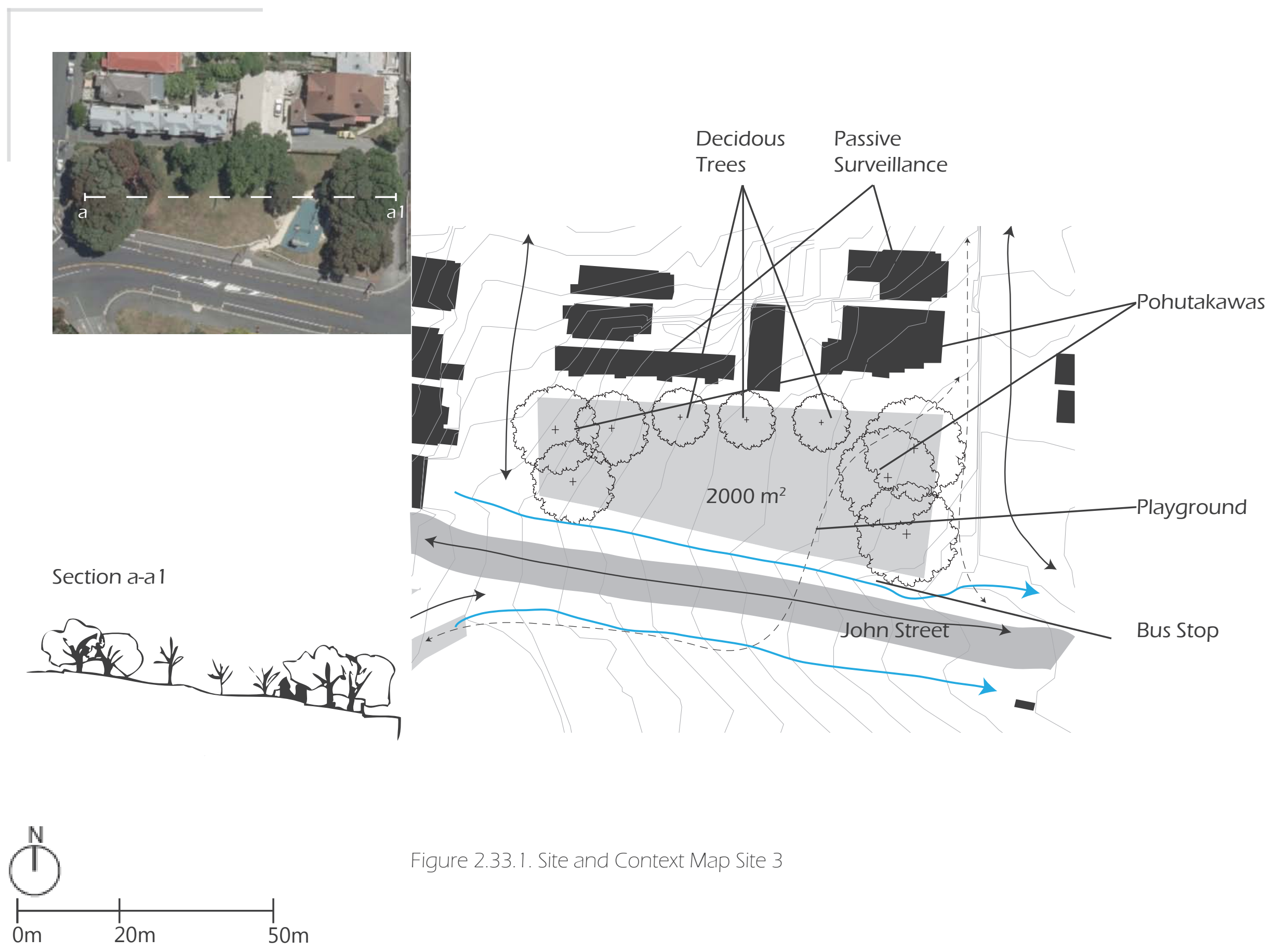

Figure 2.33.1. Site and Context Map Site 3 


\section{Site 3: Learn + Play}

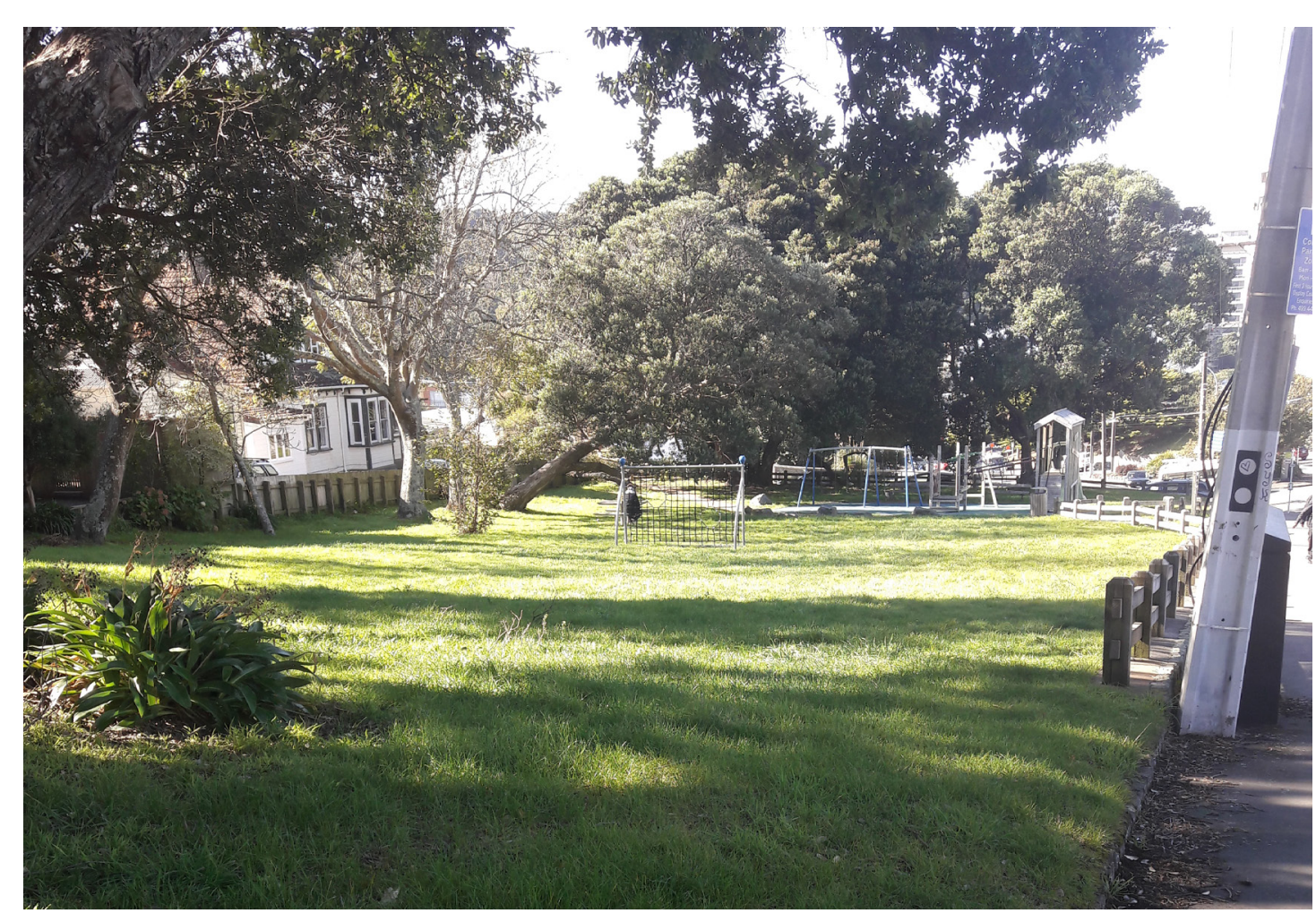

Figure 2.33.2. Image showing site
Mount Cook play area is site 3 , it is an expanse of grass with a children's playground and one picnic table. This space has a low slope and is sheltered by Pohutukawa trees on either side. It has potential for passive surveillance which promotes it as a safe space. It is opposite to Toi Whakaari on John Street, which is near site 2.

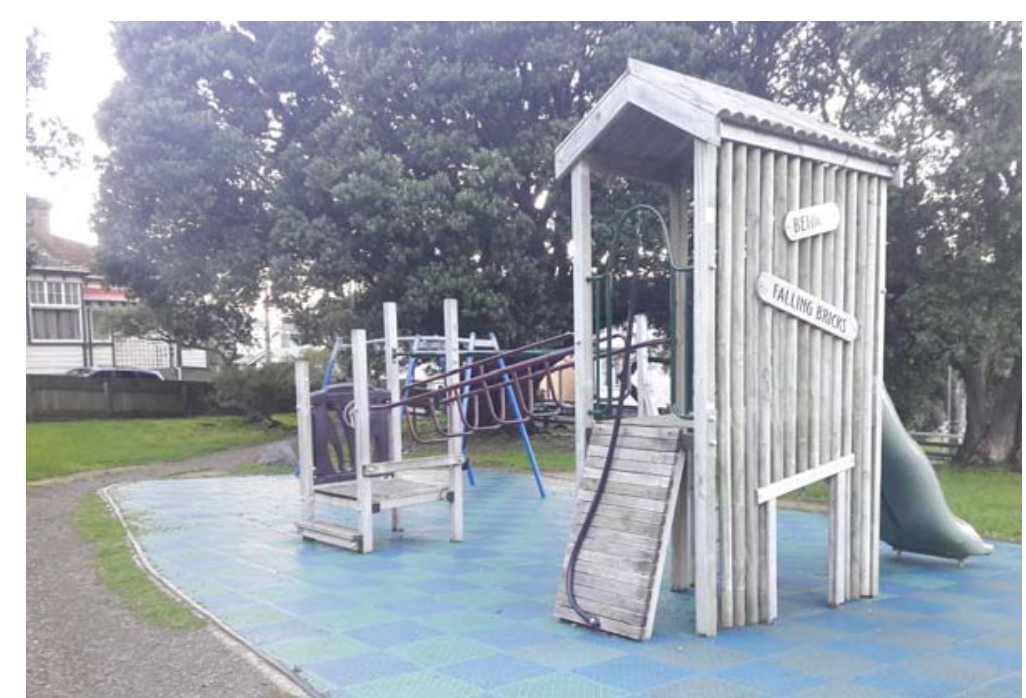

Figure 2.33.3. Playground 


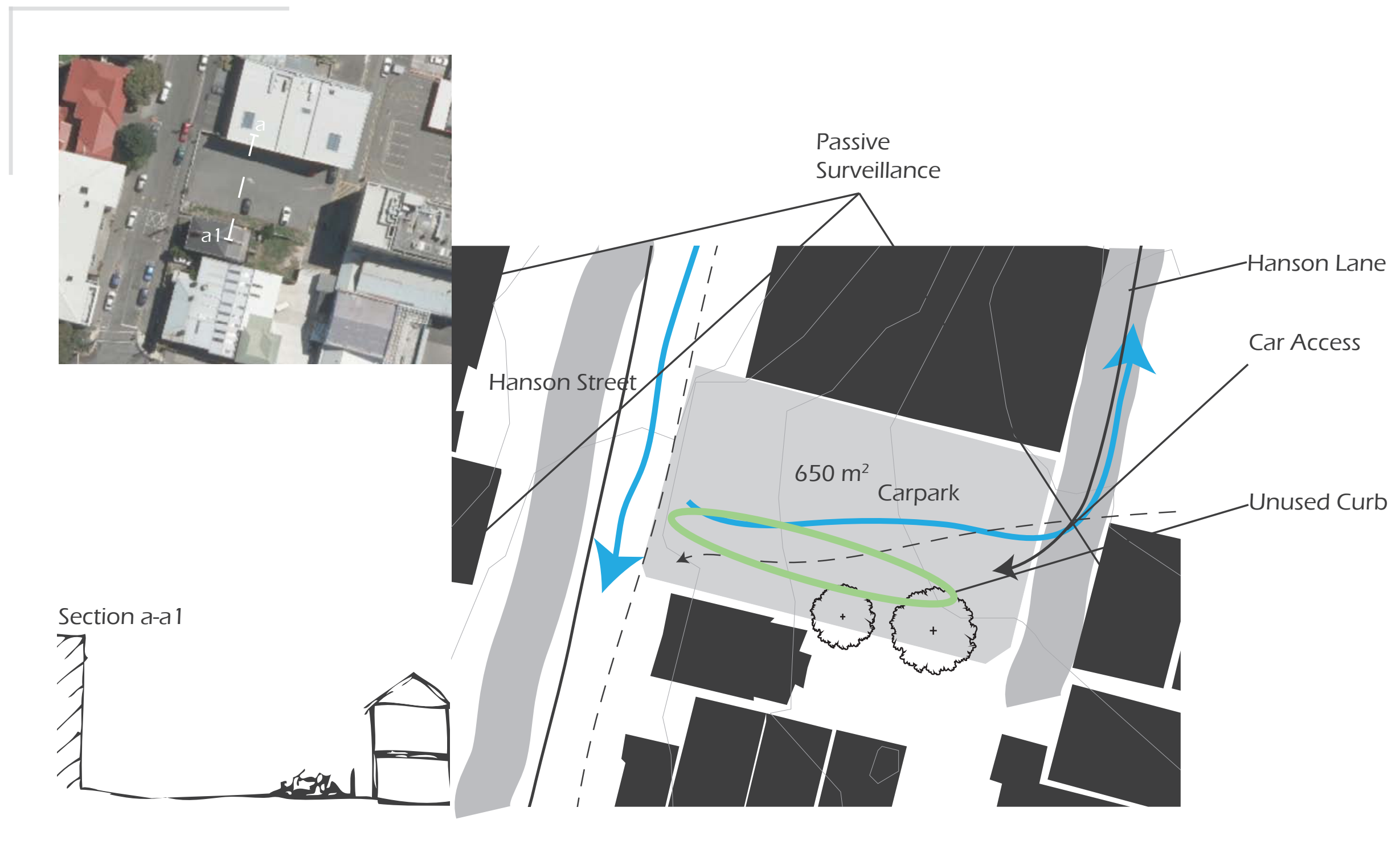

${ }^{N}$

Figure 2.34.1. Site and Context Map Site 4

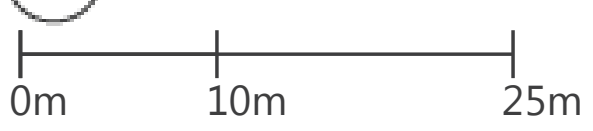




\section{Site 4: Movieable}

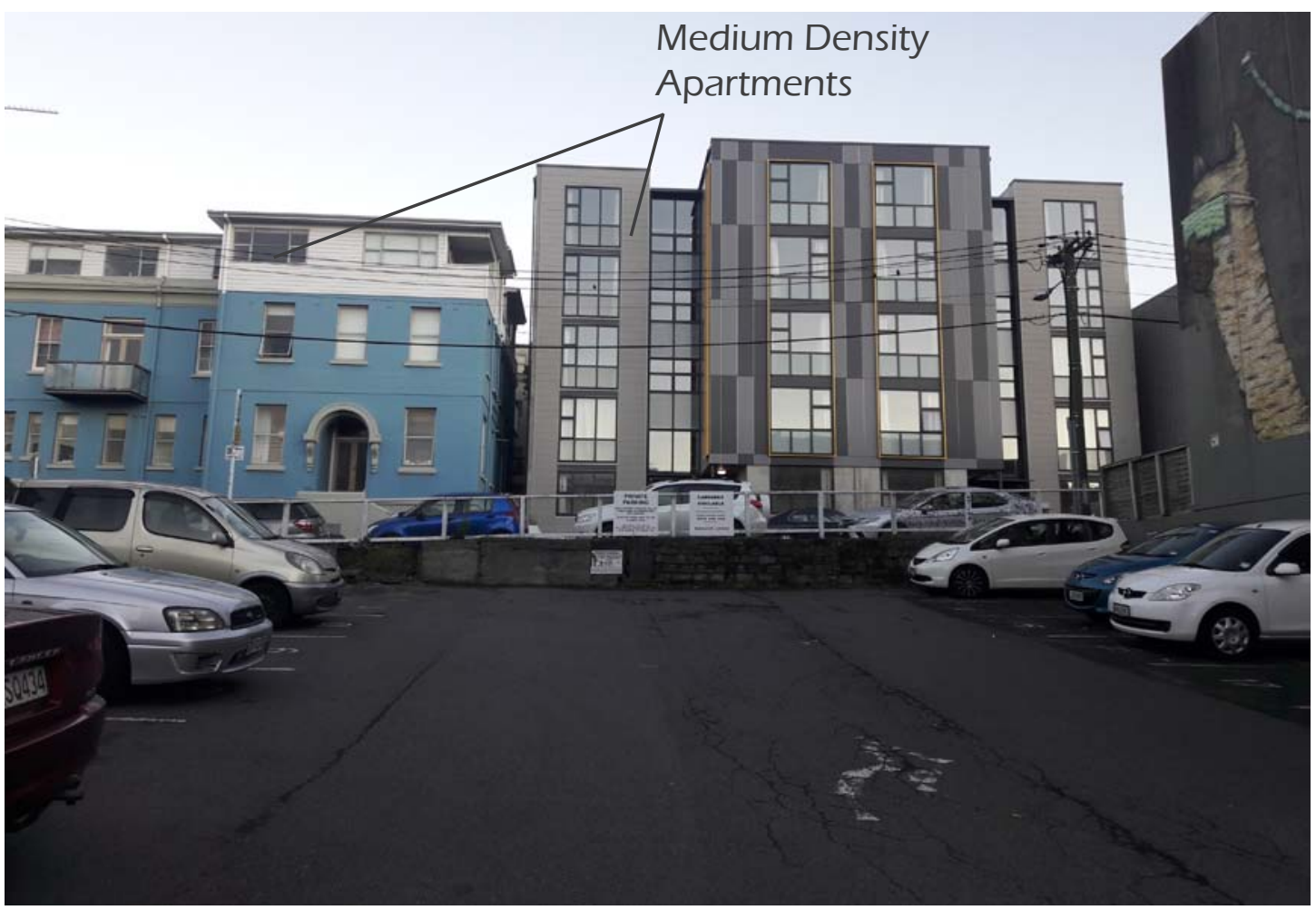

This site is a car park located between Hanson Street and Adelaide road which is surrounded by medium/high density apartments [Fig 2.34.2.]. As it has a tall building on its north side, which limits the sun it gets. Due to its location and being near a bus stop, it is a moderate thoroughfare route with people cutting through to get places quicker. The thing that first drew me to this site was the unused grass section [Fig 2.34.3.].

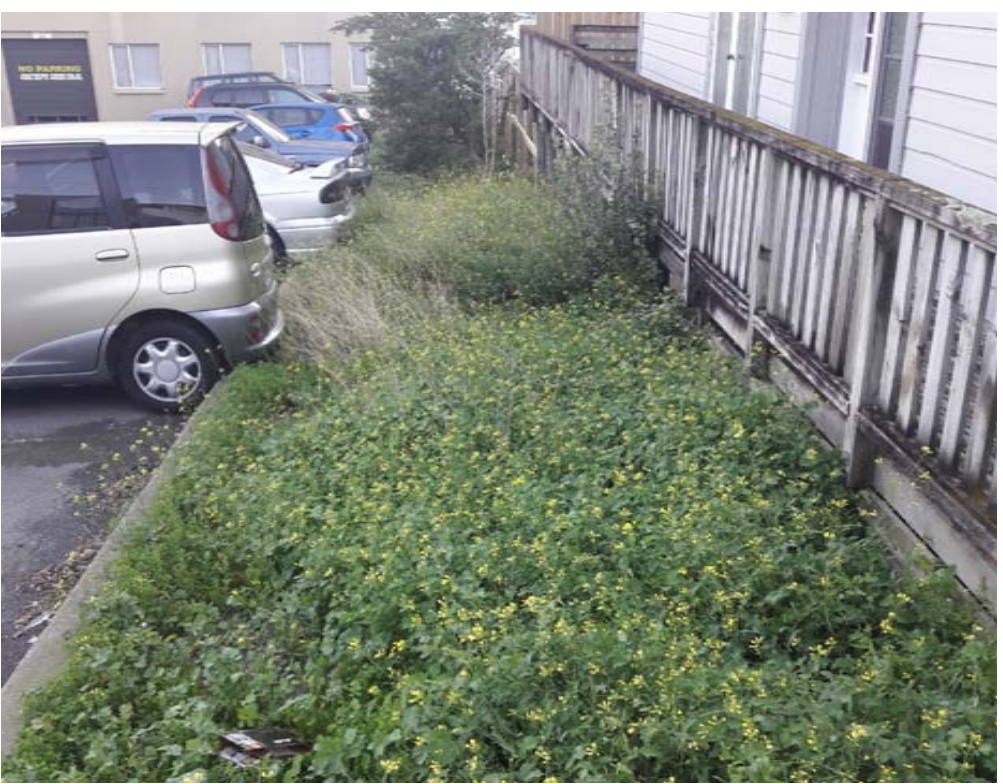

Figure 2.34.2. Image showing site and the medium density housing which overlooks it.

Figure 2.34.3. Unused space on site 


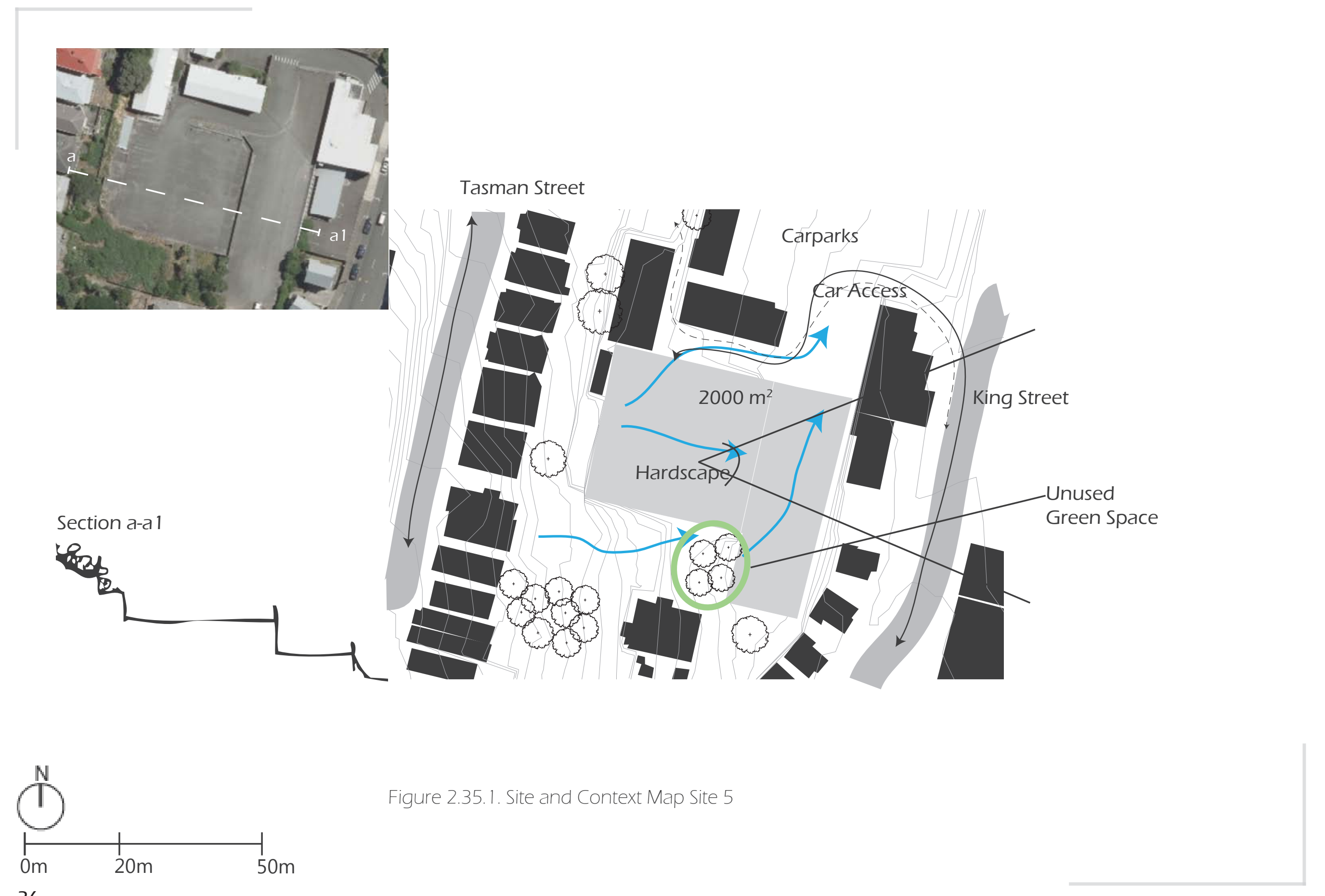




\section{Site 5: Accessible Levels}

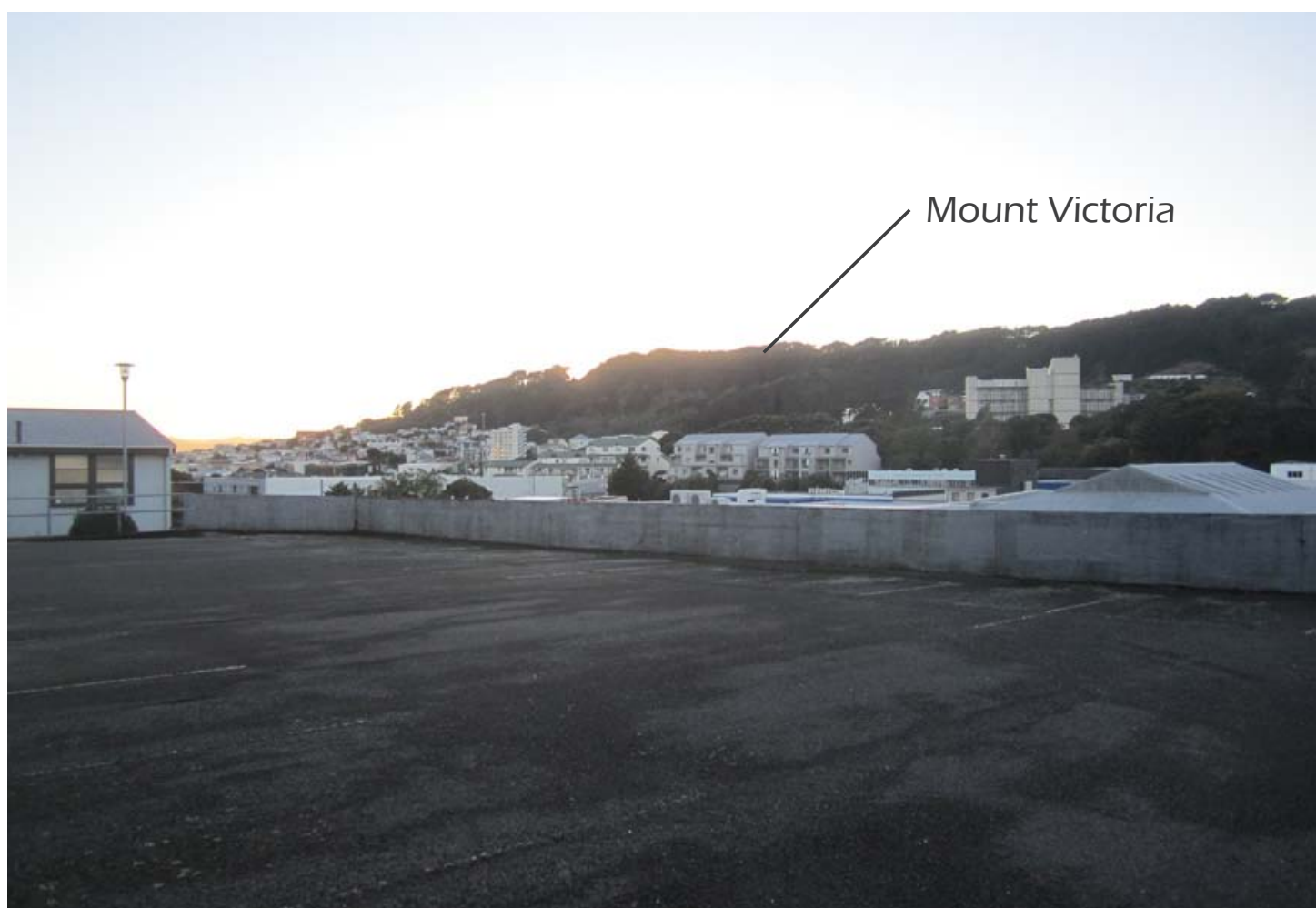

Figure 2.35.2. Image showing site view of Mount Victoria
This is a carpark for Massey University students located between Tasman Street and King Street. It is an exposed site with two levels and is visible from the street. It also looks towards Mount Victoria creating a sense of peace to be able to see the green belt. [Fig 2.35.2.]

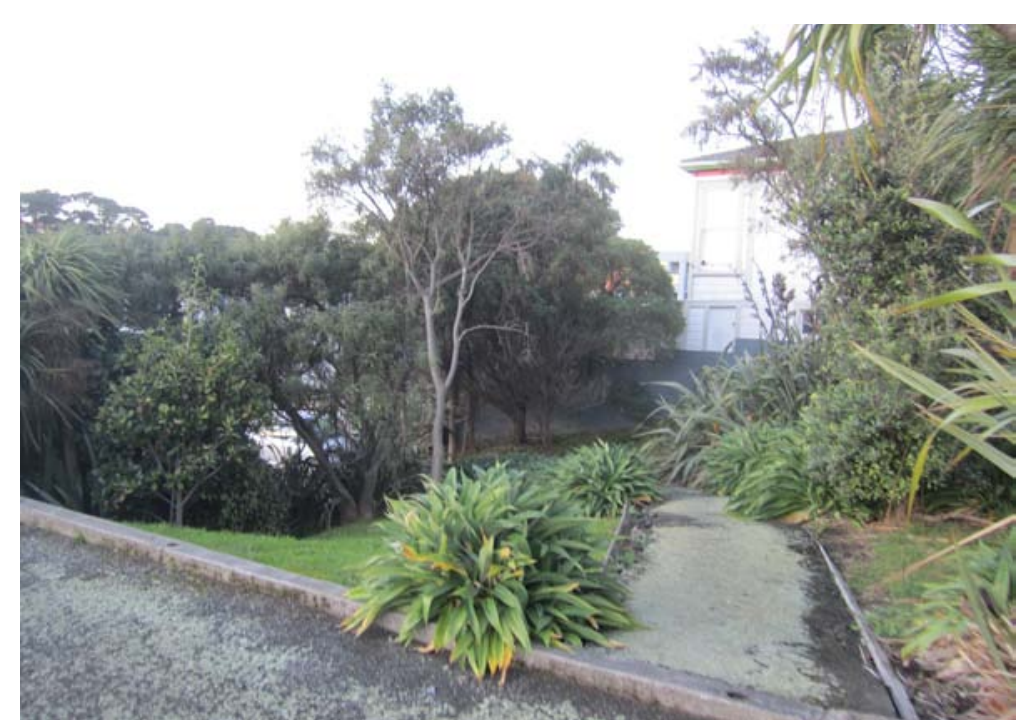

Figure 2.35.3. Unused green space on site 

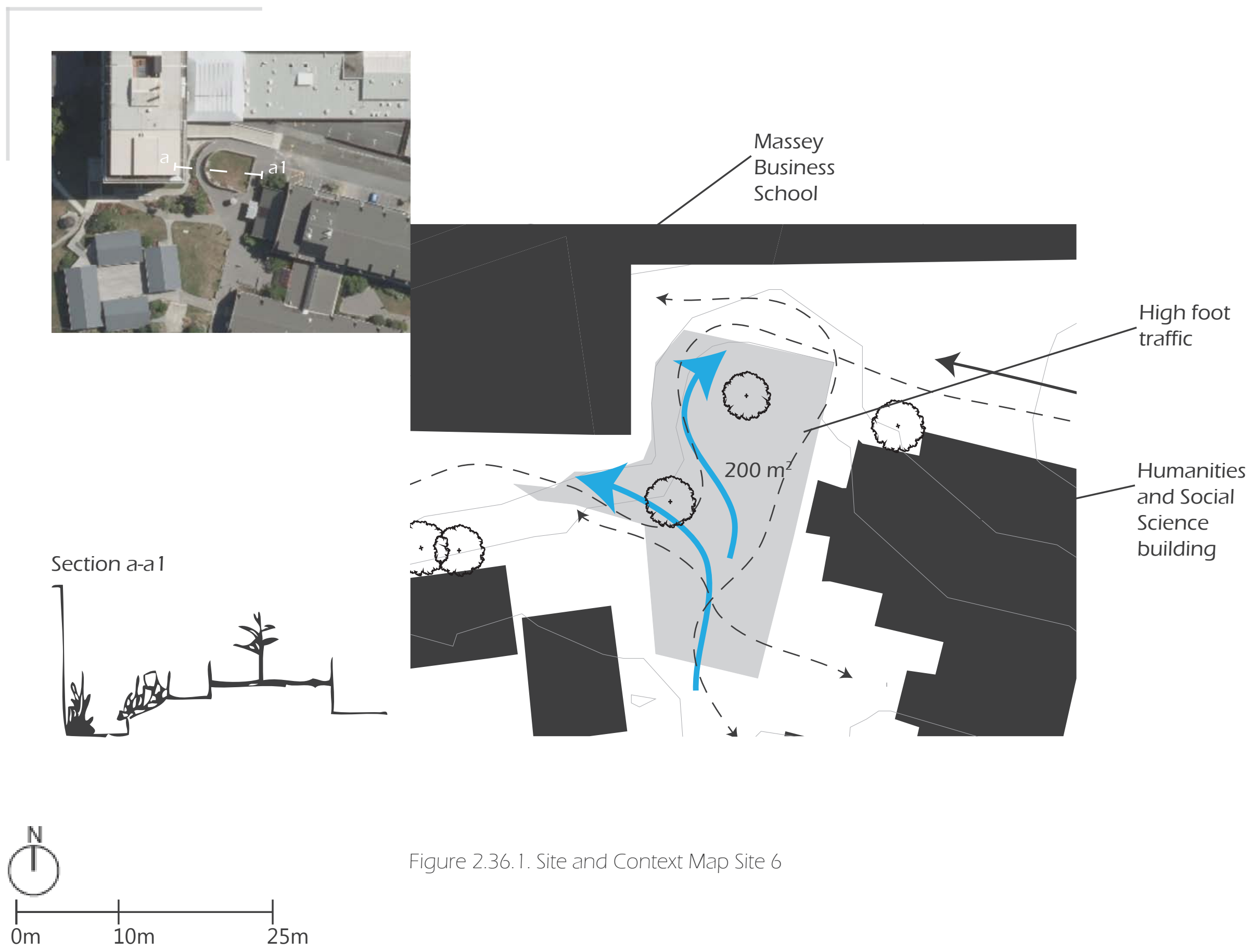

Figure 2.36.1. Site and Context Map Site 6 


\section{Site 6: Lounging Lunch}

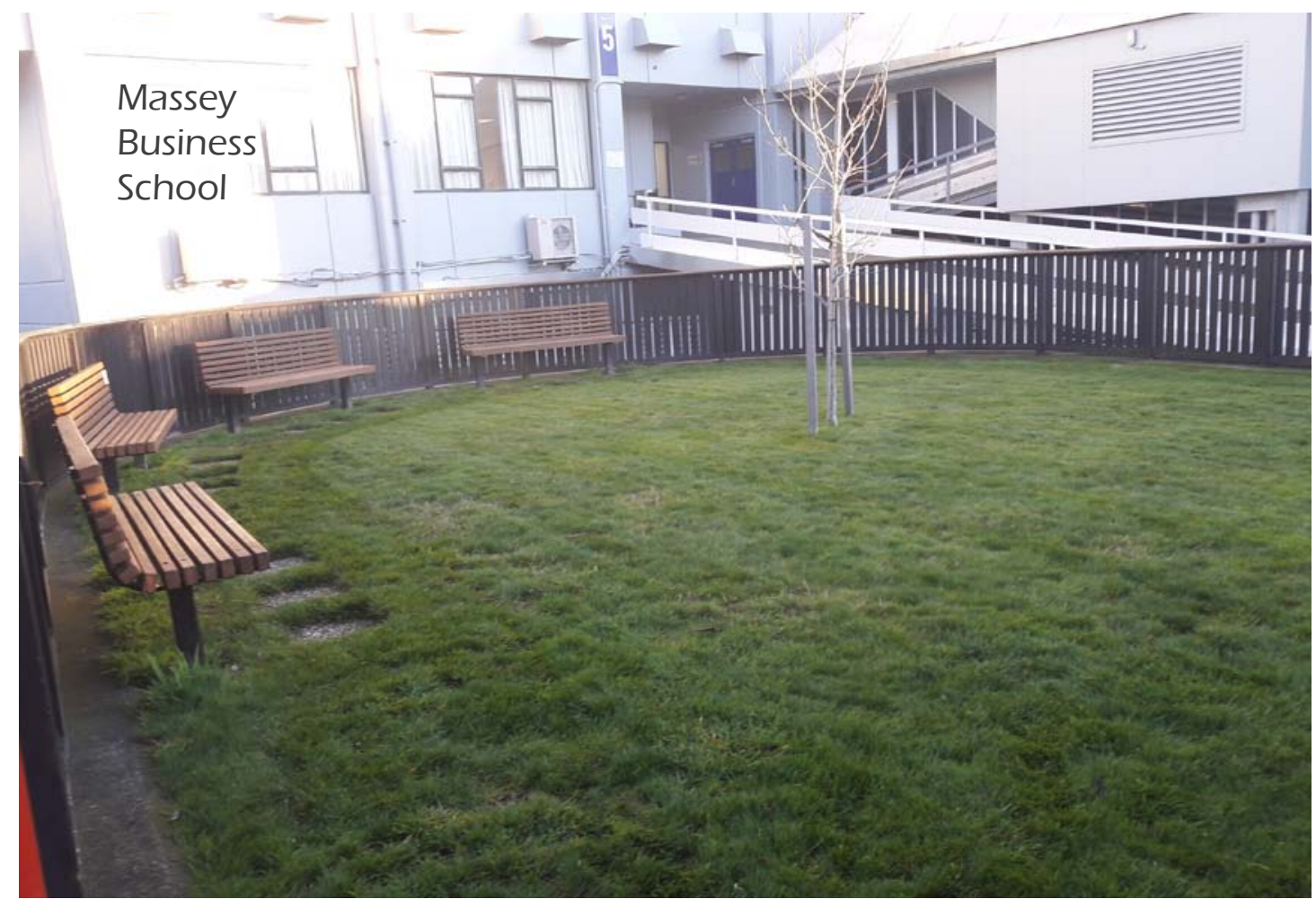

This site is part of the Massey campus located between the Business School and the Humanities and Social Science buildings. It is a high thoroughfare zone as it is one point where you can easily cross between Tasman and Wallace Street. It is the smallest site at about $200 \mathrm{~m} 2$ and currently just a couple of lawns with a few seats. [Fig 2.36.2.] 
Urban agriculture is the practice of cultivating, processing and distributing food in or around urban areas.

Permaculture is the development of agricultural ecosystems intended to be sustainable and selfsufficient; is a set of design principles centred around whole systems thinking simulating or directly utilizing the patterns and resilient features observed in natural ecosystems.

Productive public space: a space that can be used by any member of the public, that can also provide for a major need. (food, water, shelter, community)

Recovery from the 4 Rs means: the coordinated efforts and processes to bring about the immediate, medium-term and long-term holistic regeneration of a community following a civildefenceemergency.

Resilient is the ability to quickly return to their usual state after something difficult or bad has happened.

Disaster means a sudden accident or natural catastrophe that causes great damage or loss of life. 


\section{Literature:}

"The difference between being in an earthquake and being in a disaster is the level of preparation." This quote was from an article where they question why Chile manages to come out unscathed after a 8.4 scale earthquake. When lesser earthquakes have killed thousands, Chile only had 13 casualties. (Franklin)

The discipline of disaster planning considers the most appropriate strategy is to prepare the city by looking at architecture engineering solutions that resist gravity and are safe to inhabit after an event. After years of making sure the structural side of the city is safe, how do we live in it with restricted transport, food and water infrastructure?

This paper explores the literature around three key themes:

-Urban agriculture and productive spaces

-Spatial composition with urban parks and functionality

-Resiliency and public space (interaction/ hybridity)

Each theme is discussed in terms of their application to design and what I would consider a 'productive public space.' 


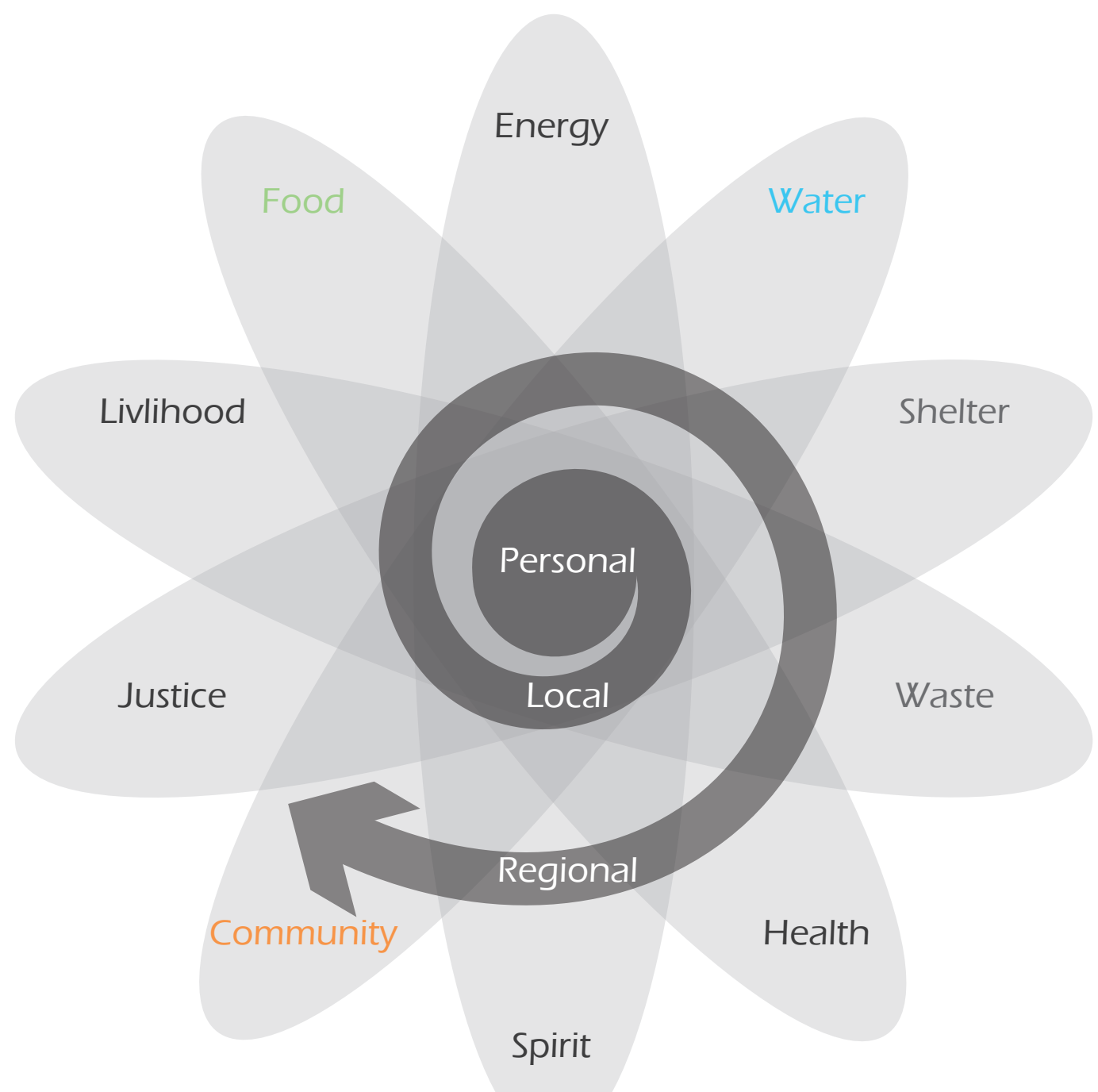

- Giles Sioen Post-Disaster Food and Nutrition from Urban Agriculture

- Toby Hemenway The Permaculture City - Anne Whiston Spirn The Garden is a Town

Key words/ideas - community gardens, urban agriculture, permaculture, food security,

Actions I can use for designing

- Networks are essential in having spaces that are resilient

- Leave some aspects for the community to design/ to make the space their own.

Figure 3.1.1. The permaculture flower that Toby Hemenway adapted. 


\subsection{Urban agriculture and Productive Spaces:}

It is important for survivors of disasters to have access to fresh fruit and vegetables that complement the food provisions that would be given out when access to food is limited. Urban agriculture can provide this to get the communities the nutrients they need (Sioen, 14).

Because food takes time to grow, it would be necessary to make sure there is always some food growing in urban agriculture throughout the year to supply this need. Due to this there would have to be some community involvement and use of the food when it is ready.

Having access to food is also an important part of the permaculture principles that are the foundation of The Permaculture City that Toby Hemenway has written.

Permaculture is the toolbox that helps us organise and decide when and how to use tools for sustainable design. The principles are sustainable based ideas that can help design our lives.

The permaculture flower that Hemenway adapted [fig 3.1.1.] establishes all our needs from physical to spiritual, and how they relate at different scales.

In terms of resilience and post disaster some of these aren't as important even though they all play a role. The most important ones are physical needs such as water, food, and shelter. Although the intangible needs like community, health and livelihood are pretty important as well.

Hemenway goes on to discuss how all these needs are important for a city to function properly.

"Is food growing an essential function of cities?" Hemenway asks himself in his book the Permaculture City. He reflects on why it isn't a critical urban function and even though the more accessible your food is, the better.

Cities do not have the space to grow all the food needed within a city. (Hemenway, 6)

It isn't important that we start urban farms in our cities to grow all of our food. We should have access to the fresh food we need, in proximity. Now this only becomes an issue for some cities if their access to the food gets cuts off. Wellington in particular would be subjected to this if our transport routes failed due to an earthquake. This is when we would need to grow some fresh produce within the city creating a more resilient city.

Are Community gardens public space? According to Toby community gardens are; "parcels of land divided into small garden plots that can be leased by individuals or families." The fact that you actually pay for a plot makes it less of a public space. It creates a divide between the public and private space. The personal perception of public space is important for creating spaces that everyone can use.

Public space refers to a place where any member of the public feels welcome, and community gardens often have physical boundaries that need to be crossed. Which when everyone looks at you then makes you feel out of place.

Spirn says in The Garden is a Town "the community garden provides a setting for most of the physical and social needs essential to human life.' They become a life force that allows 'most obviously planting, growing and harvesting food but also sharing and trading, meeting and play, making and building, and for dreaming and worship'. These are good things to have but the spatial arrangements of a community garden limit who and how many people can use the space comfortably. (7)

It makes me question the role they have in a city. Can there be more than just productive public space? 
Spacing:
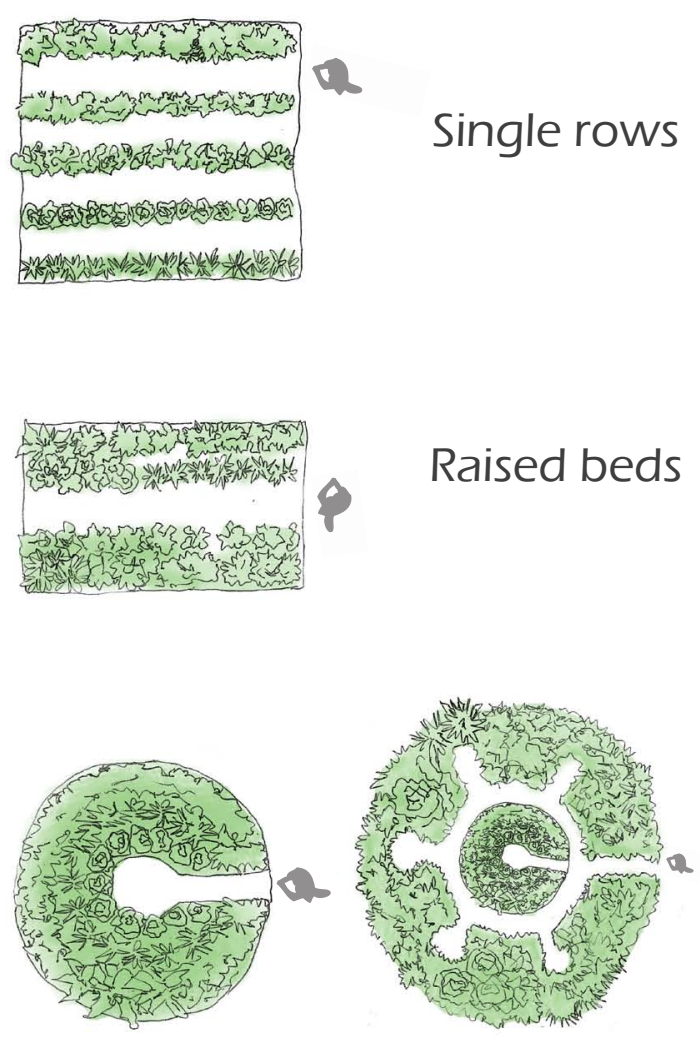

Keyhole/mandala

Gardens

Figure 3.2.1. Spacing of plantings
Vertical elements:

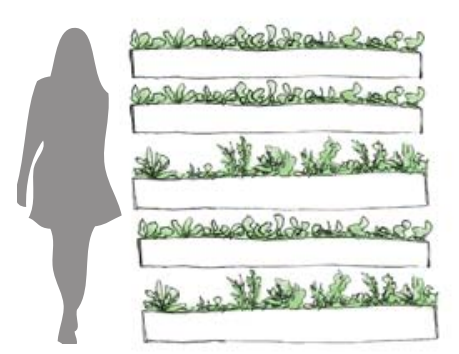

Stacking
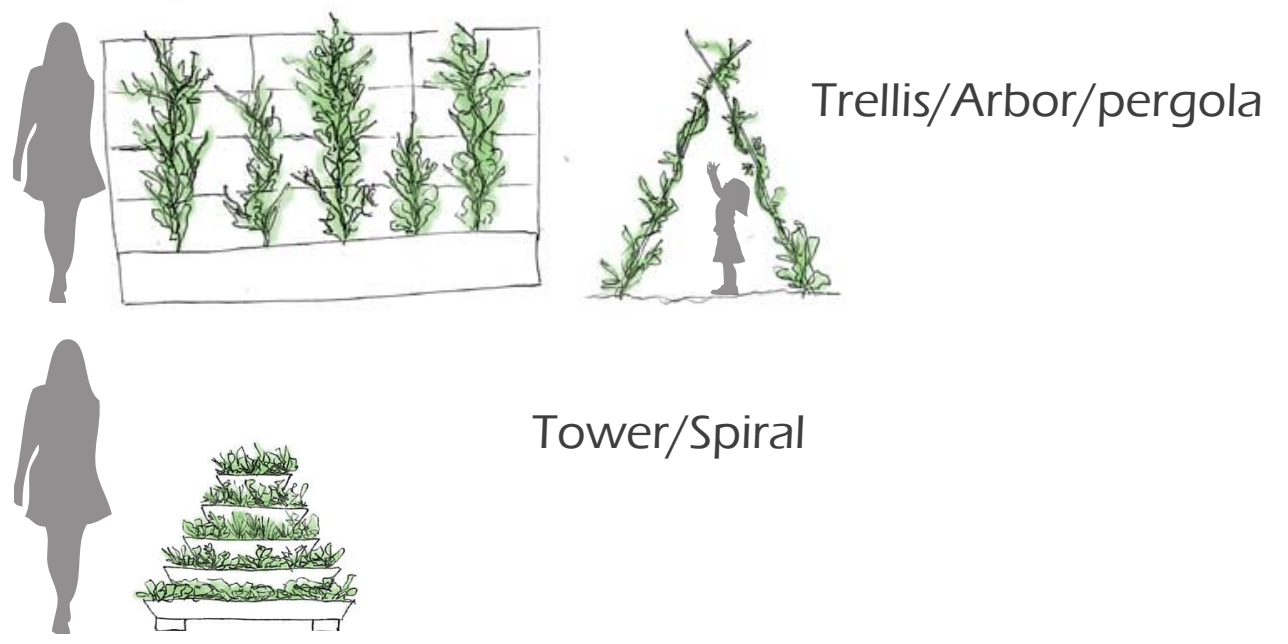

Figure 3.2.2. Vertical Plantings 


\subsection{Spatial Composition of Urban Parks and Functionality:}

Spirn looks at the common patterns of the 8 community gardens. These are; having a territory through boundaries and gateways, Pathways throughout or a border of; a meeting place; afford a sense of refuge; source of water; source of food; signs. (9)

These spatial conditions of territory through boundary and gateways, and pathways and a meeting place are key to how a person feels in the space. Along with maintenance these affect if the space feels comfortable.

Some of these gardens offer a place where the public can walk through. These are the Schuykill Park garden and the Powelton summer/winter garden. These allow it by having wide paths and open entrances. Still having a boundary but allowing flow through it.

After reading The Permaculture City I understood that small outdoor spaces for people in the city, there was a need for multifunctional elements and being very creative with how we utilise every space for maximum production. This was referring to how people could produce in their own back yards; but why couldn't we bring this into the public spaces that we design?

One of the techniques that is mentioned in The Permaculture City is 'High Yields' in the microyard. This is about using every space possible in terms of productive planting, effective spatial organisation will provide more yield. This helped my understanding of composition in smaller spaces. Using raised beds of solid plantings is a more efficient use of space than having many rows of plants with paths in-between. And improving on that is the keyhole garden bed that has one path in the middle that allows for the most production space per area. [3.2.1.](Hemenway 79).

Having vertical gardens [fig 3.2.2.] that stack on one another allows for maximising growing space while using less area, although some spaces don't suit this type of planting and it can restrict sun to other areas. Trailing plants or vines can be grown up a structure to minimise growing space while maximising productivity. These create fun differences in the way we garden and can allow children to be more interested in their food and where it comes from. This comes from the core permaculture principle of make each element perform multiple functions. (Hemenway 24).

- Anne Whiston Spirn The Garden is a Town

- Toby Hemenway The Permaculture City

Key words/ideas - multifunctional, Urban Parks, Public Space

Actions I can use for designing

-Using multifunctional design elements that can be adapted/moved if the need arises.

-Productive spaces must be reachable to $600 \mathrm{~mm}$ due to average reach.

-Creating spaces that have wide walking paths so the public feel like it their space too.

-Use less boundaries around the whole garden. 


\subsection{Resiliency and Public Space (interaction/ hybridity):}

Hemenway's last chapter, notes tools for designing resilient cities. He has applied the permaculture major design methods, (needs and resources analysis, zones, sectors and highest use) throughout the book to the needs that are represented in the permaculture flower [Fig 3.3.1.]. This establishes leverage points which he thinks can be strengthened or built upon to form a resilient city (Hemenway 229). By using local spaces that you move past often it creates a sense of identity of the space and allows public to use it as a known destination.

'Chile has one of the most effective disaster relief infrastructures in the world - led by a general who lost his wife in the 2010 quake in Haiti. How? It's all down to rigorous building codes, evacuation simulations and, above all, preparation.' Chile prepares by having earthquake and tsunami drills to prepare everyone for what will happen. For Wellington we need to prepare in terms of resources so we don't' have to be in a disaster. (Franklin)

Penny Allen and Martin Bryant look at ways communities have acted after an earthquake. Through their paper they have looked at two case studies. One in San Francisco after the earthquake and fire of 1906. This established 'in place' recovery with the evenly dispersed parks and open spaces.

In the case study in Chile after 2010 EQ Perhaps one of the most dramatic and spontaneous adaptive responses to the earthquake was the way as a survival strategy, communities constructed barricades on local roads to create smaller, modular neighbourhoods with distinct boundaries. (Allan, Bryant 123)

Survivors of the earthquake wanted and needed a place to keep going, find food, water and medicine was crucial for their survival. This adaption that people took in Chile shows that most survivors need a sense of community to hold them together and to keep going. These actions of the survivors are paramount to the conditions they had. We must make it easier so we don't have to be survivors.

- Toby Hemenway The Permaculture City - Penny Allen and Martin Bryant The attributes of resilience- $A$ tool in the evaluation and design of earthquake-prone cities

Key words/ideas - resilience, sustainability, resilient cities, adaptability, post disaster, disaster relief.

Actions I can use for designing:

-Creating local spaces that can become a hub that people know.

-Designing spaces that can adapt to change.

-Using multifunctionality to produce some of the resources needed.

-Create spaces that can bring communities together before a disaster. 


\subsection{Reflection:}

Throughout this research for this paper I have learned that urban agriculture is important to disaster recovery and should be used to build resilient communities within cites. This production can be in a variety of sizes to allow the most production for when the city needs it most. These high yield options for plantings function on less space and give out more production. This enables small spaces within cities to use this to maximise food productivity.

From Hemenway I learned the permaculture principles and how they can be implemented throughout the city. These create a sense of community in the local realm and allow you to sustainably design spaces to function with maximum efficiency.

This literature was helpful for me to understand how communities can get back up again after a disaster, using similar ideas they can build their own survival kit by assembling their community space which will help them after a disaster. This is an important factor in creating spaces that the community can look after and respect.

From these actions that each literature posed most allowed ideas to be used through all sites to create recovery spaces. Although the everyday design of these typologies had a specific purpose allowing different groups to use the space for a neighbourhood event. 
Redacted Copyright Image

Figure 4.0.1. Northern Wellington community garden 


\section{Precedent Review:}

The following project reviews aim to extend the knowledge established previously in the literature reviews. Looking at how different designers have brought food, water or shelter to landscapes has allowed critical thinking and assessing of spatial conditions and the ideas behind each design 


\section{Redacted Copyright Image}

\section{Redacted Copyright Image}

Redacted Copyright Image

\section{1 Vacant to Vibrant:}

It is an initiative for a low cost solution to stormwater management an alternative to massive, centralized sewer upgrades that cost billions. It uses landscape to capture rainwater through bioswales and rain gardens while also allowing the space to function as a play area or park. The initiative is working in three areas to improve the water quality of the Great Lakes in America. They use sites in socially deprived areas to create equality between the neighbourhoods. Small scale projects with signage allow public to understand the wider project.

This particular example [fig 4.1.l.] is set in Buffalo, New York and uses rain gardens to create play spaces for children. Using vacant lots allows increase in amenity for the neighbourhood and by allowing rain to filter through the soil it increases the quality before it gets to the Great Lakes.

This next example [fig 4.1.2.] in Gary, Indiana is one of the more active sites with a wide open lawn and rain gardens at either end to add to the curb appeal. Children use this site for small sports and running around.

Cleveland, Ohio [fig 4.1.3.] has one of the most loved parks with a swing set and balance beam. On this small site water infiltrates right into the soil while still allowing the children to play on the site.

This project got me thinking about how the water collects on each site and if a design could slow some of the water down it would infiltrate the soil rather than going down a drain. This is used in the Shared Orchard-A Passive Interaction where the slope of the hill allows for terraced gardens that can collect the water in the garden before it runs off the site creating a low maintenance garden. It also made me think about how children would act if water was collected and used as a feature onsite.

Figure 4.1.1. Buffalo, New York

Figure 4. 1.2. Gary, Indiana.

Figure 4.1.3. Cleveland, Ohio 


\subsection{The Getty Salad Garden:}

The Getty salad garden is a mosaic of gardens, for an art installation in the Getty Museum. Julia Sherman curated the garden for two special exhibitions centred around history, food and art.

This installation influenced my designs for the site through appreciating that each site can have an element of art and beauty instead of just completely be for function. And that growing anything will bring communities together and allow them to grow.

Through the spatial analysis of this precedent it became clear that spaces were created for different groups of people. Smaller spaces let intimate conversations and ideas grow whether the large group spaces allowed for lots of interactions.

Installations are temporary, they allow people to get used to something before it becomes permanent. If the public don't like an idea, an installation of it could

Redacted Copyright Image

Redacted Copyright Image change their mind. This allows shifts in the way we do things.

Some spaces could be temporary spaces that could be used differently in the future. The Movieable typology could be transformed back into a carpark or more housing could go in there. But when the sites aren't used for their full potential landscape architects could use them to create multifunctional space.

This garden was inspiration for me to use the idea of spaces that could be changed, they could be moved somewhere else, and they could be functional.

Figure 4.2.1. Showing people using and interacting with the garden

Figure 4.2.2. The event set up with a dinner table.

Figure 4.2.3. Showing the spatial configurations 


\subsection{Reinventing Vilonia:}

\section{Redacted Copyright Image}

Redacted Copyright Image

Redacted Copyright Image
Reinventing Vilonia is a design proposal that re imagines the town after it was hit by a tornado in April 2014. It is a town in Arkansas which due to its flatness and location is prone to tornados. The disaster recovery plan takes the opportunity to redesign the town with a structure for population growth and creating a safe town. By introducing a town centre, they have allowed public space to be at the forefront and creating safe spaces from containers being embedded in the ground allows for people to get to the if a tornado warning sounds. The safe scaping of Vilonia is easily accessible and prominent in the public landscapes with the emphasis on being able to see the structures from a distance [fig 4.3.1.]. The safe spaces are essentially a bunker made from cheaper materials that will survive being buried. A totem is part of the design showing public where the refuge structures are [fig 4.3.2.]. These sites are part of the public spaces and create this sense of a safe town for Vilonia.[fig 4.3.3.]

Comparing this to our disaster recovery plan allows me to point out that we don't have a plan for shelter after the earthquake. Implementing some structures could be possible on some sites and having temporary shelter could be stored on others.

Figure 4.3.1. An overview Looking south

Figure 4.3.2. A central square which has a relief bunker embedded in the landscape

Figure 4.3.3. Looking south from Long Meadow to Town square 


\section{Redacted Copyright Image}

Redacted Copyright Image

\subsection{Lafayette Square Park:}

Lafayette Square is a 1.5 acre park designed by Walter Hood. It was set up with all the amenities to allow many different people to use the space, but now has become overrun with homeless even though it was designed to give them the luxuries not everyone has. These include showers, toilets, phone charging points and barbeques, which sets it up as a start for a self-sufficient space.

This creates a space that could be city style camping where you just need a tent and some food. Due to this park being in the city, an issue would be that the systems they have in place would be connected to the city network. This would make these amenities unusable if the network was affected by an earthquake.

If I was to use this park as a plug in for a typology it wouldn't be very useful as doesn't have spaces to grow much food. Also, the amenities would all be connected to the main network and they would be unusable. This would mean that it is just a meeting place and a big park like this just being a meeting place isn't a good use of space.

Figure 4.4.1. Lafayette Square Park

Figure 4.4.2. The shower and toilet block 


\section{Redacted Copyright Image}

Redacted Copyright Image

\subsection{Case Studies: Working Community Gardens in Wellington}

In order for me to understand our local contexts, I researched existing gardens throughout the city. Looking at these gardens helped me understand what is important for them to function properly.

[Fig 4.5.1] Owhiro Bay community garden is part of the kindergarten. This allows the children to use the community garden and gain knowledge of where their food comes from.

[Fig 4.5.2] Bond street Community Garden is two raised garden beds with seating attached made for the restaurants to grow some herbs and flowers in. This is a multifunctional design that can contribute to how my typologies could look.

The newest community garden [fig 4.5.3.] in the city is on Haining street and is currently growing food for the Home of Compassion beside it. This makes it a community based project but not something anyone can just enter into. Although you can see through the boundary fences the locked gate makes you understand that its not a public place.

Figure 4.5.1. Owhiro Bay Kindergarten community garden

Figure 4.5.2. Bond Street community garden 

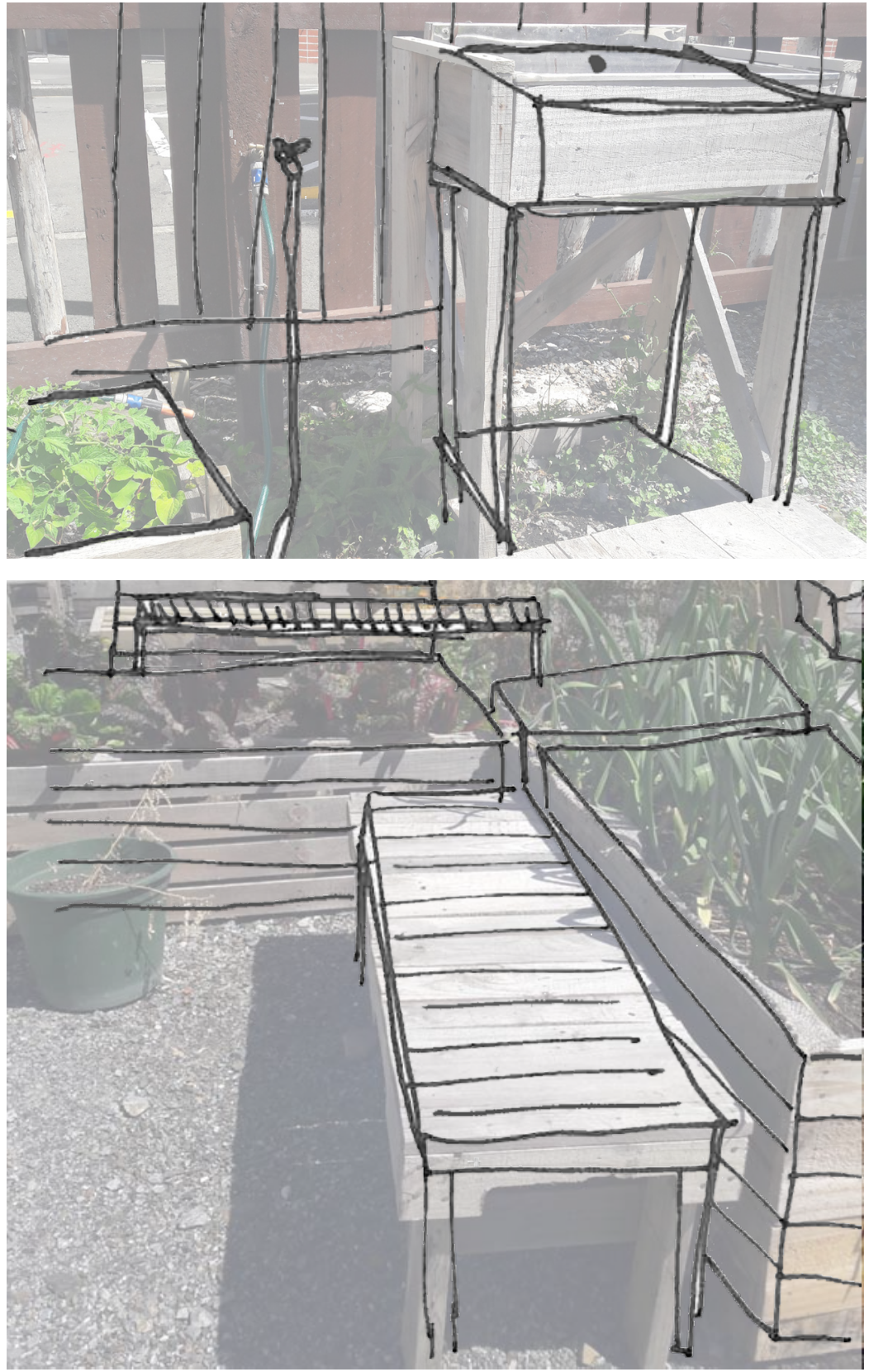

Based on these local findings, I concluded the basic elements of what may be necessary to make a basic community garden.

-to know the people that use it. -for everyone to have their own plot to use. -to have water onsite.

-having resting areas. (some in the shade) -to have a compost bin.

-designed for a specific community group.

The circulation around these community gardens is not thought about in a way to move lots of people as they only cater for small groups at a time. This creates a barrier for if these were possible recovery spaces.

The location of the community gardens serve the people around them but due to the limited number some people have to walk a while to get to the closest one. Access to most of these gardens is done by foot although some have car access possible.

These community gardens allowed me to see what was working throughout these gardens but it also allowed me to see why just using these gardens to provide the supplemented fresh

Figure 4.5.3. The water situation at Haining Street

Figure 4.5.4. Seating at Haining Street 


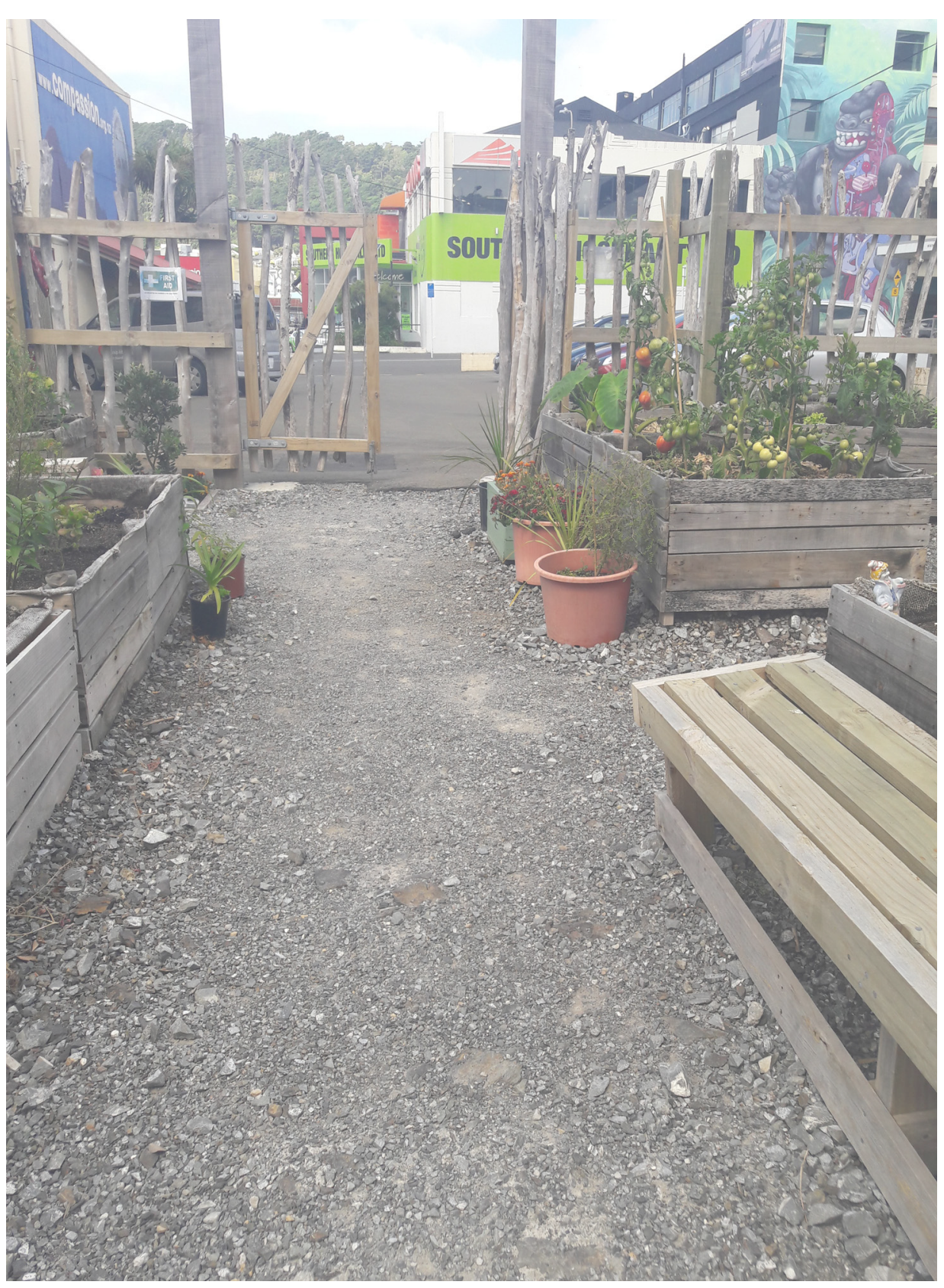

food we would need would be an issue. Through reading the permaculture city one thing Hemenway referenced to was to not put all your vegetables in one row because when a parasite finds what they like they'll go through it all. This is why a whole network of spaces is needed so when the earthquake hits it is able to effect some of the spaces but there is enough of them spread out to make sure there is still food available.

Water is used on the sites to water the gardens and to rinse the produce.

The spaces are organised in a block fashion with very simply built garden beds allowing them to be fixed by whoever works in the garden. This bring a very community feel to each garden.

These community gardens can become a recovery space, but as most of them are small sites and are making use of all of the space they have, there is no room for them to have big groups of people. These can help to provide the fresh fruit and vegetables that would be needed following an earthquake.

Figure 4.5.5. Haining Street Community Garden 


\subsection{Design Criteria from Literature and Case studies:}

\section{Criteria for a Community Garden:}

-to know the people that use it. (Sense of Community)

-for everyone to have their own plot to use.

to have water onsite.

-having resting areas. (some in the shade)

-to have a compost bin.

-Is designed for a specific community group.

\section{Design Criteria:} Emergency Space

-the ability to feel safe and secure. -calming/relaxing spaces. -protection from weather. -abilty to move through the space, room for walking and gathering. -comfortable spaces for all. - ease of access for all people. -positive sense experiences.

-spaces that provide some level of distraction.

\section{Criteria for a Good} Public Space: from Jan Gehl

-feeling safe and secure.

-ability to move through the space, room for walking.

-enough seating and not in weird places. -the ability to see, no unhindered views. -low noise level, possibilty for talking. -invitation for play/activities.

-places to enjoy aspects of climate. -positive sense experiences. 
This page was intentionally left blank. 


\section{Design with and for Opportunities and Constraints:}

Initial/ design looked at how the spaces needed to function and what their key features were that needed to be designed around. Each design makes up a typology that is prominent in many places around Wellington and is potentially applicable to other spaces.

The initial design focused on how the spaces and furniture would work at a close scale and how they could fit together to create multifunctional spaces for different purposes. These adaptable elements would fit with the current site to allow minimal earth works and designs could be implemented quickly. 
Opportunities that were used to design:
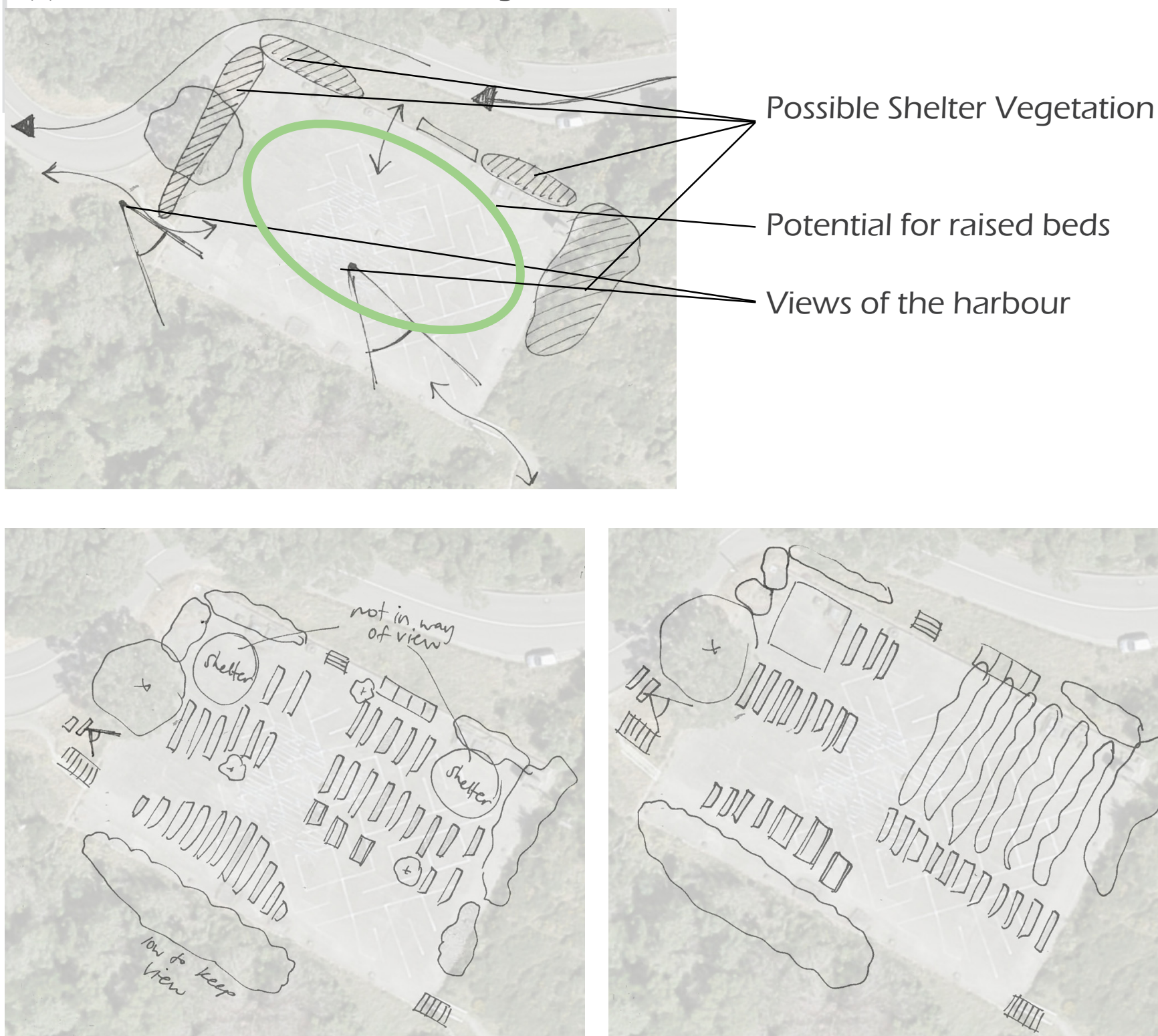

Figure 5.1.1. Concept 1

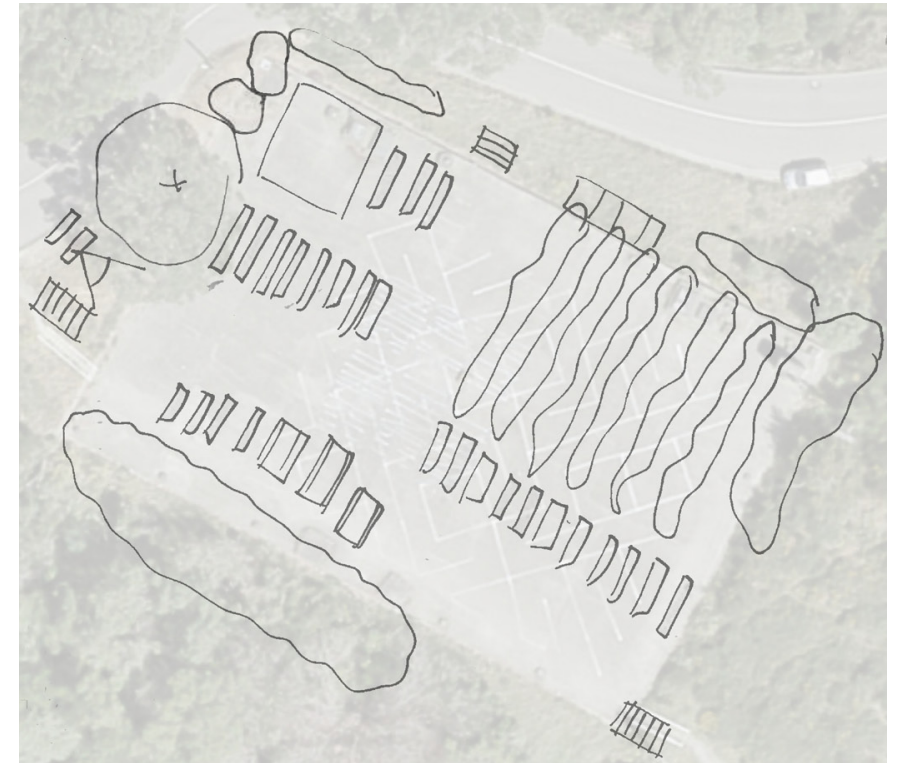

Figure 5.1.2. Concept 2

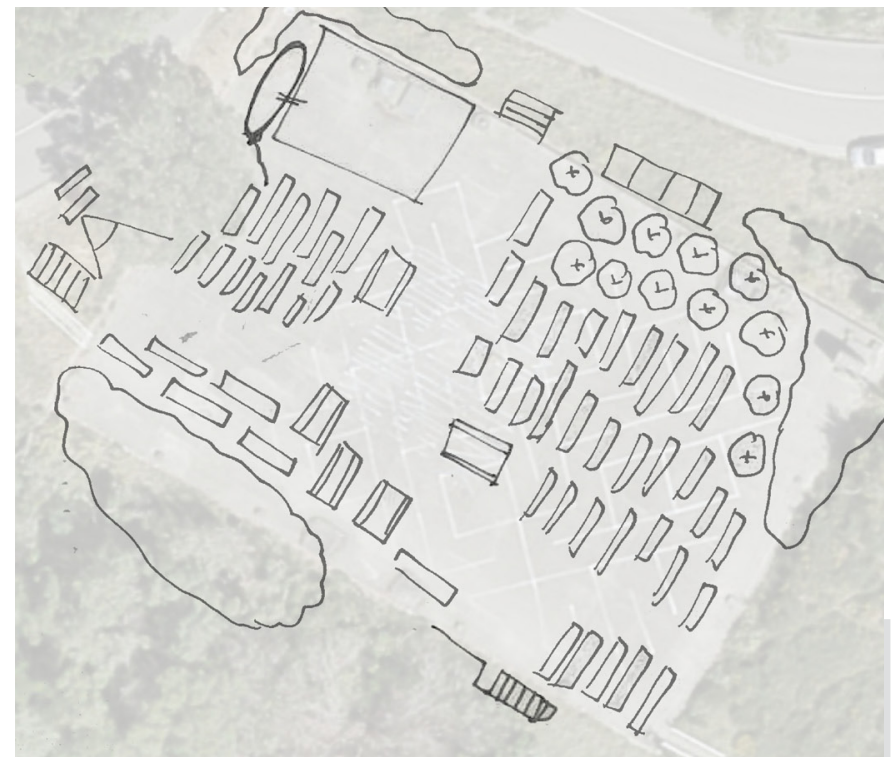

Figure 5.1.3. Concept 3 


\subsection{Typology 1: The View}

The Bell Road reservoir, is due to be upgraded because they don't know if it will handle a big earthquake. This is an opportunity to create a typology on top of the new reservoir, having this as a community space

[fig5.1.1.] This concept has shelter out of the views of the harbour. The vegetation creates some barriers from the wind without obstructing the views.

[fig5.1.2.] This concept has a shelter, and then an orchard in rows of trees to maximise production.

[fig5.1.3.] This concept has a shelter that collects water for onsite usage. It has raised beds throughout most of the site allowing many different people to garden at one time.

[fig5.1.4.] This shows the site model and how exposed to the elements it is creating opportunities to shelter the site but also to use the sun times for food production. Due to the site flatness it could collect water but isn't as necessary as it is a reservoir.

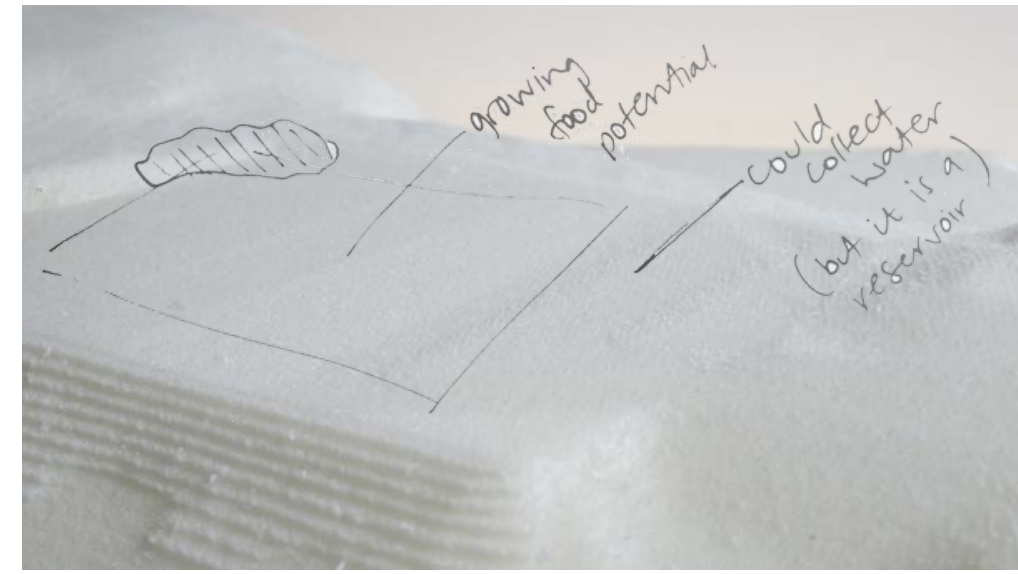

Figure 5. 1.4. Model photo with annotations 


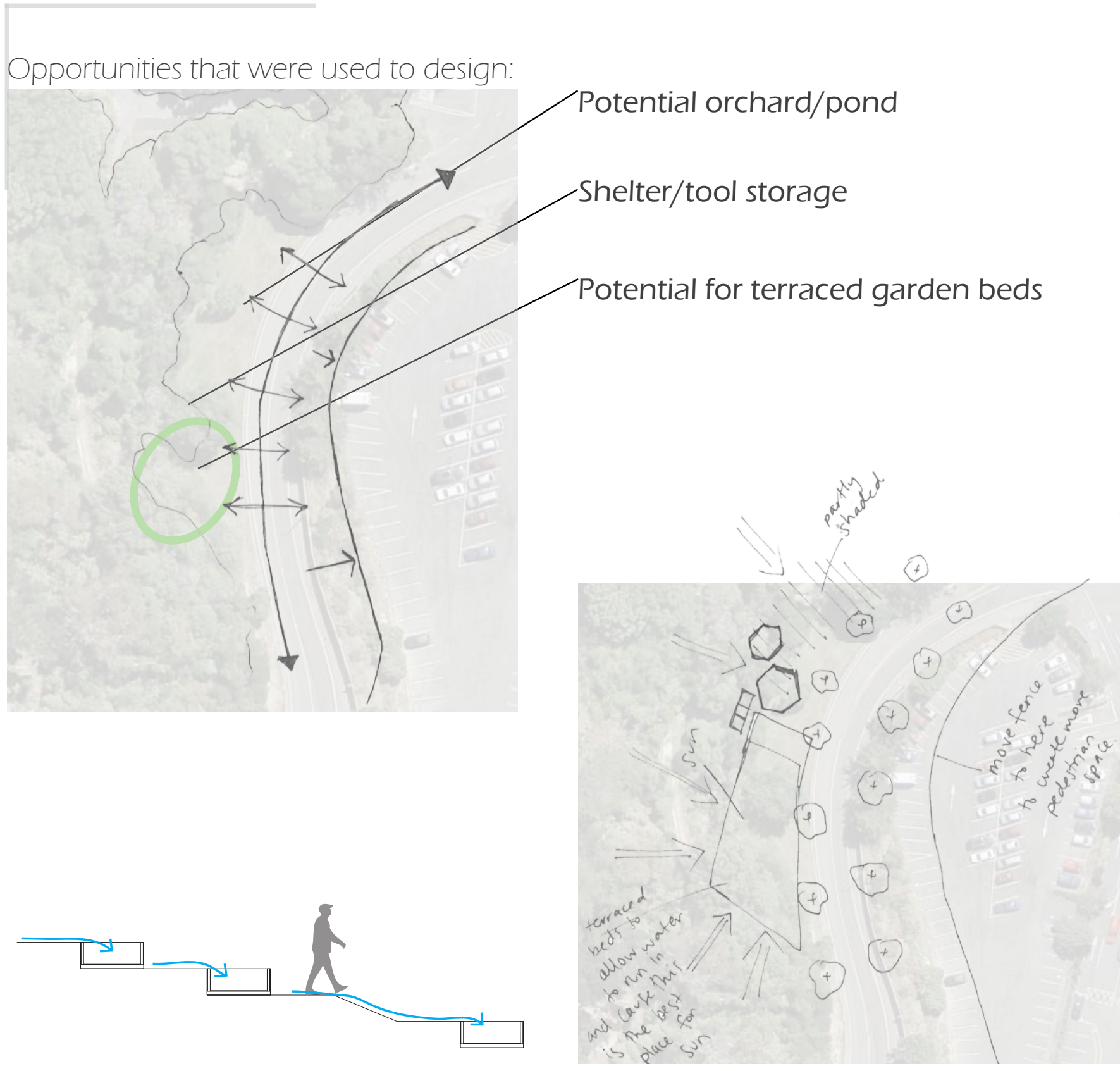

Figure 5.21 A section showing how the terraced gardens would function

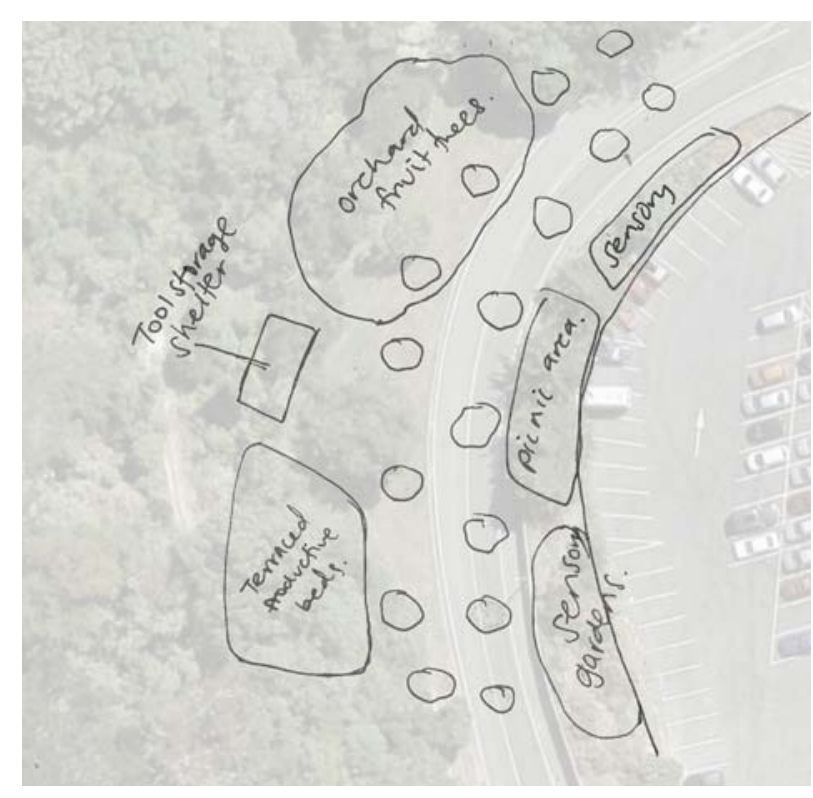

Figure 5.2.3. Concept 2 


\subsection{Typology 2: The Orchard}

Due to this being one of the more out of the way sites it makes sense to have it as very low maintenance. Having self-watering gardens is a perfect opportunity. It is also near site 3 so they can be used in conjunction in the event of a disaster.

[fig5.2.1.] This concept has terraced garden beds to allow water to run into them slowing it down. it has an orchard to grow fruit and nuts that are recommended for Wellington.

[fig5.2.2.] This concept a shelter with tool storage which could possibly be converted to compostable toilets in the event of a disaster.

[fig5.2.2.] this site model allowed me to better understand the contours of the site and established a design that worked with them to create a low maintenance garden.

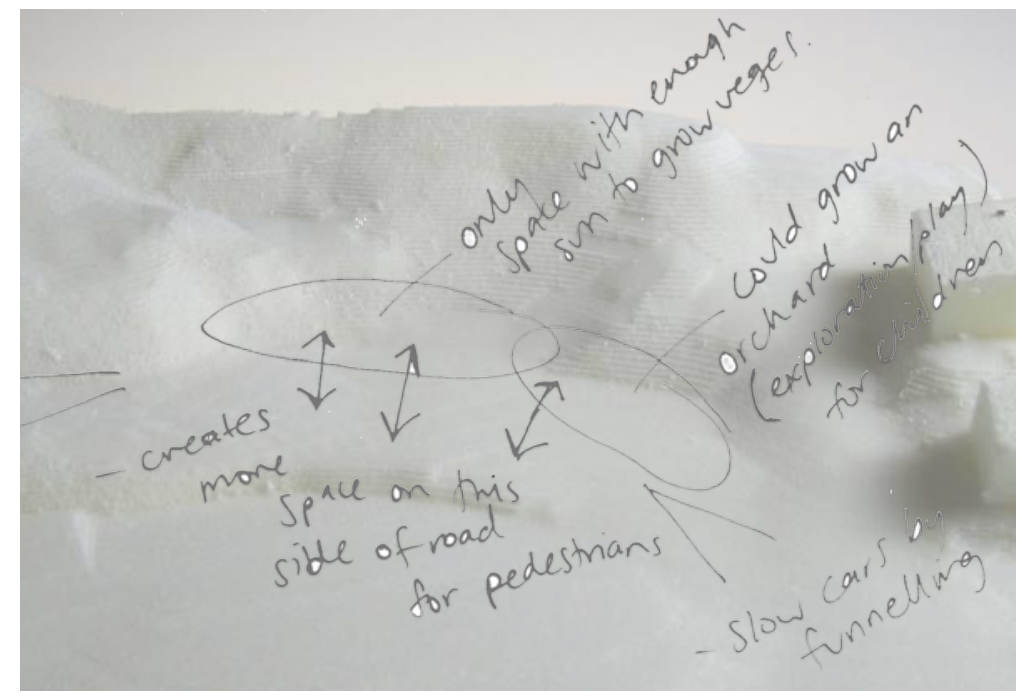

Figure 5.2.4. Model photo with annotations 


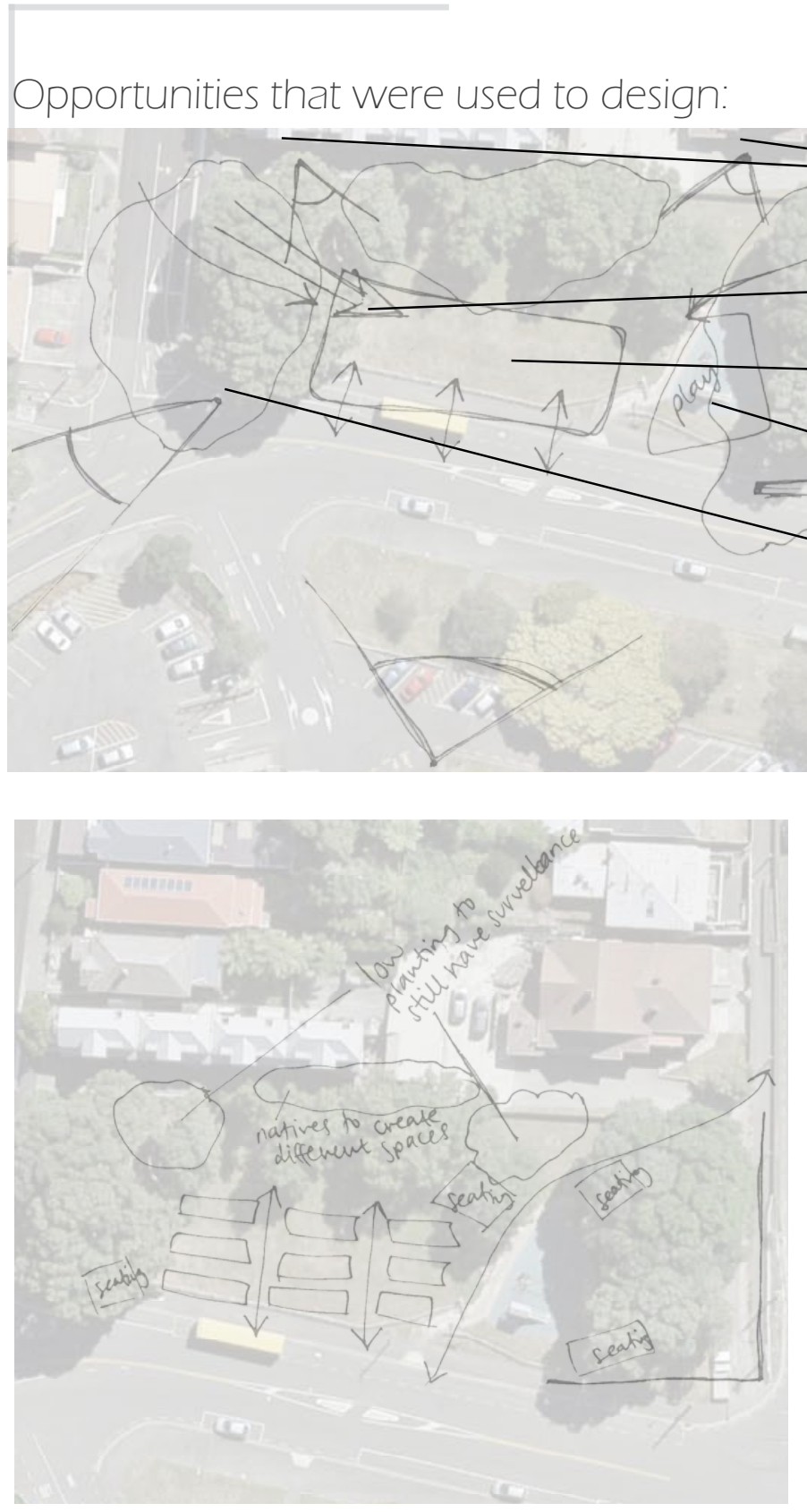

Figure 5.3.1. Concept 1

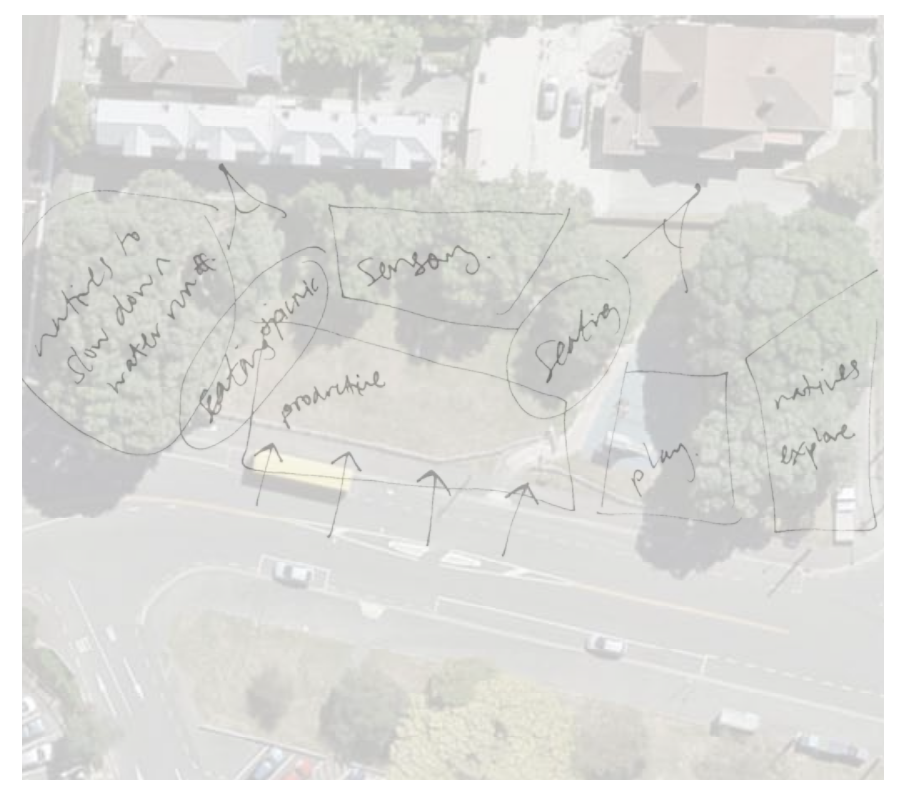

Figure 5.3.2. Concept 2

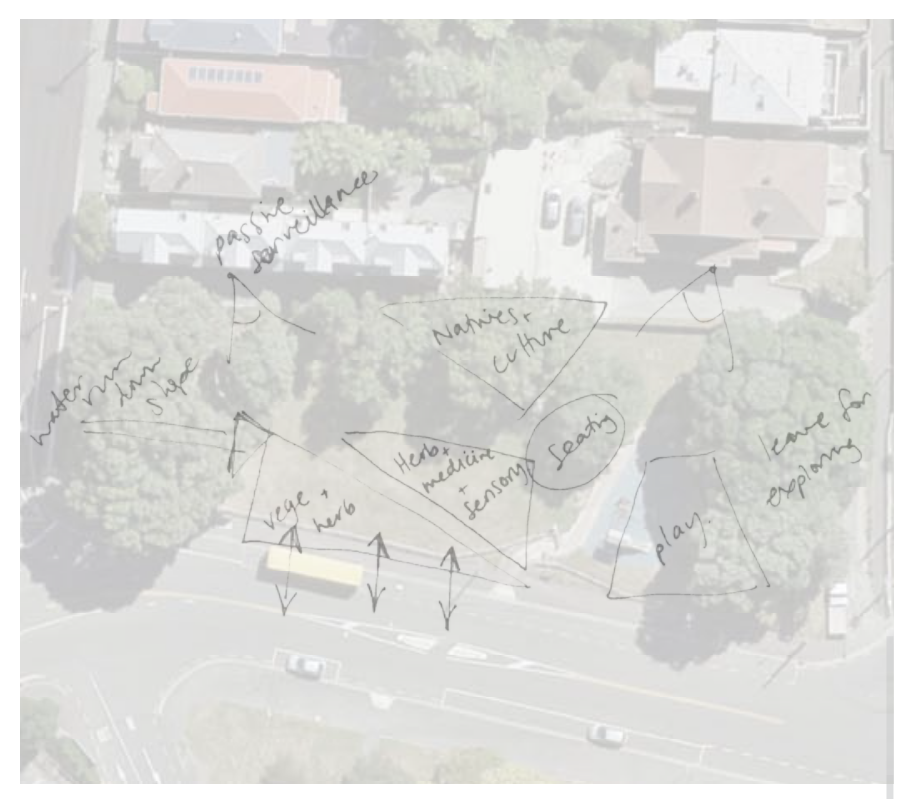

Figure 5.3.3. Concept 3 


\subsection{Typology 3: Learn and Play}

Mount Cook play area has potential for creating a space that children can learn about food and what to do in a disaster. While also having a playground that can entertain them. When designing with children as users, elements that interest them are key to creating a space they want to use.

[fig5.3.1.] This concept has raised beds in the centre bringing the people through them. it has low vegetation creating a bit of privacy to the houses while still allowing passive surveillance.

[fig5.3.2.] This concept has a sensory garden and native areas to allow children to explore and creates a distraction for them in the worst of times.

[fig5.3.3.] This concept has productive gardens and a sensory garden in the centre with seating to watch over the play areas and passive surveillance form the nearby houses.

[fig5.3.4.] This model photo allowed me to see where it would be possible to grow food due to the sun the hours of sun that parts of the site received. This also brought the idea that water could be used naturally on the site to create low maintenance garden beds.

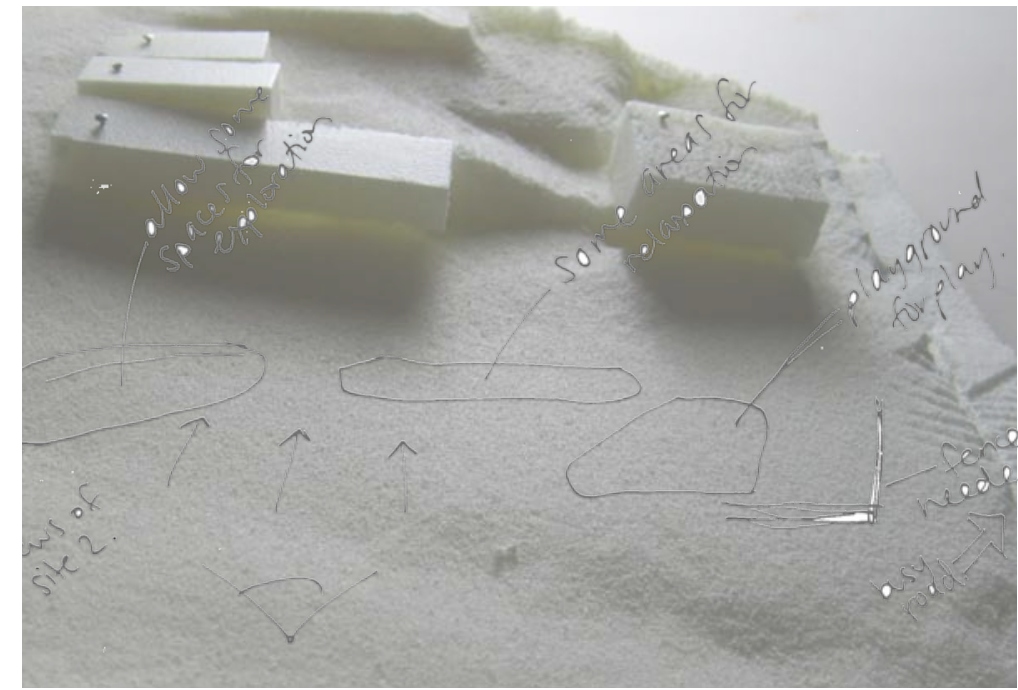

Figure 5.3.4. Model photo with annotations 


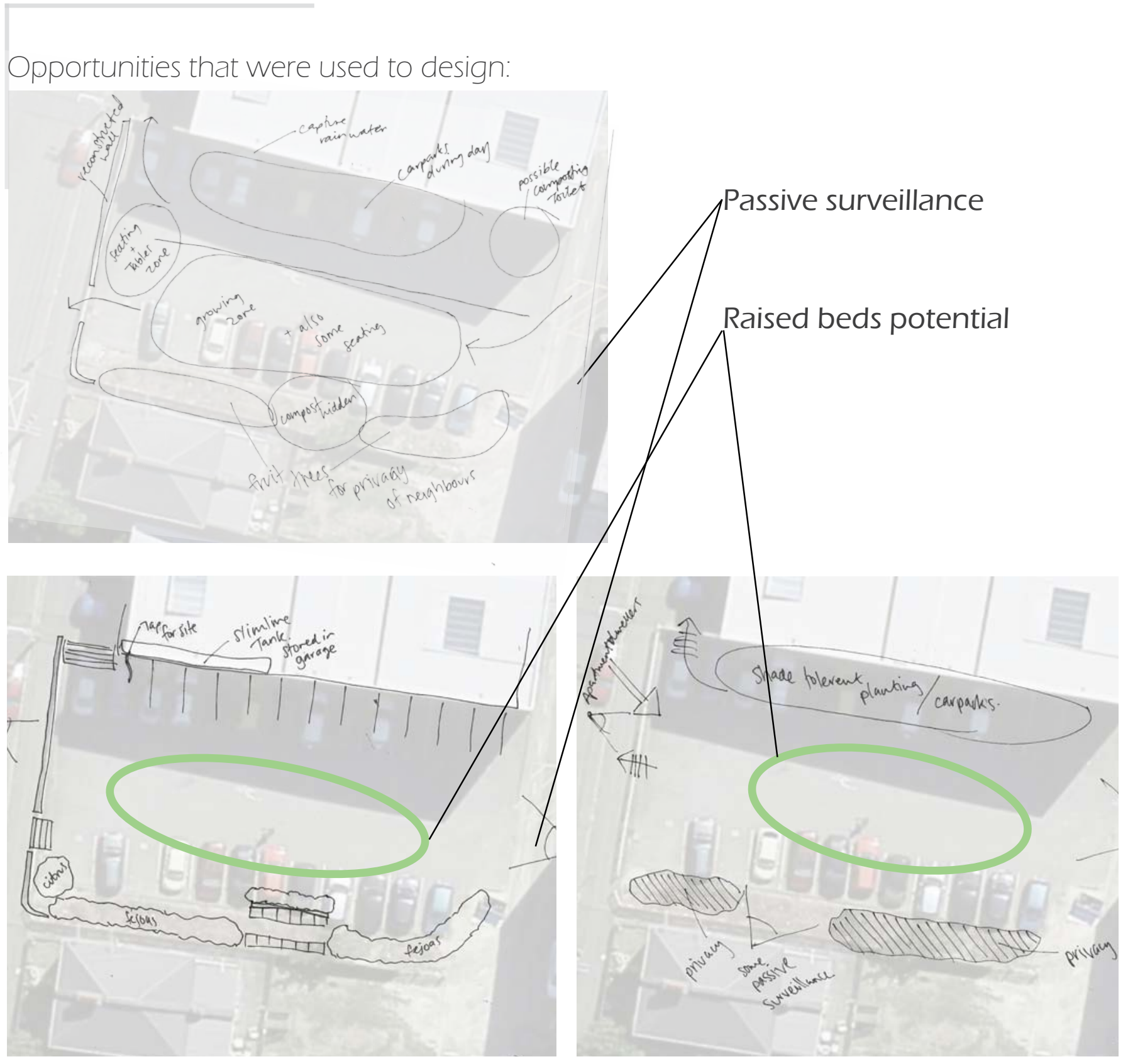

Figure 5.4.1. Concept 1

Figure 5.4.2. Concept 2 


\subsection{Typology 4: Movieable}

This carpark provides the opportunity to create a public space for medium density apartment dwellers to use. This provides and outdoor space that they can grow some food and compost their scraps. As this site has a south facing wall, food growing plants wouldn't get enough sun to grow so some parking spaces could be used daily. This wall also brings in an opportunity to project a movie/documentary onto the wall. This would bring people out to meet their neighbours.

[fig5.4.1.] This concept has raised beds in the centre bringing the people through them. it has vegetation creating a bit of privacy to the house next door while still having passive surveillance from the apartments at each end.

[fig5.4.2.] This concept has productive gardens in the centre with feijoas as a privacy screen and windbreak. It also has passive surveillance from both ends.

[fig5.4.3.] The model of this site wasn't as helpful as some of the others due to its flatness of the site. Although it did allow for spatial arrangements on the site.

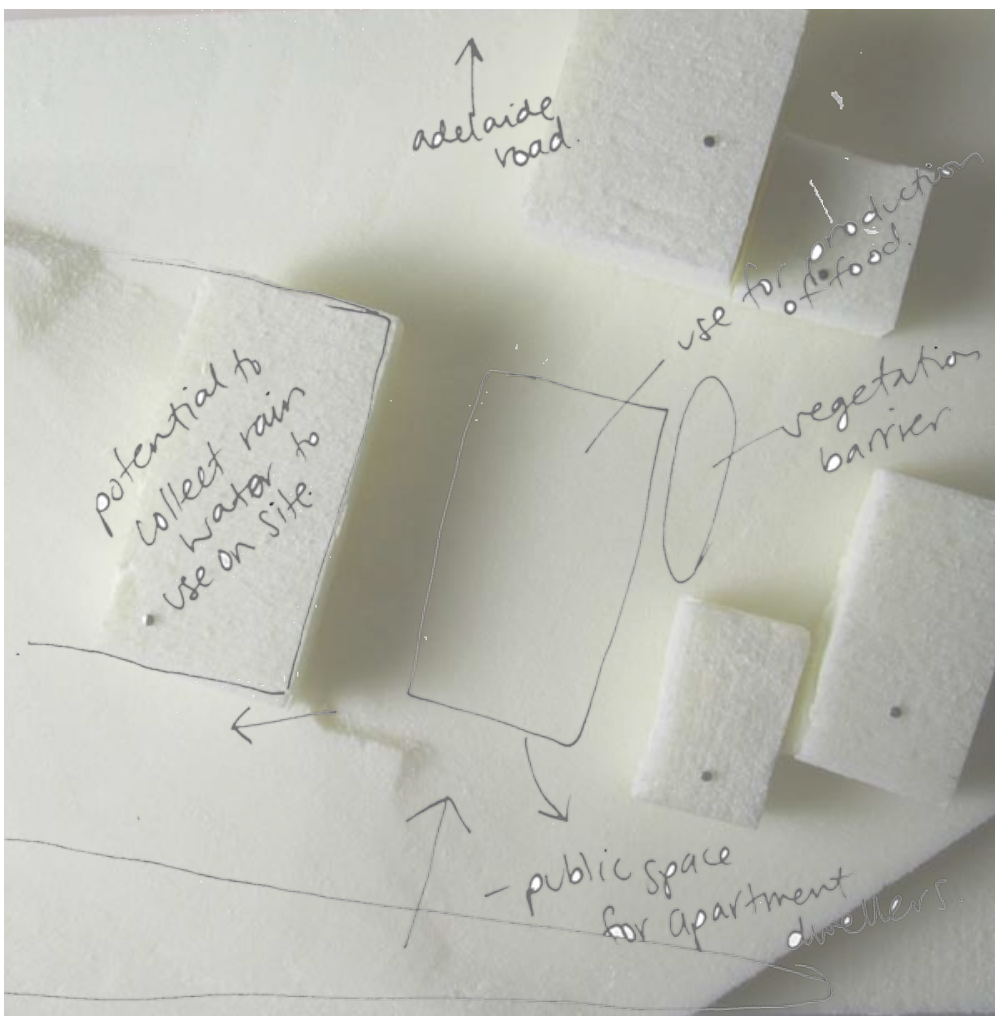

Figure 5.4.3. Model photo with annotations 
Opportunities that were used to design:

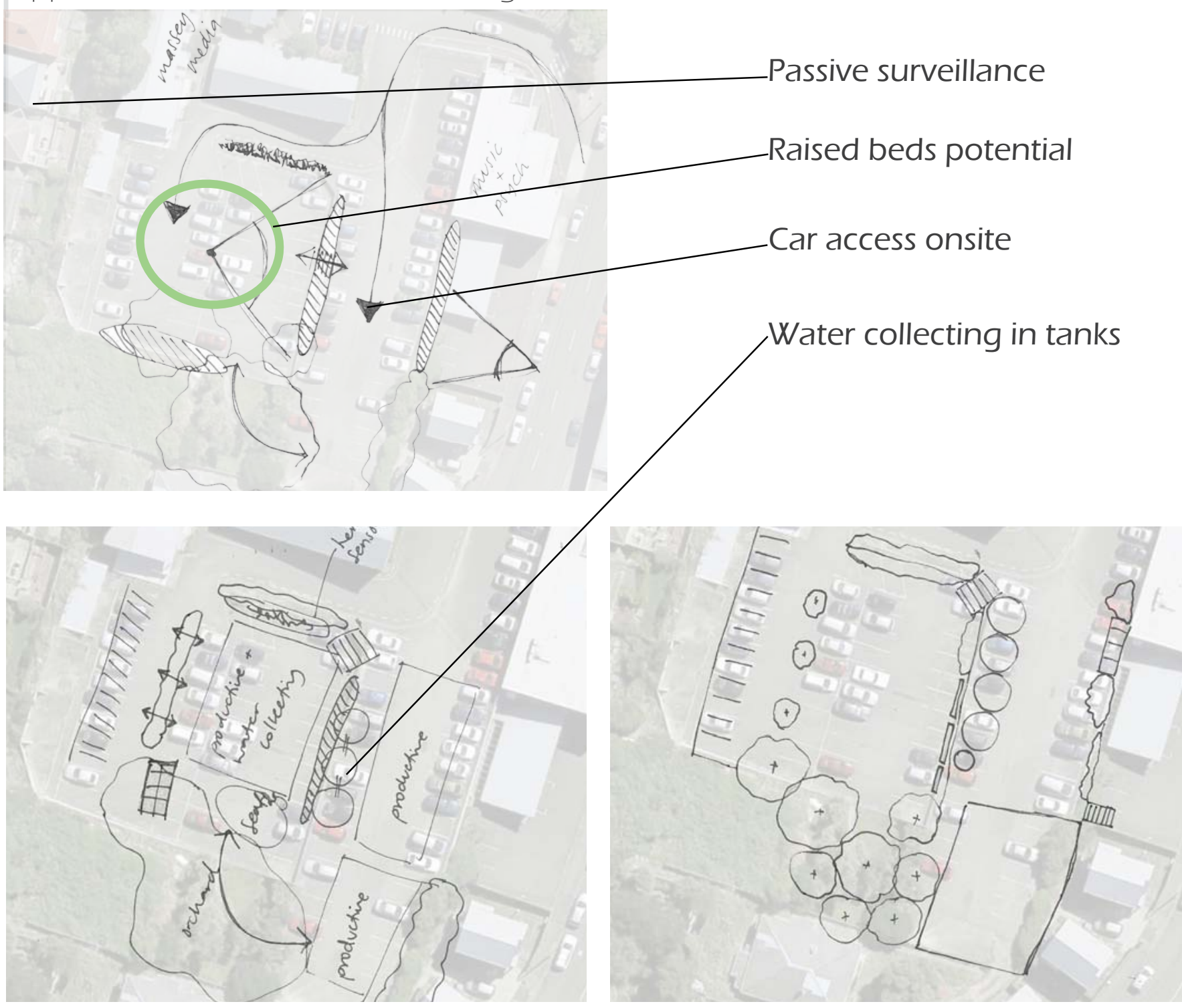

Figure 5.5.1. Concept 1
Figure 5.5.2. Concept 2

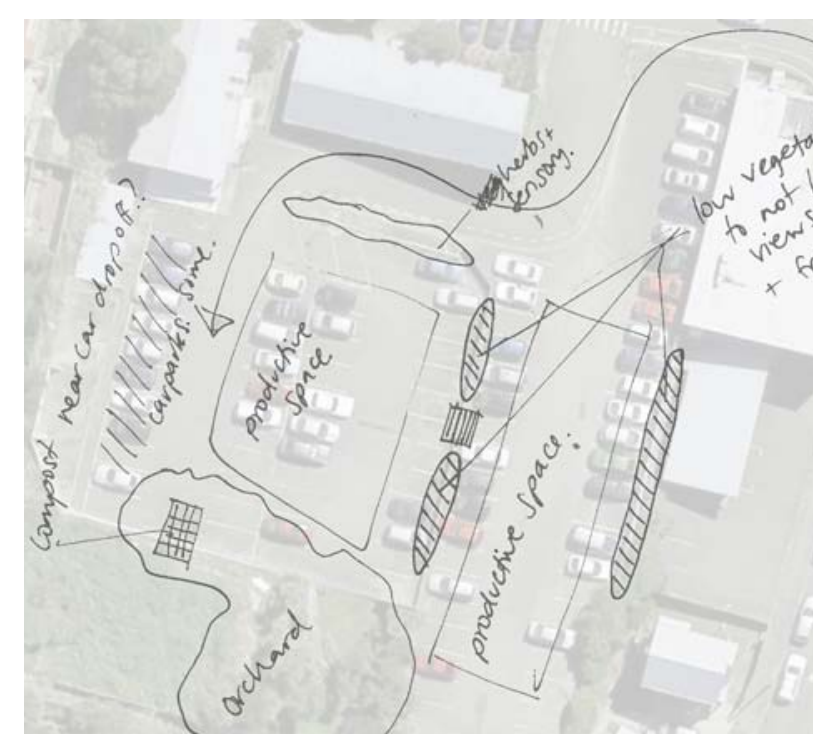

Figure 5.5.3. Concept 3 


\subsection{Typology 5: Accessible Levels}

Creating the opportunity to collect water and store it onsite. Allowing cars onsite is an opportunity to bring elderly/disabled people onto the site where they can relax through gardening.

[fig5.5.1.] This concept has different areas for different groups and has different types of production, it has an orchard which also provides some shade and raised beds for vegetables.

[fig5.5.2.] This concept has a shelter to protect plants and people form the weather in wellington, this allows recovery due to giving people some place to go after a disaster

[fig5.5.3.] This site has car access onto the site to allow for elderly and disabled people to come and visit the site and to get outside and relax.

[fig5.5.4.] The model allowed me to show how I've looked at the three-dimensional aspects of this site including using the $3 \mathrm{~m}$ difference to capture and store water.

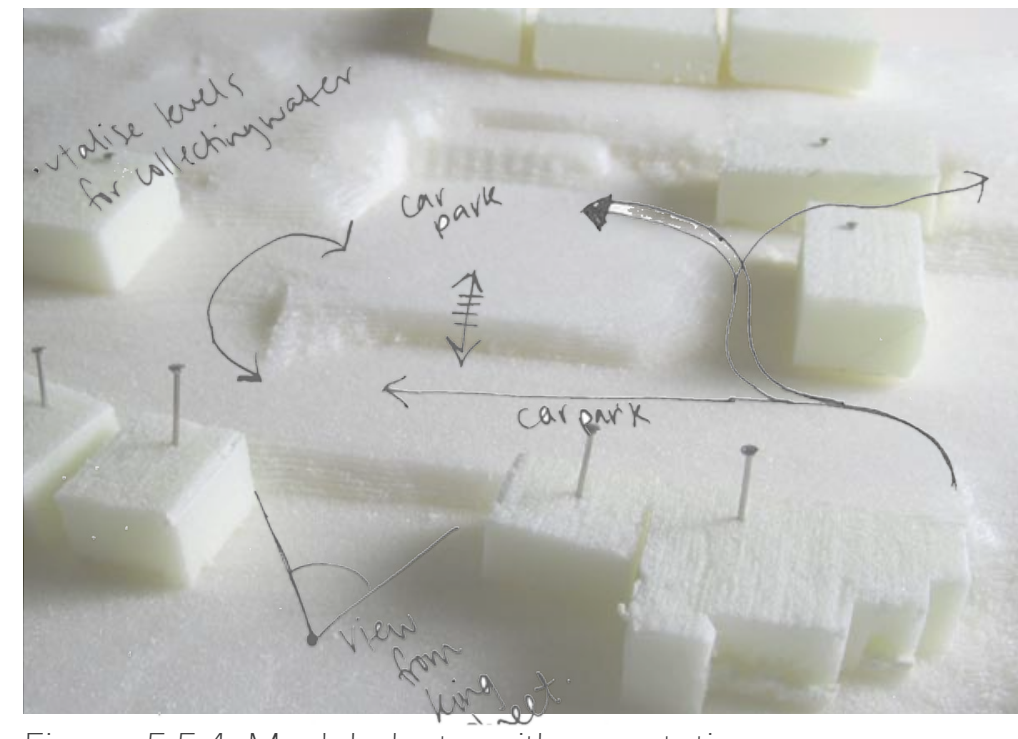

Figure 5.5.4. Model photo with annotations 
Opportunities that were used to design:

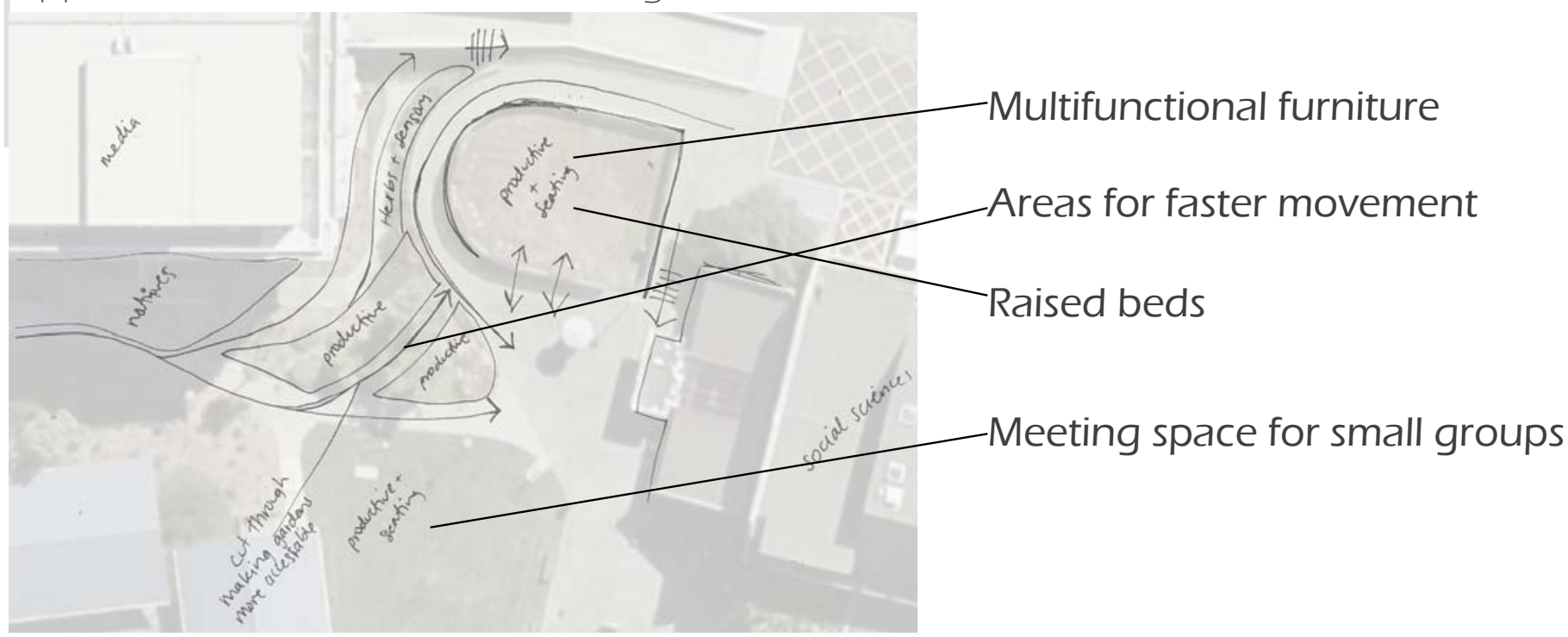

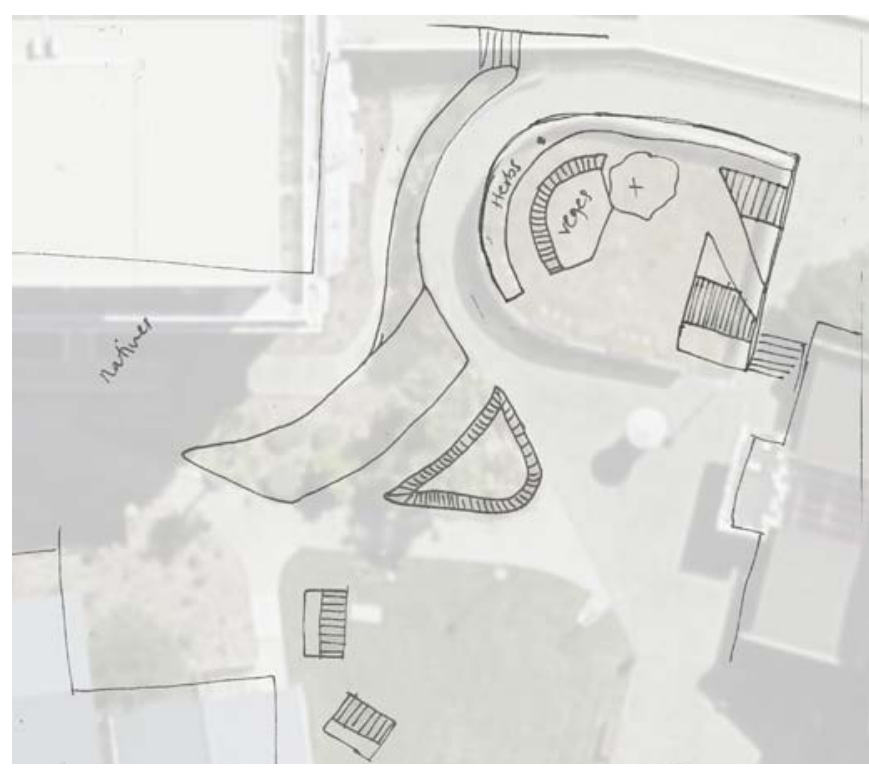

Figure 5.6.1. Concept 1

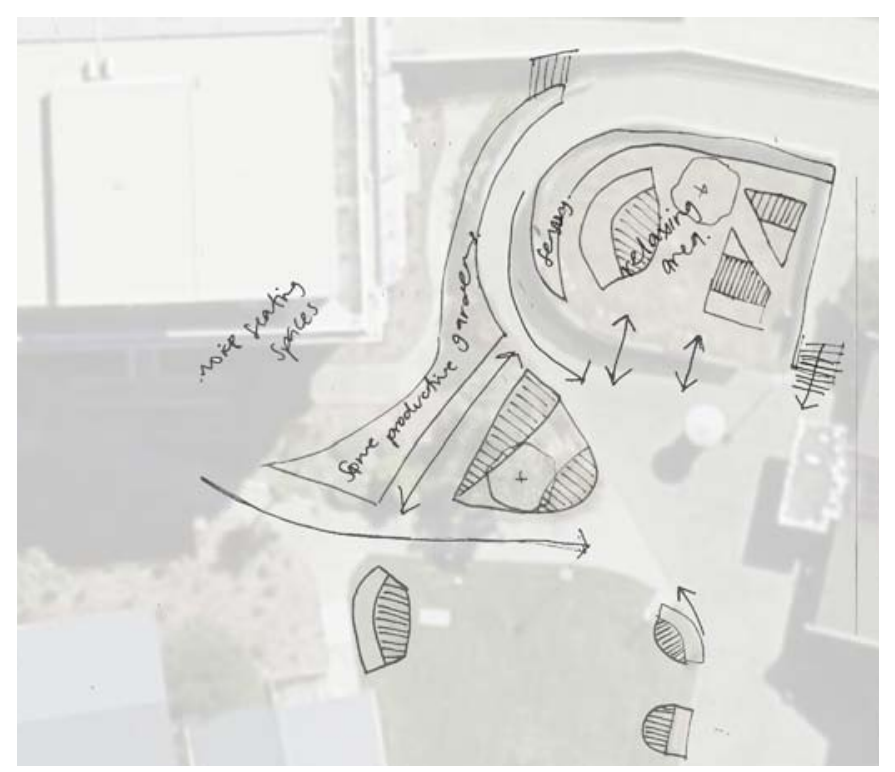

Figure 5.6.2. Concept 2

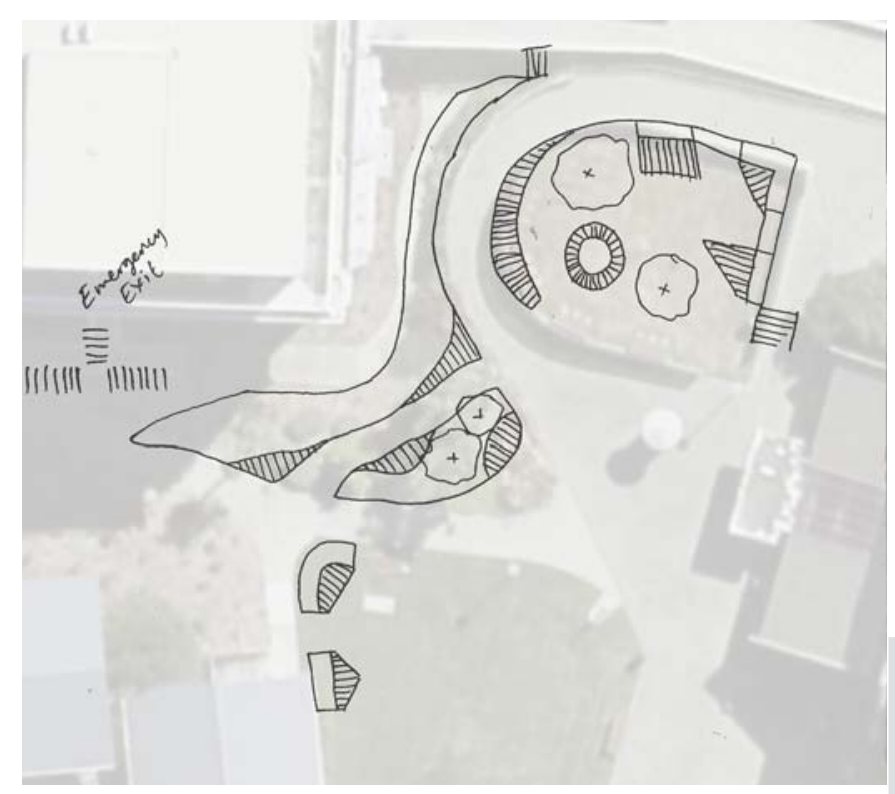

Figure 5.6.3. Concept 3 


\subsection{Typology 6: Lounging Lunch}

This creates an opportunity to provide conversation space where people can sit and eat lunch as well as some lounging space making multi-functionality the key to design.

[fig5.6.1.] This concept has an area off set which can be used for sitting and eating or chatting as well as extra seating in between the garden beds.

[fig5.6.2.] This concept has angled garden to allow more growing space for herbs and vegies as well as an offset area for relaxation.

[fig5.6.3.] This concept has different shaped seating for different sized groups and has vegies in the raised gardens.

[fig5.6.4.] This model got me to look at the spatial arrangements of the buildings and allowed me to establish where people would gather and what would be important on this site.

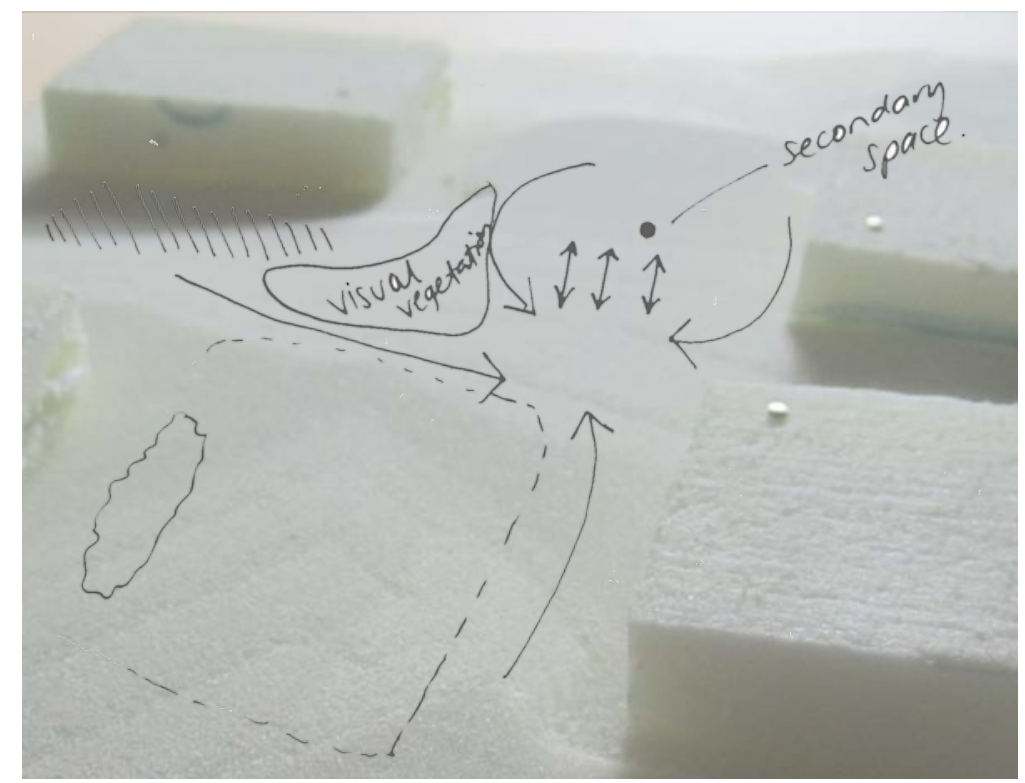

Figure 5.6.4. Model photo with annotations 
This page was intentionally left blank. 


\section{Developed Design:}

The purpose of this design investigation is to show that we can increase the productivity of our public spaces to ensure they can help provide known and useful community spaces to be more resilient against earthquakes in Wellington city. 


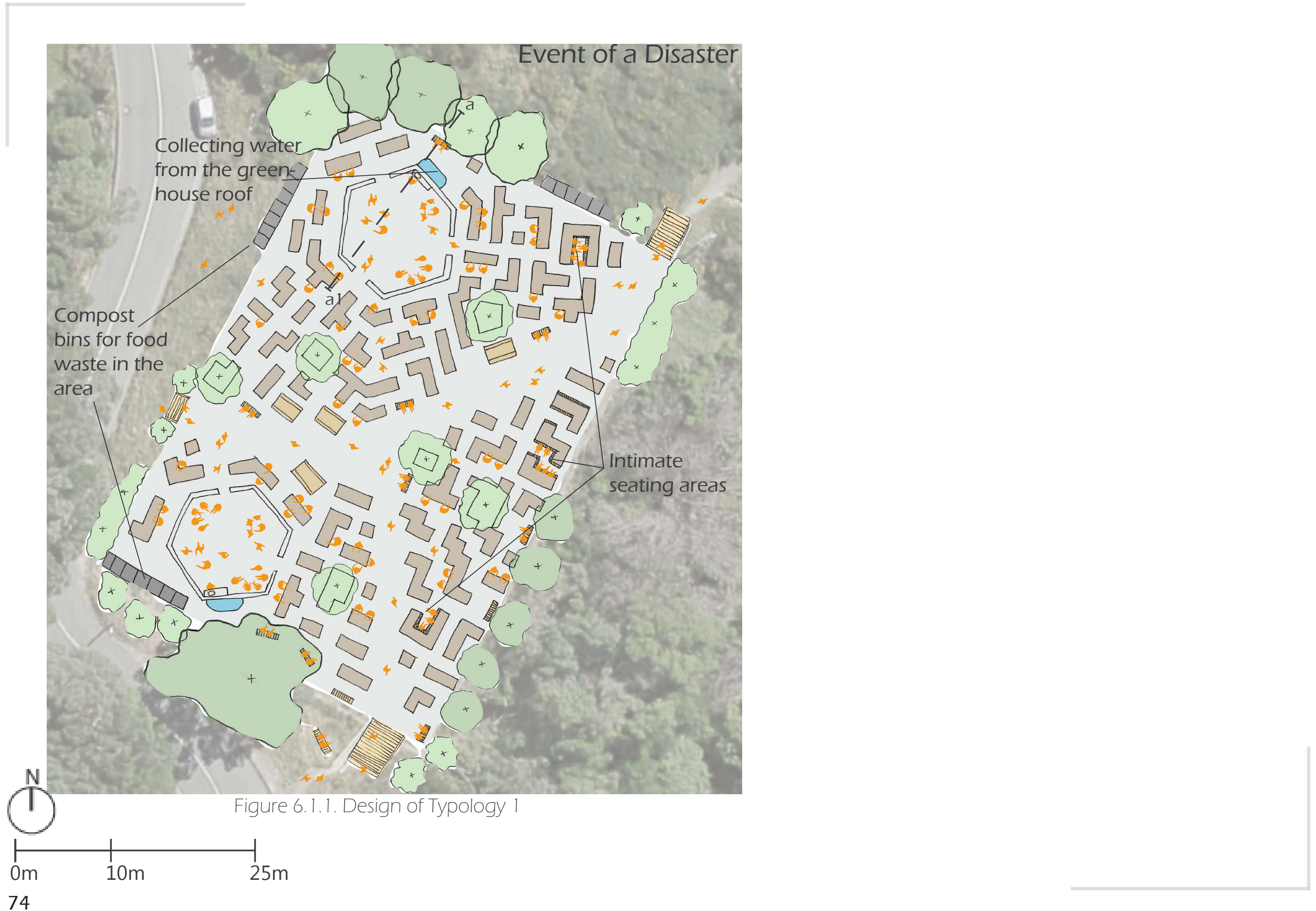




\subsection{Typology 1: The View, To See or To Be Seen}

This typology is designed to be a major productive space for fruit and vegetables to add flavour to grains and canned goods while in the survival service after a disaster. The spacing of the garden beds allow movement through, while maximising the growing space available.

This space is designed as 'The View' because it is a high point that can be seen from a few places while also allowing a view from it. In this particular site it is located on top of a water reservoir but due to it possibly being damaged in an earthquake there is a proposed new reservoir to replace it. This provides an opportunity to increase the productivity of any proposed water reservoirs by using the space above them for community gathering and production.

Section showing the reservoir with a greenhouse on top and it also collecting its own water for washing vegetables. [fig 6.1.1.] The design of this typology on this site allows for a marketplace feel with main paths to allow flow of people through the site. In a disaster there is plenty of space throughout the site that you could hold a massive meeting, or each of the greenhouses could establish a 'leader' position for information. The rest of the site is for production of food and using gardening to unwind from the stress of an event.

In terms of readiness this typology has food production and some water collection. This is also creating a community through the people that use each site.

This typology acts as recovery by having greenhouses that can be emergency shelters, having somewhere for big groups to gather and having somewhere that water and food waste can go. This creates a good public space that is productive and can help respond to a disaster by creating a known community hub.

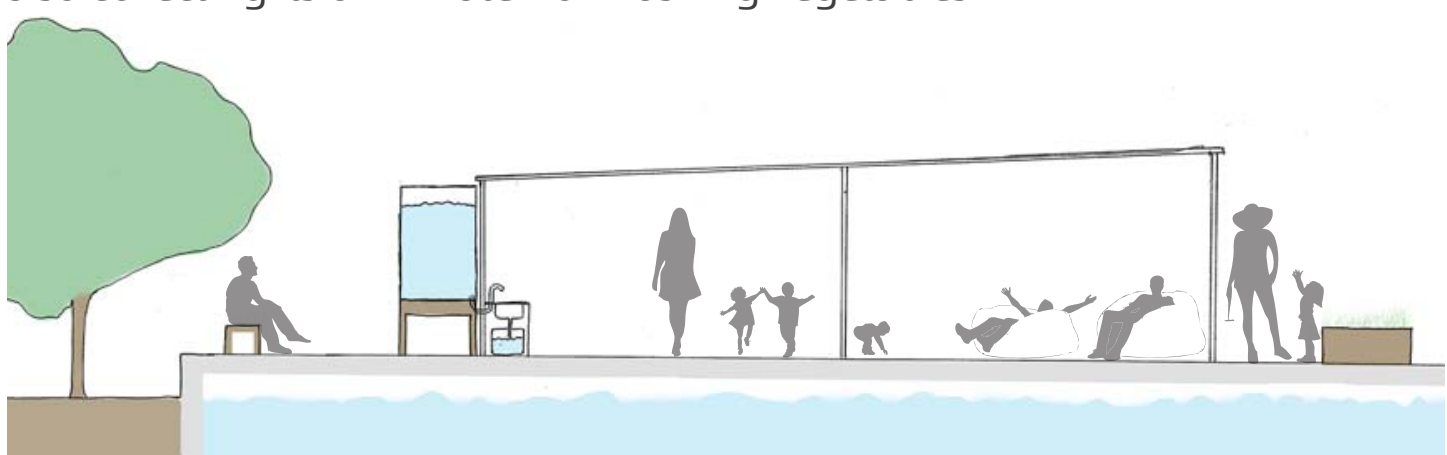

Figure 6.1.2. Section a-al greenhouse as an emergency shelter 


\section{Community Space}

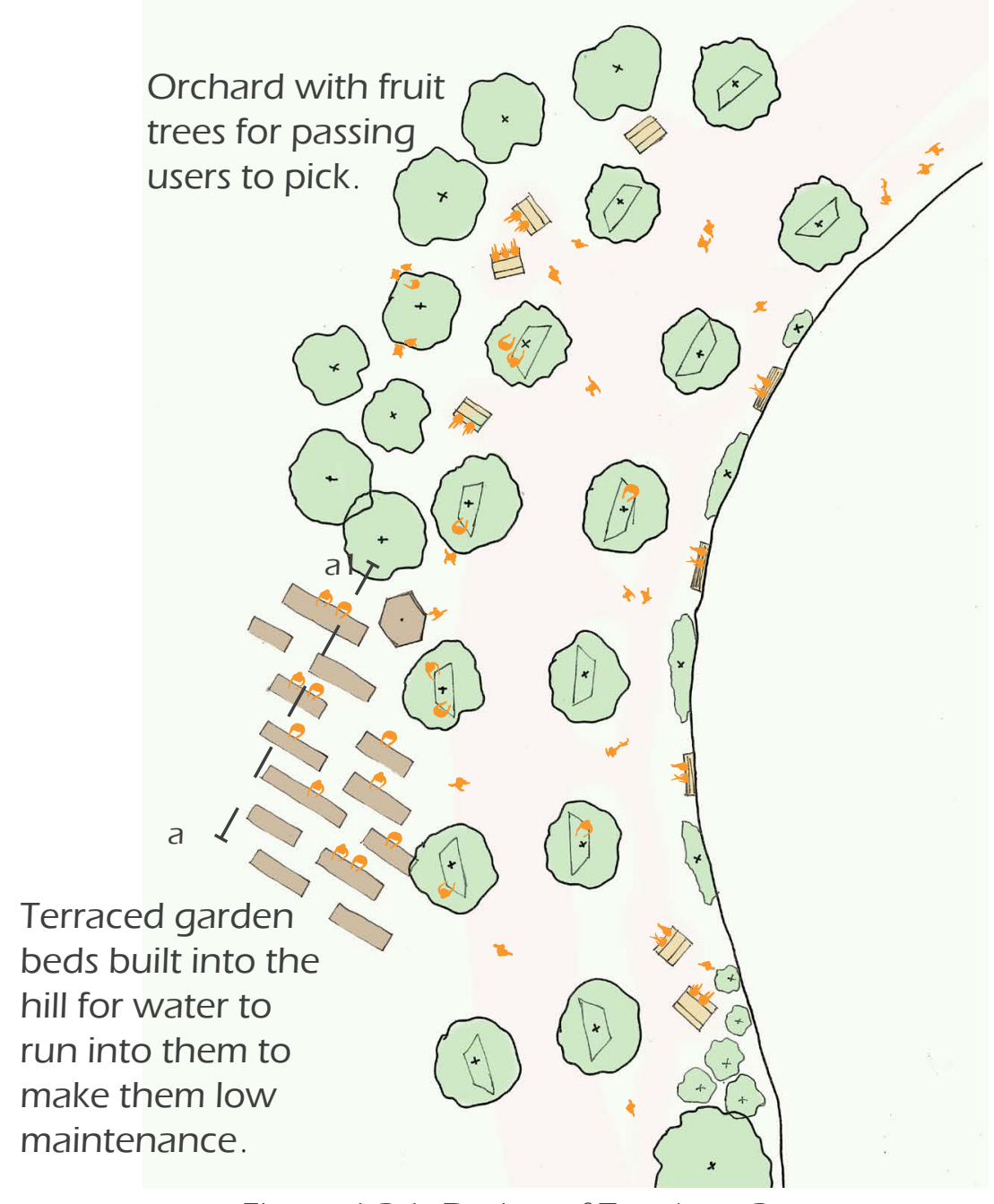

Figure 6.2.1. Design of Typology 2

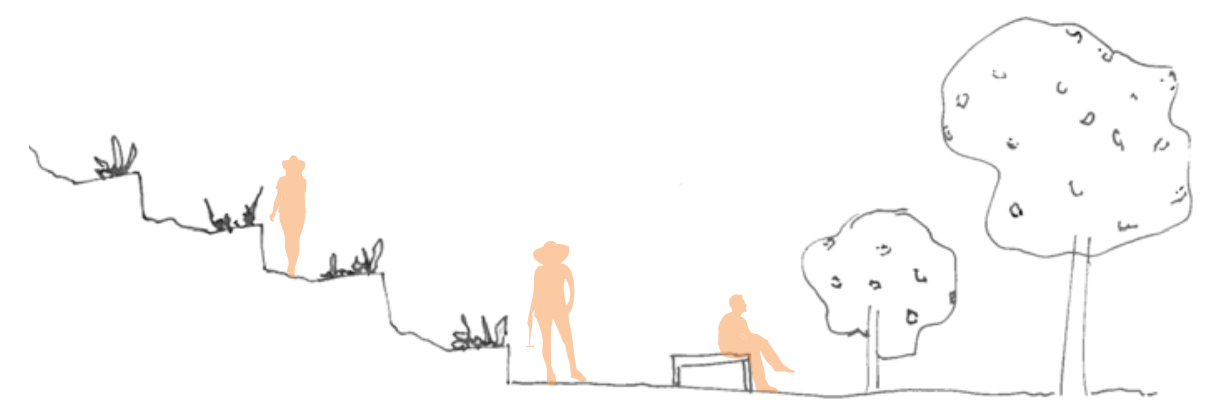

Figure 6.2.2. Section a-al greenhouse as an emergency shelter

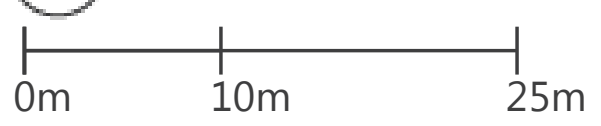




\subsection{Typology 2: The Orchard, A Passive Interaction}

This site is designed as an extra space to be productive throughout the network. This allows it to be added next to spaces with big meeting spaces to allow more food nearby. This site is an added part to site 3 allowing unruly adolescents to have a space away from the younger children. It is set out as an orchard to provide easy eating of food that doesn't need cooking.

[fig 6.2.1.] shows the design of this particular site. But the ideas of creating easy accessible food which doesn't need preparation to eat and using some space for vegetables plots is key to make this a key productive site. And depending on the exact space this typology would be used it could still provide a low maintenance site by allowing water to filter through the garden plots.

This topology contributes to the readiness of a disaster by producing food. This allows food to be used in the period of recovery but doesn't directly act as a meeting space or provide a shelter for people in need. 

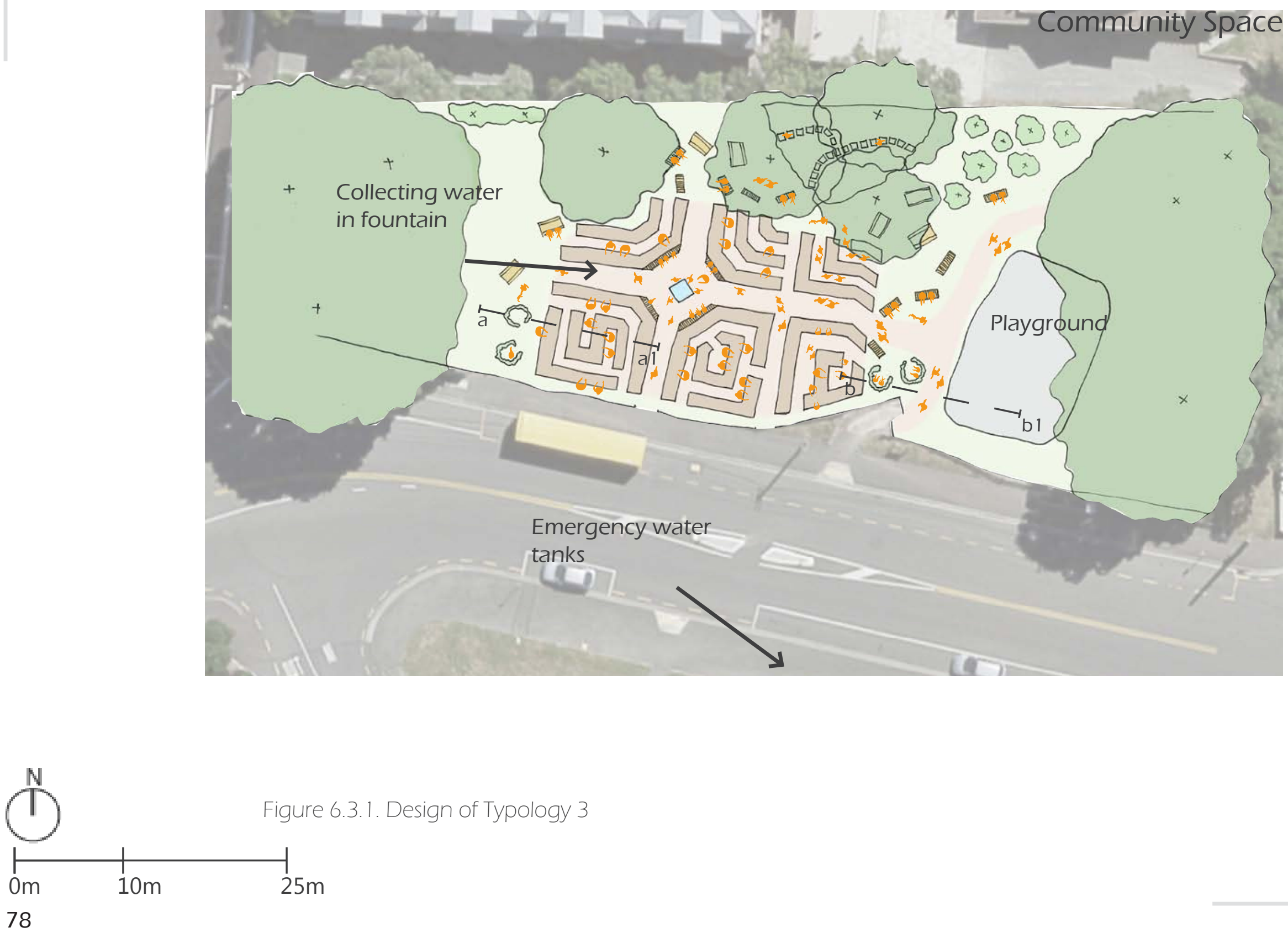


\subsection{Typology 3: Learn and Play, Multigenerational Production}

Designed as a typology that can accommodate all ages that want to learn and garden. It has different height plots for the needs of different people and to keep some children out of the bigger plots. It is designed with many things to do. Having a sensory garden to relieve stress and some plants could be traditional medicines. And having a native's area for a new learning experience for children.

[fig 6.3.1.] this shows the site as a community space where children can run through some paths due to the wideness of them while other spatial arrangements allow some people to be left alone.

This space allows readiness by producing food and creating a community base that children know.

Recovery in this typology is creating a distraction for children and keeping them occupied and active.

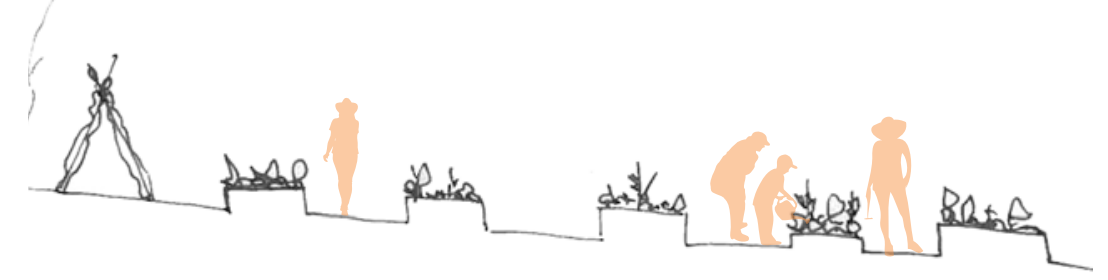

Figure 6.3.2. Section a-a1 in 2 parts across the site

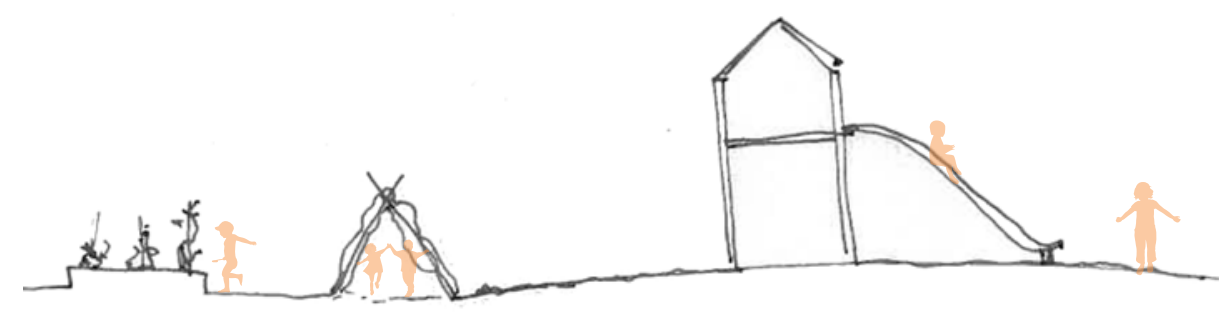

Figure 6.3.3. Section b-b 1 in 2 parts across the site 

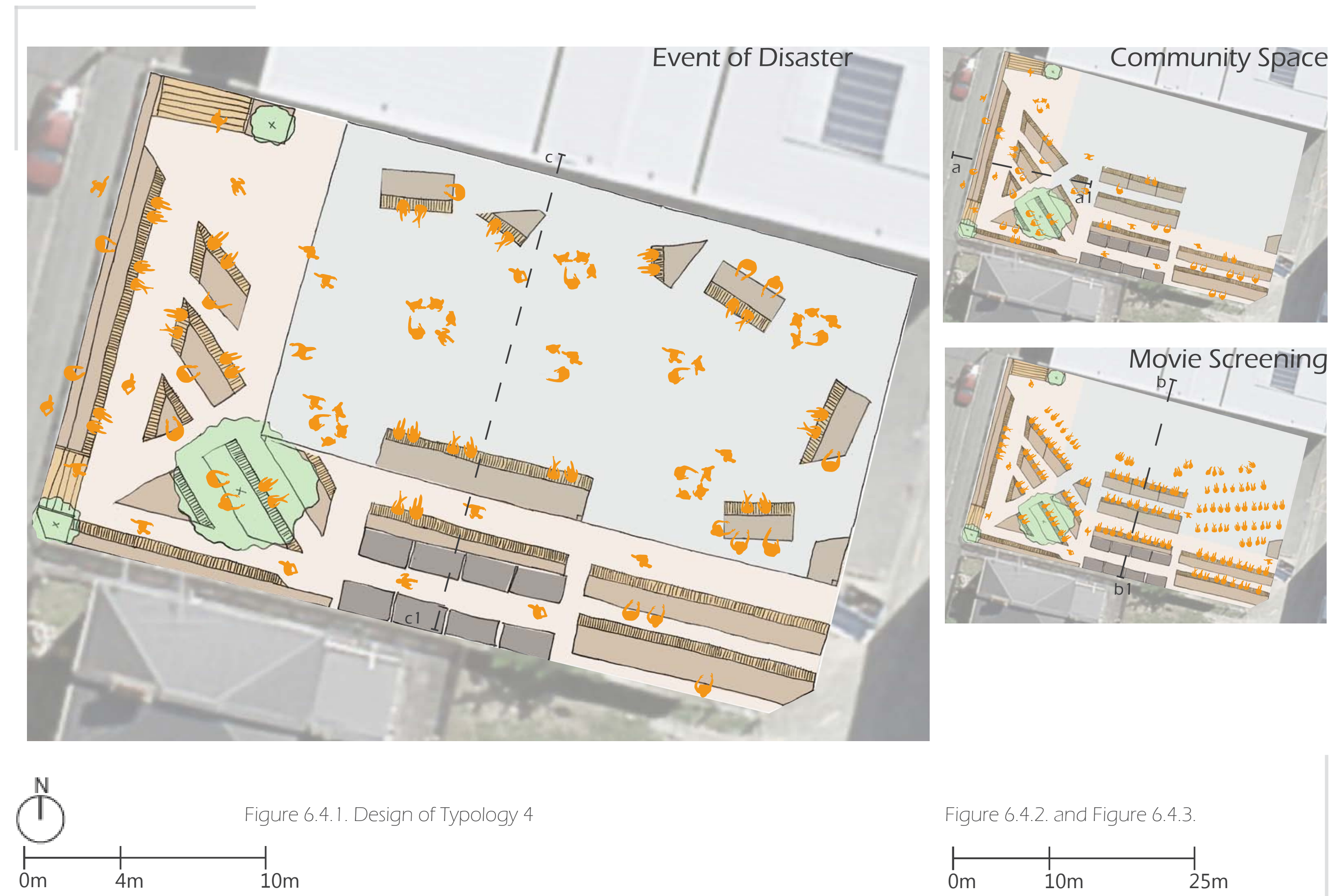

Figure 6.4.2. and Figure 6.4.3.

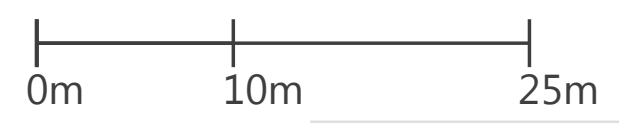




\subsection{Typology 4: Movieable, Multifunctional Programming for Resilience and Recovery}

Is a designed to be a gathering space with a 'screen' that before an earthquake could project community-based movies or a different movie some nights to get the surrounding communities out of their homes and interacting with each other.

After an earthquake it becomes a community hub which can have a temporary shelter put up if needed. It provides some food on the site but is primarily a gathering spot. The designed seating moves to allow the tent to be put up and can be moved to have the seating inside the tent. This particular site also provides composting options for its surrounding residents.

[fig 6.4.1.] shows what the space would look like after a disaster with a tent like structure set up against the wall. This provides shelter and a place of refuge for those in need.

[fig 6.4.2.] and [fig 6.4.3.] show how it could be used every day as a public space or for an event as projecting a movie onto the wall. This could be an opportunity for different neighbourhoods to get to know who lives around them.

This typology prepares for a disaster by producing food, and bringing people together through having an event space neighbours can meet.

This typology acts as recovery by having the space for a temporary shelter to be put up for weather protection and also for somewhere to put food waste and to put water waste into the gardens.
Section a-a 1 of people picking herbs on their way past.

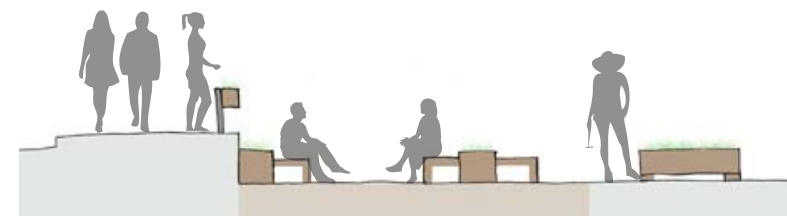

Section b-b1 showing how the movie would work

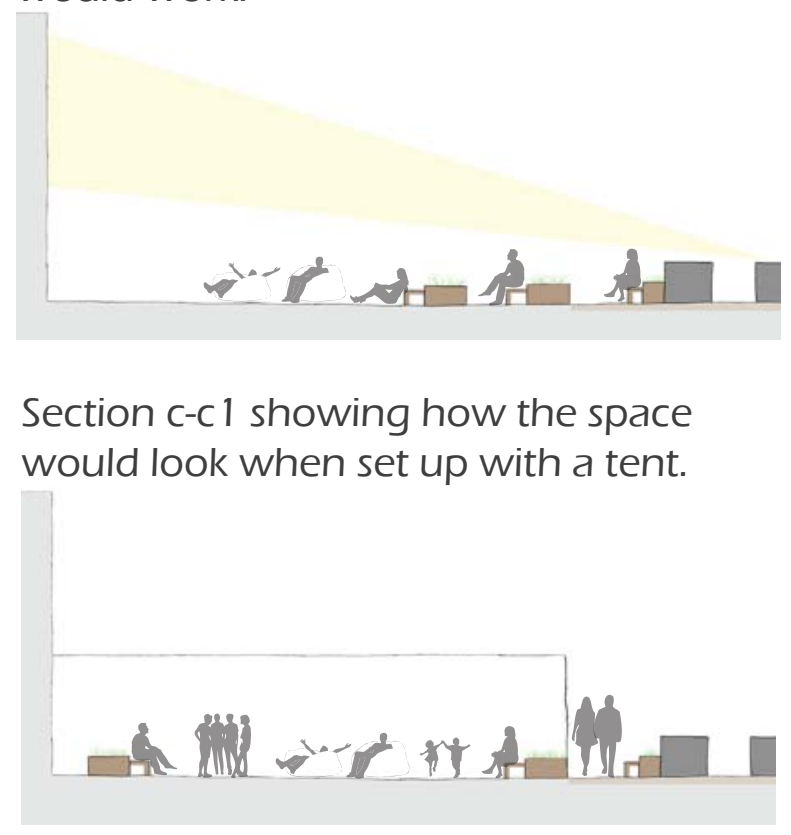

Figure 6.4.4. Set of sections 


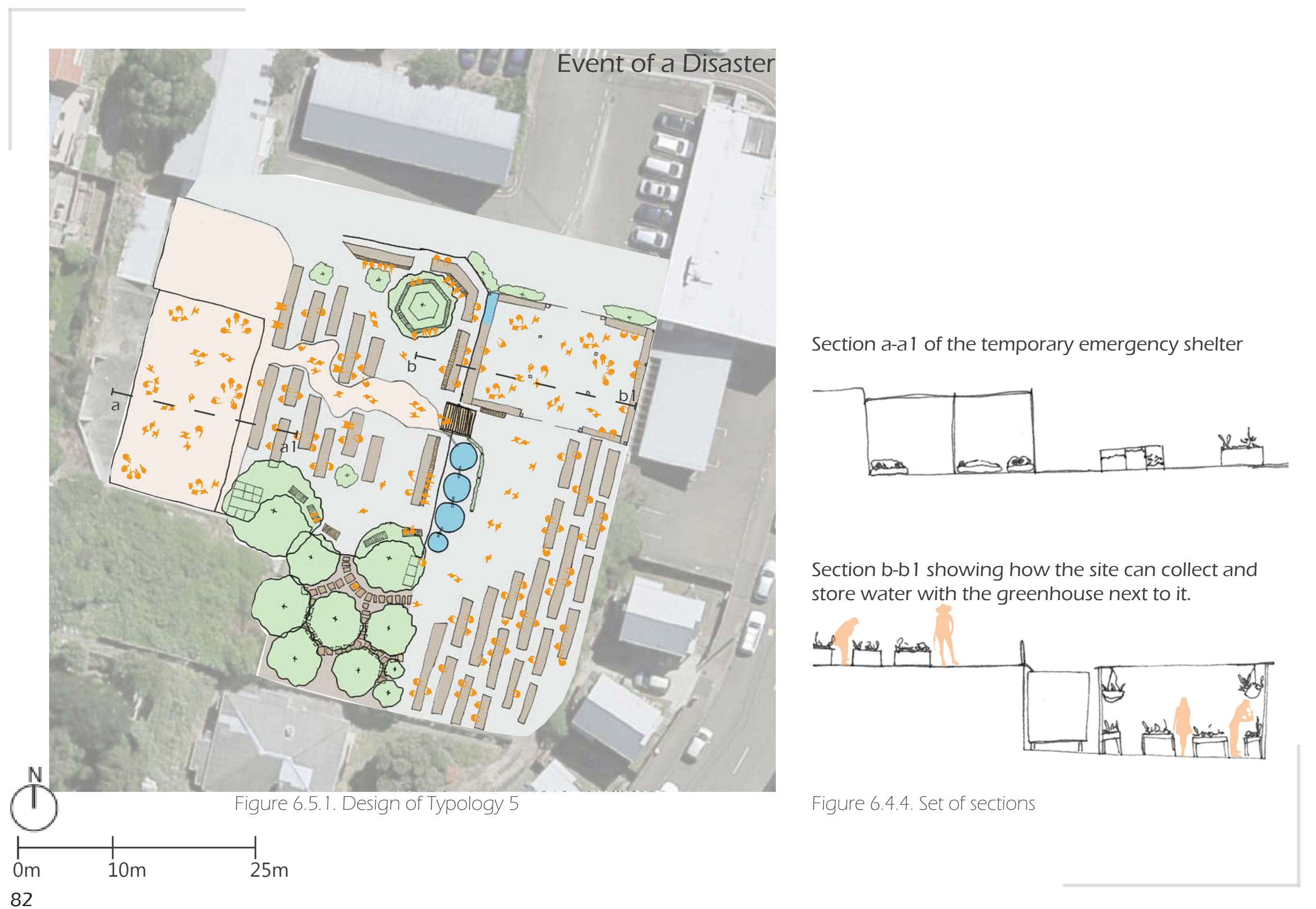




\subsection{Typology 5: Accessible Levels, Paradigm For Context and Community}

Is designed to collect water and store it onsite allowing it to function as an emergency water tank. This typology has a very marketplace community feel and is built on gathering of people of all ages. It is designed first as a meeting place with supplementary gardens to produce food.

This particular site is currently a carpark and so being able to have onsite car access means that elderly and disabled people can be transported to the site for fresh air, relaxing the mind through gardening or to spend time with family.

[fig 6.5.1.] in a disaster this site has many shelter options with a tent like structure that can be erected on the site to allow additional shelter from the permanent greenhouse.

This typology prepares for a disaster by producing lots of food, and collecting water from the top level as well as from the roof of the greenhouse.

This typology acts as recovery by having space for a temporary structure additional to having a permeant greenhouse onsite. It also has plenty of space for gathering big groups of people and allows the composting of food waste and the second use of wastewater by pouring it on the gardens. 


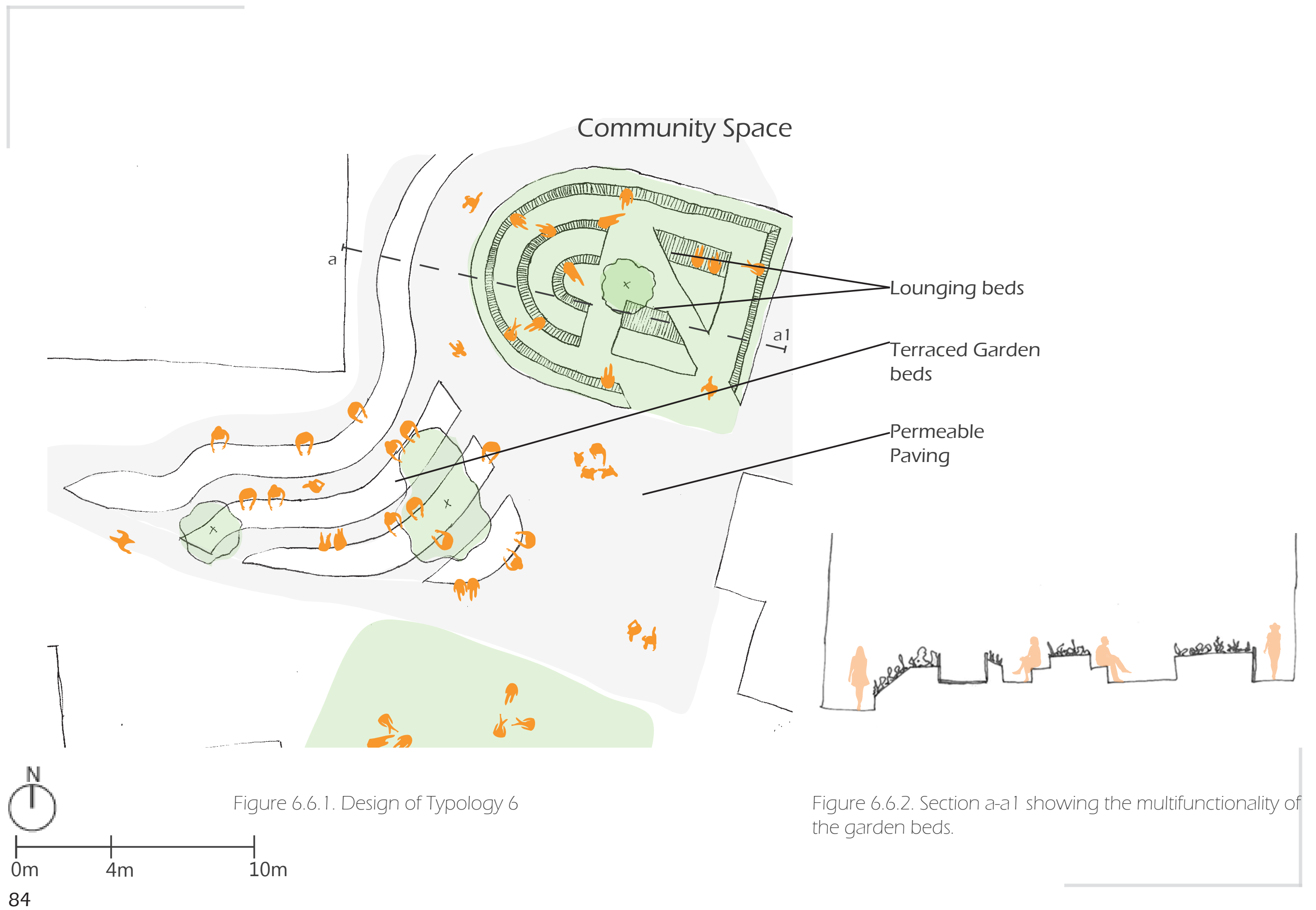




\subsection{Typology 6: Lounging Lunch, Active Social Construct}

It is designed for various seating types that can also be a planter so that students from within Massey can relax at lunch time and hangout while also being sustainable with their food consumption as it can be picked right out of the garden.

[fig 6.3.1.] This site is a very small site and may be a good gathering place after an earthquake if the buildings are open but doesn't provide any good amount of resilience except that it already has a community within the university.

This typology prepares for a disaster by producing food, even in small amounts.

The way for this typology to act as recovery would be if the buildings surrounding it could be used as shelter for the space. But this would require structure test after the earthquake. it also would serve as a small meeting place but not many people could fit in it.

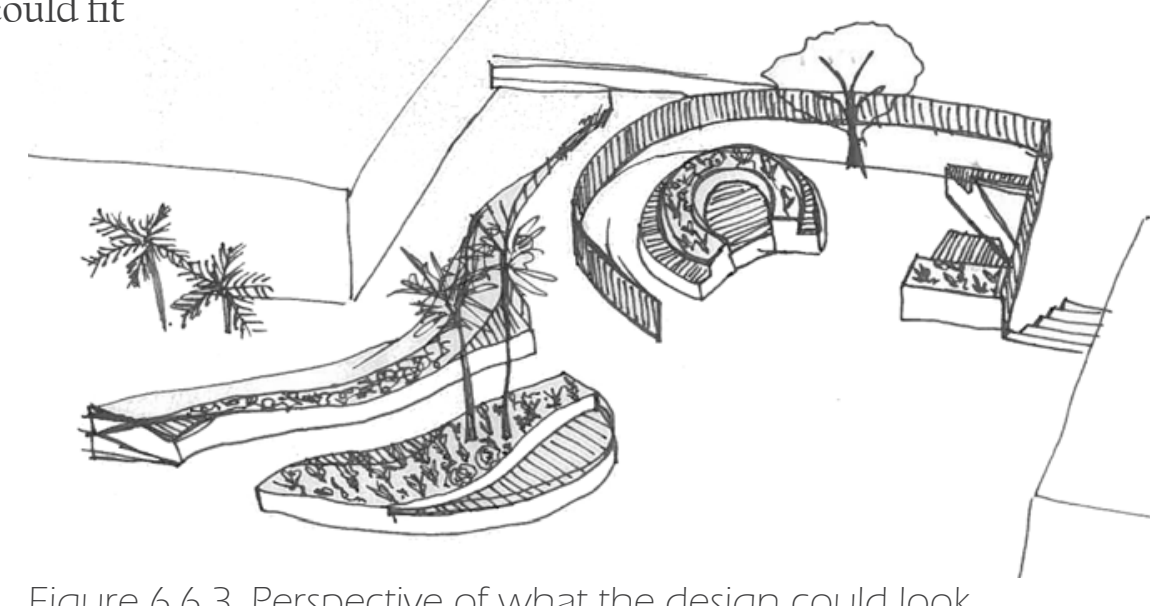

Figure 6.6.3. Perspective of what the design could look like. 


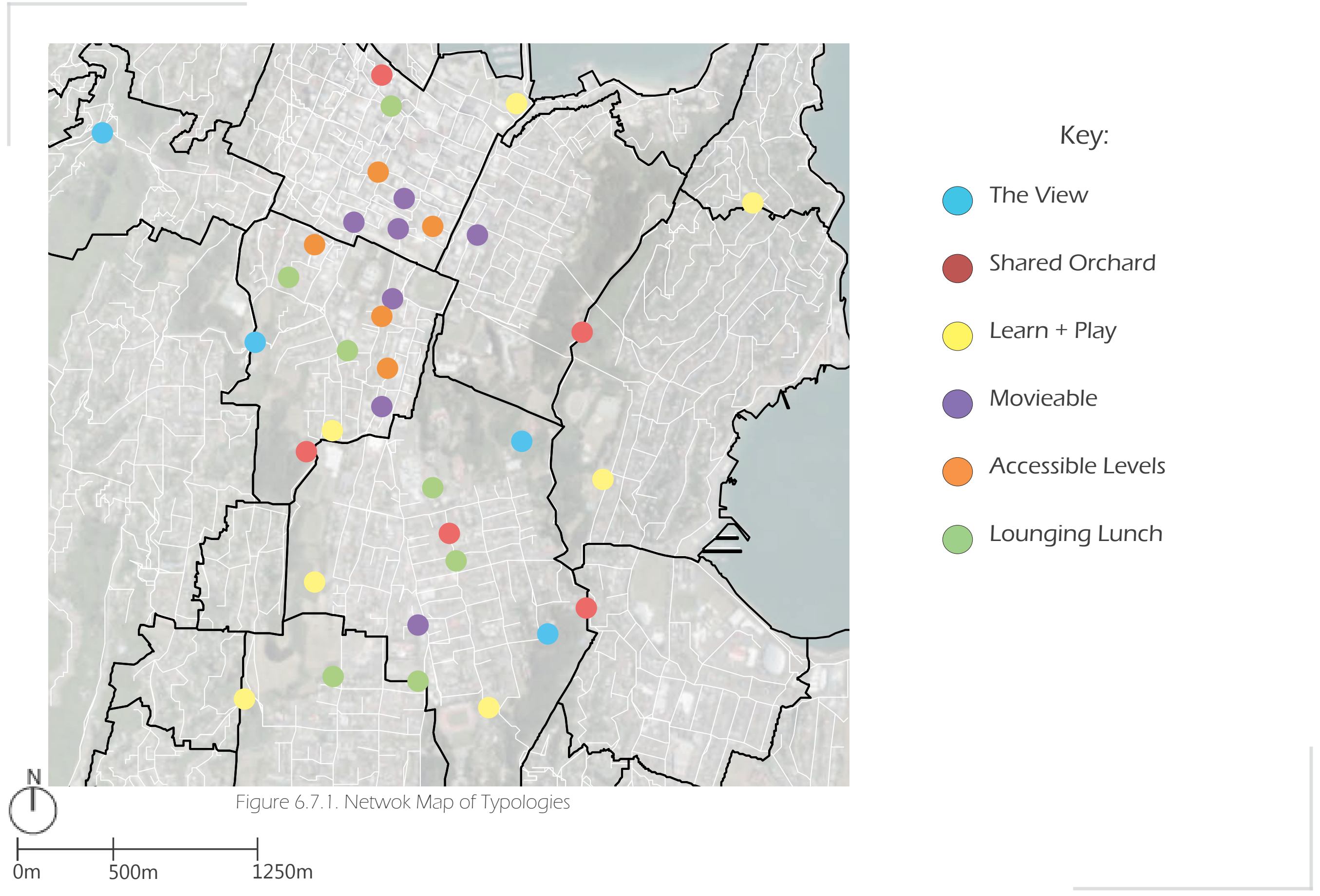




\subsection{Network of Spaces:}

If the sites were to be organised in a particular hierarchy of usability after an earthquake, they would go: $5,1,3,4,2,6$. this is due to the need for lots of food production and meeting spaces as well as water collection. These spaces would all contribute to the overall network and the city would only get more resilient the more spaces it had.

These spaces would be best built up over time and with communities wanting to be a part of a resilient city. Having many small spaces allows for some to be unusable if the earthquake affects them but it means there are still many other spaces to fall back on.

[fig 6.7.2.] The typologies in this network are just the spaces I have noticed while living in this city. There are probably many more that could contribute to this network.

Typology 1 fits across the city because it's an idea for all existing and new reservoirs to be able to be used as community space and contribute to the resiliency that wellington city council is looking for. It also could be an idea for hilltop parks and be used in spaces that aren't on a reservoir but are relatively flat.

Typology 2 fits across the city because it changes a road barrier into an opportunity so that no space is left unused.

Typology 3 fits across the city because it brings the next generation into the equation and allows them to have the knowledge of what is happening around them. It allows play and creates and interest for some in how things grow.

Typology 4 fits across the city because it allows residents of apartments to be more sustainable and be more community orientated. As well as providing local food resiliency in each area.

Typology 5 fits across the city because it creates an extra backup of the city's water supply, which in summer has to be rationed. This typology could become a community water station for the council to supply water from.

Typology 6 fits across the city because it allows people to relax while providing resiliency in terms of local food supply.
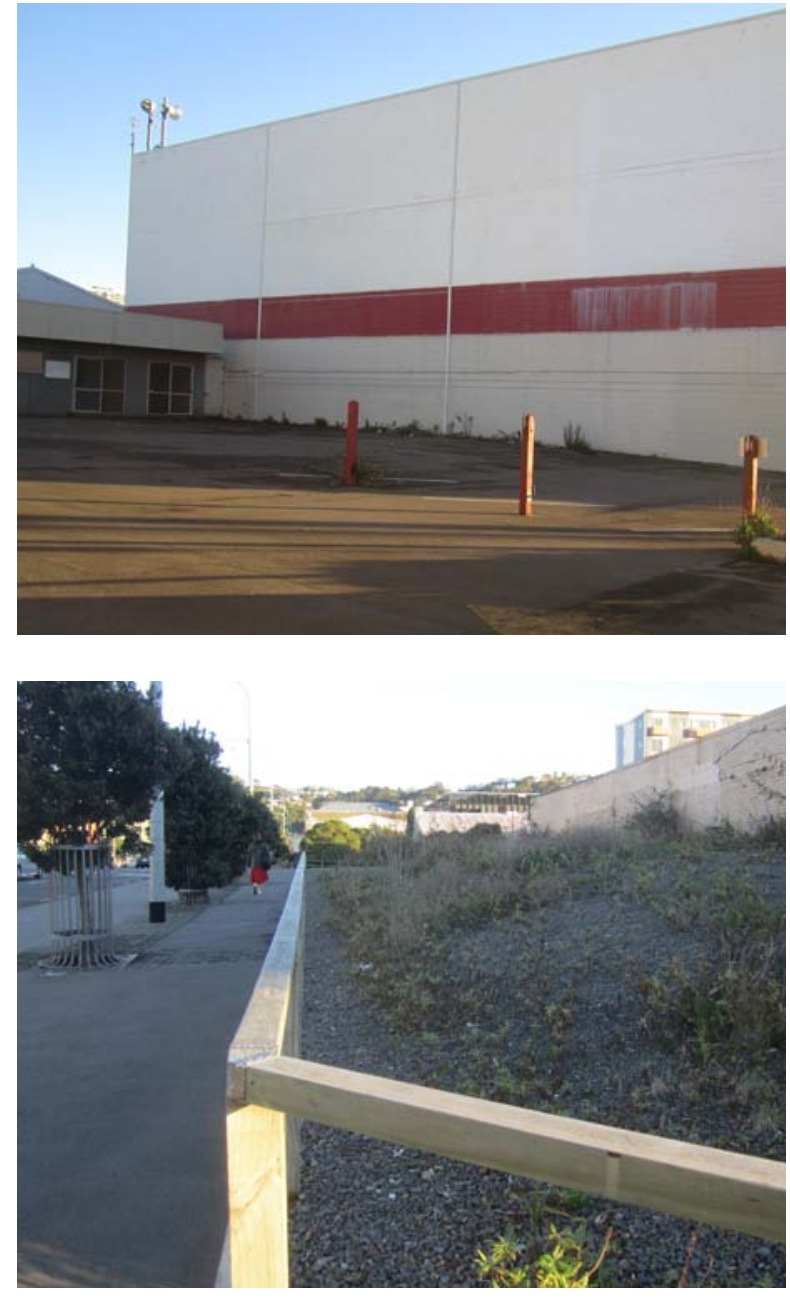

Figure 6.7.2. Sites in the city that could have a plug in typology. 


\section{Conclusions:}

Throughout the research there have been many changes to the question in trying to work out the best way to phrase what I was doing. It came in the form of Can we design typologies in landscape architecture to integrate community gardens, with public space by preparing for and acting as recovery from a disaster?

This allowed me to reflect on if community gardens can be designed into public space, and if that space could then provide for the needs of a community after a major disaster.

Each site has shown that community gardens and public space can be integrated to allow public to use the site as well as having a productive space.

In terms of readiness every site produces some sort of food, and these band together to create a network of food sources throughout the city. These spaces allow communities to function and destress in desperate times making these spaces

In terms of recovery spaces, the main typologies that achieved this were: $1,3,4$ and 5 . this is due to them all having a meeting space and either some shelter or some way to collect water.

Although each typology has a different function they individually and collectively provide readiness and recovery in their own ways. This is a result of a clear need for more community-based spaces within Wellington city.

The typologies that I have created are made to adapt with the needs and wants of the communities and will allow different functions depending on the situation.

The need for a resilient city is imminent with the growing risk of a large magnitude earthquake. This causes some fear when we get a big shock and everyone goes into survivor mode. But preparing for an earthquake is something we should be thinking about before 
we get that shock.

I've established that we can create different typologies that integrate community gardens and public space while preparing for and acting as recovery from a disaster. Throughout this research I've encountered some limitations. Finding examples of landscape architecture that actively prepares for an earthquake was a difficult situation. Many landscape architects have designed for flooding, tsunamis, rising tides and tornados, and out of these disaster situations I examined which I thought to be most relevant.

Designing 6 typologies was a challenge as they all had different factors and because of this there were some limits I set myself. I decided that minimal site works were to be done to allow for quicker establishments of the community spaces. I also limited myself to the political boundary of Mount Cook to restrict my scope so I wasn't designing 20 sites. These let me experiment more with the sites and typologies I had to work with. I also didn't allow community involvement in these designs but chose simple elements that could be created by community to allow involvement in actually creating the space.

Making models of my sites was an important step for me to better understand the relation my site had with its context. Using these models to help portray my thoughts and show how it would work in the three dimensional aspect.

The research through design has shown that we can create typologies in landscape architecture to integrate community gardens with public space. Although these seem simple ideas, having spaces that can accommodate communities while also preparing for the recovery of a disaster by having food production and a water source onsite, remains the key ingredient for resilience.

Many factors go into being able to survive a disaster. Where it hits, its magnitude, how far from the surface it ruptures. These are things we can't control but allowing ourselves to be prepared for 'the big one' is something we can, and should do in terms of being a resilient city. 


\section{Bibliography:}

Allan, Penny and Martin Bryant. "6th Australasian Hazards Management Conference.” Mancom, The Critical Role of Open Space in Earthquake Recovery: A Case Study, 2012.

Bryant, Martin and Penny Allan. Open Space Innovation in Earthquake Affected Cities. INTECH Open Access Publisher, 2013.

Cindy. "LaFayette Square in Oakland, California - Brainstorm Overload - Small Design Studio. Big Ideas.” Brainstorm Overload, 2009, brainstormoverload.com/2009/05/lafayette-square-in-oakland-california/.

Cooper, Sarah. "The Getty Salad Garden an Installation of Organic Heirloom Vegetables and Salad Greens |." World Landscape Architecture, 27 Apr. 2016, worldlandscapearchitect.com/the-getty-salad-garden/\#. XGXnTDMzaUk.

"Community: Above-Ground Emergency Water Network." Community: Above-Ground Emergency Water Network - Wellington Water, 2017, www.wellingtonwater.co.nz/your-water/emergency-water/community/.

Cooper, Sarah. "The Getty Salad Garden." The Photography of Ray K. Metzker and the Institute of Design (Getty Center Exhibitions), J. Paul Getty Museum, Los Angeles, 2016, www.getty.edu/museum/programs/ courses/getty_salad_garden.html.
Devlin, Collette, and Ged Cann. "Wellingtonians Still Aren't Ready for the Big One, a Year after the November 14 Earthquake." Stuff-Stuff.co.nz, 14 Nov. 2017, www.stuff.co.nz/national/98660318/san-francisco-adoptswellingtons-earthquake-community-hubs.

George, Damian. "Major Earthquake Could Split Wellington Region into 'Seven Islands'." Stuff- Stuff.co.nz, 24 Mar. 2017, www.stuff.co.nz/national/nz-earthquake/90790889/major-earthquake-could-split-wellingtonregion-into-seven-islands.

"Greater Wellington Regional Council - Home | Greater Wellington Regional Council." Sustainable Schools | Greater Wellington Regional Council, www.gw.govt.nz/.

Fong, Olivia. "Form Follows Food: an Examination of Architecture's Role in Urban Farming: a 120-Point Thesis Submitted to the Victoria University of Wellington in Partial Fulfilment of the Requirements for the Degree of Master of Architecture (Professional)." Victoria University of Wellington, 2017, p. 28.

Franklin, Jonathan. "How Did Chile Manage to Survive Its Recent Earthquake Virtually Unscathed?" The Guardian, Guardian News and Media, 25 Sept. 2015, www.theguardian.com/cities/2015/sep/25/how-chile-survive-earthquake-virtually-unscathed. 
Hemenway, Toby. The Permaculture City Regenerative Design for Urban, Suburban, and Town Resilience. Chelsea Green Publ., 2015.

"Home - Wellington Water." Regional: New Reservoirs and New Supply - Wellington Water, www.wellingtonwater.co.nz/.

“LAMCAST: Vacant to Vibrant." Landscape Architecture Magazine, 23 Aug. 2018, landscapearchitecturemagazine.org/2018/08/23/lamcast-vacant-to-vibrant/.

Mortice, Zach. "SHELTER AND PLACE." Landscape Architecture Magazine, 27 Mar. 2017, landscapearchitecturemagazine.org/2017/03/27/shelter-and-place/.

Mowll, Richard. "Lifeline Utilities Restoration Times." Lifeline Utilities Restoration Times, Wellington Lifelines Group, 2013. wremo.nz/assets/ Publications/Lifeline-Utilities-Restoration-Times.pdf.

Owens Viani, LISA. “LOTS OFOPPORTUNITY.” Landscape Architecture Magazine, 30 Aug. 2018, landscapearchitecturemagazine.org/2018/08/02/ lots-of-opportunity/.

Petty, Matthew. "The Idea of Vilonia." University of Arkansas Community Design Center, University of Arkansas Community Design Center, 16 Mar. 2015, uacdc.uark.edu/work/the-idea-of-vilonia.
Sioen, Giles, et al. "Post-Disaster Food and Nutrition from Urban Agriculture: A Self-Sufficiency Analysis of Nerima Ward, Tokyo." International Journal of Environmental Research and Public Health, vol. 14, no. 7, 10 July 2017, p. 748., doi:10.3390/ijerphl4070748.

statsnz. "Mt Cook." Profile.id, 2013, profile.idnz.co.nz/wellington/ population?WebID=300.

Steel, Carolyn. "How Food Shapes Our Cities." TED, 2009, www.ted. com/talks/carolyn_steel_how_food_shapes_our_cities.

"Welcome to the Wellington Region Emergency Management Office (WREMO)." WREMO - Earthquake Hazards, wremo.nz/.

"Wellington City Council." News - Wellington Officially a Fair Trade City - Wellington City Council, 23 Jan. 2019, wellington.govt.nz/.

"Wellington Population 2019." Wellington Population 2019 (Demographics, Maps, Graphs), worldpopulationreview.com/world-cities/wellington-population/.

Whiston Spirn, Anne, and Michele Pollio. "This Garden Is a Town.” Anne Whiston Spirn, Anne Whiston Spirn, 2008, www.annewhistonspirn. 


\section{Source of figures:}

Figure 1.1.2. Wellington Water Above-ground-emergency-water-network-A5-Booklet page 2 Figure 1.1.3. Wellington Water Above-ground-emergency-water-network-A5-Booklet page 5 and 7

Figure 2.1.5. Images of proposed water stations. Wellington Water https://www.wellingtonwater.co.nz/your-water/emergency-water/community/what-is-a-community-water-station/ Figure 3.1.1. Permaculture flower, The Permaculture City adapted by Toby Hemenway pg 231 Figure 4.0.1. northern community garden https://ncg.org.nz/about-us/

Figure 4.1.l. http://www.cbgarden.org/lets-learn/research/vacant2vibrant/buffalo-final-sitephotos.aspx

Figure 4.1.2.http://www.cbgarden.org/lets-learn/research/vacant2vibrant/gary-final-sitephotos.aspx

Figure 4.1.3. http://www.cbgarden.org/lets-learn/research/vacant2vibrant/cleveland-finalsite-photos.aspx

Figure 4.2.1. Abby Han, https://worldlandscapearchitect.com/the-getty-salad-garden/\#.XPTwR5gzaUk

Figure 4.2.2. Abby Han, https://worldlandscapearchitect.com/the-getty-salad-garden/\#.XPTwR5gzaUk

Figure 4.2.3. Abby Han, https://worldlandscapearchitect.com/the-getty-salad-garden/\#.XPTwR5gzaUk

Figure 4.3.1. https://landscapearchitecturemagazine.org/2017/03/27/shelter-and-place/

Figure 4.3.2. https://landscapearchitecturemagazine.org/2017/03/27/shelter-and-place/

Figure 4.3.3. http://uacdc.uark.edu/work/the-idea-of-vilonia

Figure 4.4.1. http://brainstormoverload.com/2009/05/lafayette-square-in-oakland-california/

Figure 4.4.2. http://www.hooddesignstudio.com/lafayette

Figure 4.5.l. owhiro bay photo http://www.wmkindergartens.org.nz/Find-Kindergarten/

Wellington/Owhiro-Bay-Kindergarten__I.2788_C.1458_N.135

Figure 4.5.2. bond street photo https://www.rnz.co.nz/national/programmes/ninetonoon/ audio/201802574/a-taste-of-inner-city-gardens
All these Figures have data from LINZ or maps from Arc Gis.

Figure 1.5.1.

Figure 5.5.1.

Figure 2.0.1

Figure 2.1.1.

Figure 2.1.4.

Figure 2.1.6.

Figure 2.1.7.

Figure 2.2.1.

Figure 2.2.2.

Figure 2.3.1.

Figure 5.1.1.

Figure 5.1.2.

Figure 5.1.3.

Figure 5.2.2.

Figure 5.2.3.

Figure 5.3.1.

Figure 5.3.2.

Figure 5.3.3.

Figure 5.4.1.

Figure 5.4.2.

All figures not referenced are authors own. 
Appendix A:

Wellington Water's emergency water network.

Redacted Copyright Image

Wellington Water, "Store-Water-Now" pamphlet, Page 2 


\section{Appendix B:}

Earthquake Planning Guide

Redacted Copyright Image

"Earthquake Planning Guide." Get Prepared - Earthquake Planning Guide, getprepared.nz/personal-preparedness/guide/. 〈https://getprepared.nz/assets/Publications/EarthquakePlanning-Guide.pdf> 
Appendix C:

Preparedness Guide WREMO

Redacted Copyright Image
"Get Prepared for an Emergency." Civil Defence Management, https://wellington.govt.nz///media/services/communityand-culture/resources-for-neighbourhoods/files/emergencyresource.pdf 